\title{
UICN
}

\section{Orientación para usar el Estándar Global de la UICN para soluciones basadas en la naturaleza}

Un marco fácil de usar para la verificación, diseño y ampliación de las soluciones basadas en la naturaleza

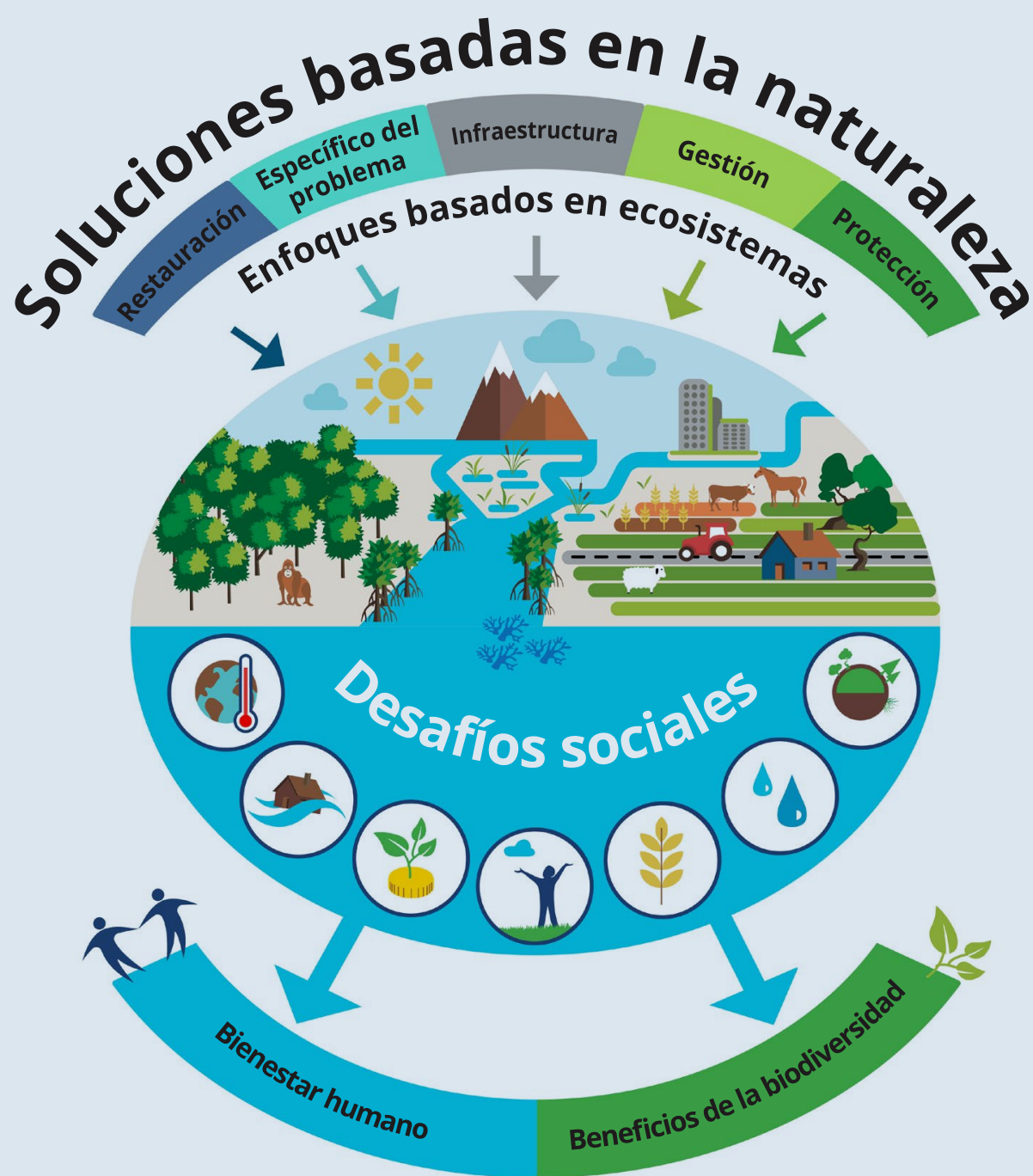




\section{Acerca de la UICN}

La UICN es una Unión de Miembros compuesta por Estados soberanos, agencias gubernamentales y organizaciones de la sociedad civil. La UICN pone a disposición de las entidades públicas, privadas y no gubernamentales, los conocimientos y las herramientas que posibilitan, de manera integral, el progreso humano, el desarrollo económico y la conservación de la naturaleza.

Creada en 1948, la UICN se ha convertido en la red ambiental más grande y diversa del mundo. La UICN cuenta con la experiencia, los recursos y el alcance de sus más de 1400 organizaciones Miembro y los aportes de más de 15000 expertos. La UICN es uno de los principales proveedores de datos, evaluaciones y análisis sobre conservación. Su extensa y diversa membresía hacen de la UICN una incubadora y un repositorio confiable de las mejores prácticas y herramientas de conservación, así como de las directrices y estándares internacionales.

La UICN proporciona un espacio neutral en el que actores diversos, incluyendo gobiernos, ONGs, cientificos, empresas, comunidades locales, grupos indígenas, organizaciones religiosas y otros pueden trabajar juntos para crear e implementar soluciones a los retos ambientales y lograr un desarrollo sostenible.

La UICN trabaja con diversos socios y simpatizantes para llevar a la práctica un amplio y diverso portafolio de proyectos de conservación en todo el mundo. Estos proyectos, que combinan los últimos avances científicos con los conocimientos tradicionales de las comunidades locales, procuran detener y revertir la pérdida de hábitats, restaurar los ecosistemas y mejorar el bienestar humano.

http://www.uicn.org/es

https://twitter.com/IUCN/ 


\section{Orientación para usar el Estándar Global de la UICN para soluciones basadas en la naturaleza}

Un marco fácil de usar para la verificación, diseño y

ampliación de las soluciones basadas en la naturaleza

Primera edición 
La presentación del material en esta publicación y las denominaciones empleadas para las entidades geográficas no implican en absoluto la expresión de una opinión por parte de la UICN o de otra organización participante sobre la situación jurídica de un país, territorio o zona, o de sus autoridades, o acerca de la demarcación de sus límites o fronteras.

Los puntos de vista que se expresan en esa publicación no reflejan necesariamente los de la UICN o de otra organización participante.

La UICN se complace en agradecer el apoyo de sus socios marco por su financiación del programa de la UICN: el Ministerio de Asuntos Exteriores de Finlandia; el Gobierno de Francia y la Agencia Francesa de Desarrollo (AFD); el Ministerio del Medio Ambiente de la República de Corea; la Agencia Noruega para la Cooperación al Desarrollo (Norad); el Agencia Sueca de Cooperación Internacional para el Desarrollo (Asdi); la Agencia Suiza para el Desarrollo y la Cooperación (COSUDE) y el Departamento de Estado de Estados Unidos.

La UICN y las organizaciones participantes declinan cualquier error u omisión en la traducción de este documento de la versión original en [inglés] al español. En caso de discrepancia, remítase, por favor, a la edición original. Título de la edición original: Guidance for using the IUCN Global Standard for Nature-based Solutions. First edition (2020). Publicado por: UICN, Gland, Suiza. DOI: https://doi. org/10.2305/IUCN.CH.2020.09.en

Esta publicación ha sido posible gracias a la generosidad de la Agencia Francesa de Desarrollo (AFD) a través de la Alianza entre Francia y la UICN por la Naturaleza y el Desarrollo.

Esta Orientación acompaña el Estándar Global de la UICN para soluciones basadas en la naturaleza (https://doi.org/10.2305/IUCN. CH.2020.08.es) para proporcionar el fundamento científico y la orientación de los usuarios.

Publicado por:

Derechos reservados:

Citación:

ISBN:

DOI:

Illustration de la cubierta:

Diagramado por:

Disponible en:

\section{UICN, Gland, Suiza}

(c) 2020 UICN, Unión Internacional para la Conservación de la Naturaleza y de los Recursos Naturales

Se autoriza la reproducción de esta publicación con fines educativos y otros fines no comerciales sin permiso escrito previo de parte de quien detenta los derechos de autor con tal de que se mencione la fuente.

Se prohíbe reproducir esta publicación para la venta o para otros fines comerciales sin permiso escrito previo de quien detenta los derechos de autor.

UICN (2020). Orientación para usar el Estándar Global de la UICN para soluciones basadas en la naturaleza. Un marco fácil de usar para la verificación, diseño y ampliación de las soluciones basadas en la naturaleza. Primera edición. Gland, Suiza: UICN.

978-2-8317-2063-0

https://doi.org/10.2305/IUCN.CH.2020.09.es

Defining Nature-based Solutions (־ UICN.

Imre Sebestyén jr / Unit Graphics

UICN, Unión Internacional para la Conservación de la Naturaleza

UICN Grupo SbN

Rue Mauverney 28

1196 Gland, Suiza

NbSStandard@iucn.org

www.iucn.org/resources/publications 


\section{Índice}

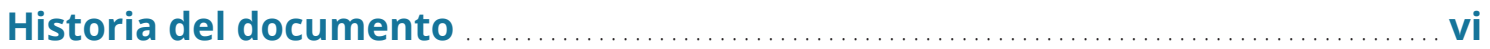

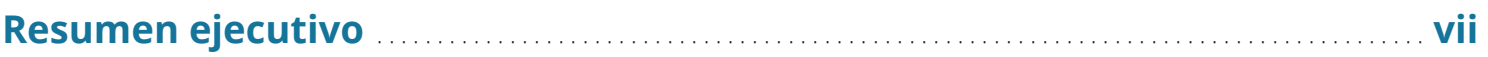

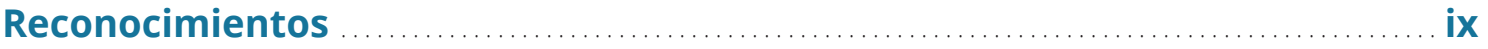

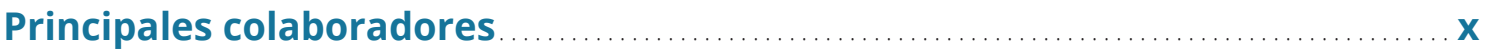

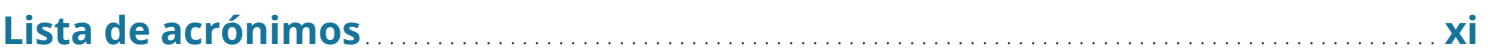

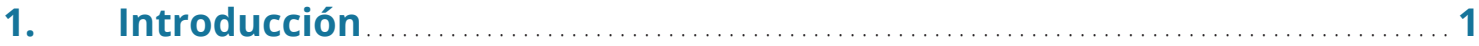

$1.1 \mathrm{El}$ desarrollo desde el concepto inicial hasta el enfoque global ...................... 1

1.2 Las soluciones basadas en la naturaleza como marco general para abordar desafíos sociales 3

1.3 Las SbN en el contexto de la crisis de la biodiversidad ............................... 4

1.4 Las SbN en el contexto de la crisis climática ...................................... 5

1.5 Las SbN en el contexto de la crisis de inclusividad .................................. 8

2. Presentación del Estándar Global para SbN de la UICN ..................11

2.1 Necesidad de un Estándar Global ............................................... 11

2.2 Alcance del Estándar .......................................................... 12

2.3 Uso y público objetivo ............................................................. 12

3. Proceso de codesarrollo del Estándar Global .................................14

3.1 Fundación en el marco de definición de la UICN para SbN ..........................14

3.2 Visión general del proceso de codesarrollo ..................................... 15

3.3 Código internacional de normas de sostenibilidad ................................ 15

4. Orientación sobre los criterios ............................................

4.1 Resumen 17

Criterio 1: Las SbN responden eficazmente a los desafíos sociales .................... 18

C-1.1 Se da prioridad a los retos sociales más apremiantes para los titulares de derechos y los beneficiarios ......................................... 18

C-1.2 Los retos sociales que se abordan se entienden y documentan claramente............................................................ 19

C-1.3 Los resultados del bienestar humano derivados de las SbN se identifican, se comparan y se evalúan periódicamente ....................19

Criterio 2: El diseño de las SbN se adapta a la dimensión ................................20

C-2.1 El diseño de la SbN reconoce y responde a las interacciones entre la economía, la sociedad y los ecosistemas.................................20

C-2.2 El diseño de SbN está integrado con otras intervenciones complementarias y busca sinergias entre sectores

C-2.3 El diseño de SbN incorpora la identificación y la gestión de riesgos más allá del lugar de intervención 
Criterio 3: Las SbN dan lugar a una ganancia neta en términos de biodiversidad

e integridad de los ecosistemas

C-3.1 Las intervenciones con SbN responden directamente a una evaluación basada en datos del estado actual del ecosistema y de los principales impulsores de su degradación y pérdida.

C-3.2 Se identifican resultados claros y cuantificables en términos de conservación de la biodiversidad, se establecen niveles de referencia para ellos y se evalúan periódicamente

C-3.3 El monitoreo incluye evaluaciones periódicas de las consecuencias adversas no deseadas sobre la naturaleza que surgen de la SbN .........25

C-3.4 Las oportunidades para mejorar la integridad y la conectividad de los ecosistemas se identifican e incorporan en la estrategia de SbN .......... 26

Criterio 4: Las SbN son económicamente viables

C-4.1 Se identifican y documentan los beneficios y costos directos e indirectos asociados a las SbN, determinando quién asume los gastos y quién se beneficia de ellas

C-4.2 La elección de SbN se apoya en un estudio de costo-efectividad que incluye los efectos probables de cualquier regulación o de los subsidios pertinentes

C-La eficacia del diseño de la SbN se justifica en función de las soluciones alternativas disponibles, teniendo en cuenta cualquier externalidad asociada

C-4.4 El diseño de SbN considera una cartera de opciones de recursos tales como basadas en el mercado, sector público, compromisos voluntarios y acciones para apoyar el cumplimiento de la normativa.....28

Criterio 5: Las SbN se basan en procesos de gobernanza inclusivos,

transparentes y empoderadores.

C-5.1 Se pone a disposición de todos los interesados directos un mecanismo de retroalimentacion y solución de reclamaciones definido y plenamente acordado antes de poner en marcha una intervención de SbN

C-5.2 La participación se basa en el respeto mutuo y la igualdad, independientemente del género, la edad o la condición social, y defiende el derecho de los pueblos indígenas al consentimiento libre previo e informado (CLPI)

C-5.3 Se han identificado los las partes interesadas afectadas directa e indirectamente afectados de forma directa o indirecta por la SbN, y se les ha implicado en todos los procesos de la intervención

C-5.4 Los procesos de toma de decisiones documentan y responden a los derechos e intereses de todas las partes interesadas participantes y afectadas

C-5.5 Cuando la dimensión de las SbN trasciende los límites jurisdiccionales, se establecen mecanismos para posibilitar la toma de decisiones conjunta de los interesados directos en las jurisdicciones afectadas

Criterio 6: Las SbN ofrecen un equilibrio equitativo entre el logro de sus objetivos

principales y la provisión constante de múltiples beneficios

C-6.1 Se reconocen explícitamente los costos y beneficios potenciales de las compensaciones asociadas a la intervención de SbN, y se utiliza esta información para adoptar salvaguardias y cualquier otra medida correctora que resulte adecuada 
C-6.2 Se reconocen y respetan los derechos, el uso y el acceso a la tierra y los recursos de las diferentes partes interesadas directos, junto con sus responsabilidades respectivas.

C-6.3 Las salvaguardias establecidas se revisan periódicamente para garantizar que se respetan los límites mutuamente acordados de las compensaciones y que dichos límites no desestabilizan las SbN en su totalidad

Criterio 7: Las SbN se gestionan de forma adaptativa, con base en datos

C-7.1 La estrategia de SbN se establece y utiliza como base para la vigilancia continua y la evaluación periódica de la intervención

C-7.2 Se elabora un plan de vigilancia continua y evaluación, y se aplica a lo largo de todo el ciclo de vida de la intervención ........................37

C-7.3 Se aplica un marco de aprendizaje iterativo que posibilita la gestión adaptativa a lo largo de todo el ciclo de vida de la intervención.

as SbN son sostenibles y se integran en un contexto jurisdiccional

Criterio 8: Las SbN
adecuado.

C-8.1 El diseño, la aplicación y las lecciones extraídas de las SbN se comparten para impulsar un cambio transformador

C-8.2 Las SbN aportan información a los marcos normativos y reglamentarios facilitadores y ayudan a perfeccionarlos con el fin de respaldar su adopción y generalización

C-8.3 Cuando resulte pertinente, las SbN contribuyen a los objetivos nacionales y mundiales en las esferas del bienestar humano, el cambio climático, la biodiversidad y los derechos humanos, incluida la Declaración de las Naciones Unidas sobre los Derechos de los Pueblos Indígenas

\section{Cómo utilizar el estándar}

5.1 Cómo autoevaluarse 


\section{Historia del documento}

Orientación para usar el Estándar Global de la UICN para soluciones basadas en la naturaleza.

\begin{tabular}{|c|c|}
\hline Edición & 1.0 \\
\hline Idioma de origen & Inglés. Hay traducciones oficiales disponibles. \\
\hline $\begin{array}{l}\text { Unidad } \\
\text { responsable }\end{array}$ & $\begin{array}{l}\text { Programa Global de Gestión de Ecosistemas; Comisión de Gestión de Ecosistemas de la } \\
\text { UICN }\end{array}$ \\
\hline Desarrollado por & $\begin{array}{l}\text { Grupo de soluciones basadas en la naturales de la UICN; Comisión de Gestión de } \\
\text { Ecosistemas de la UICN }\end{array}$ \\
\hline Tema (taxonomía) & Soluciones basadas en la naturaleza; Estándar; Eficacia de la gestión; Garantía \\
\hline $\begin{array}{l}\text { Fecha de } \\
\text { aprobación }\end{array}$ & Febrero de 2020 \\
\hline Aprobado por & Consejo de la UICN \\
\hline Objetivo & $\begin{array}{l}\text { Ofrecer orientación y un marco global para el diseño, verificación y ampliación de } \\
\text { las soluciones basadas en la naturaleza. El Estándar incluye criterios e indicadores } \\
\text { globalmente coherentes, respaldados por los principios para las soluciones basadas en } \\
\text { la naturaleza, para medir la fuerza de las intervenciones. }\end{array}$ \\
\hline Forma parte del & Grupo de soluciones basadas en la naturales de la UICN \\
\hline Cumple con & Sistema de Gestión Ambiental y Social de la UICN \\
\hline $\begin{array}{l}\text { Documentos } \\
\text { asociados }\end{array}$ & $\begin{array}{l}\text { Documento de Antecedentes del Estándar Global Estándar Global de la UICN para } \\
\text { soluciones basadas en la naturaleza }\end{array}$ \\
\hline Distribución & COMPASS de la UICN; Union Portal de la UICN, y sitio web de la UICN \\
\hline
\end{tabular}

\begin{tabular}{|c|c|c|}
\hline \multicolumn{2}{|c|}{ Historia del documento } & \multirow{2}{*}{$\begin{array}{l}\text { Primera edición } \\
\text { Resumen de cambios }\end{array}$} \\
\hline Versión & Fecha de publicación & \\
\hline 0.1 & Octubre de 2018 & $\begin{array}{l}\text { Compartido internamente con los Miembros, las Comisiones y la } \\
\text { Secretaría de la UICN. }\end{array}$ \\
\hline 0.2 & Diciembre de 2018 & $\begin{array}{l}\text { Se realizaron ajustes a partir de la retroalimentación interna y la } \\
\text { nueva versión presentada en la primera consulta pública de un } \\
\text { mes de duración. }\end{array}$ \\
\hline 0.3 & Enero de 2019 & $\begin{array}{l}\text { Se realizaron importantes ajustes a partir de la retroalimentación } \\
\text { externa y la nueva versión fue presentada en la segunda consulta } \\
\text { pública de dos meses de duración. }\end{array}$ \\
\hline 0.4 & Febrero de 2020 & 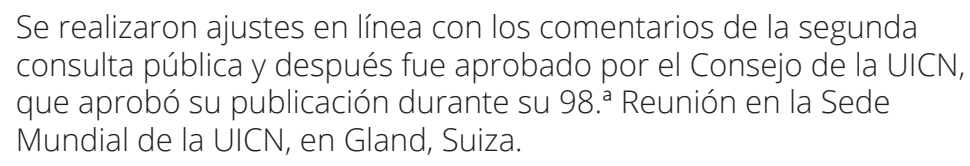 \\
\hline 0.5 & 2020 de marzo & Se hicieron revisiones basadas en la revisión externa por pares. \\
\hline
\end{tabular}




\title{
Resumen ejecutivo
}

\author{
Si bien las crisis planetarias que enfrentamos hoy pueden parecer abrumadoras, \\ la sociedad también ha demostrado que podemos trabajar juntos para resolver las \\ principales amenazas globales. En el decenio de 1970, el mundo adoptó con éxito medidas \\ para detener e invertir el agotamiento de la capa de ozono. De no haberlo hecho, el \\ "agujero de ozono" se habría extendido ahora a los trópicos, y afectaría la salud de las \\ personas, los servicios ecosistémicos y la biodiversidad. Para alterar la trayectoria prevista \\ de una crisis es necesario disponer de soluciones fiables y eficaces. En este sentido, \\ las soluciones basadas en la naturaleza (SbN) ofrecen al mundo una oportunidad real \\ de abordar de manera decisiva múltiples crisis de sostenibilidad, incluidos el cambio \\ climático, la seguridad alimentaria e hídrica, la degradación de la tierra y la pérdida de \\ biodiversidad.
}

Mediante el trabajo conjunto, y guiados por la experiencia de las mejores prácticas, ya tenemos la capacidad de ofrecer soluciones duraderas y sostenidas que nos puedan ayudar a hacer la transición a una forma más justa, equitativa y sostenible de habitar este planeta. El Estándar Global de la UICN sobre soluciones basadas en la naturaleza es el resultado de la combinación de conocimientos y puntos de vista de más de 800 expertos sobre cómo tornar la naturaleza en un aliado eficaz en la lucha contra el cambio climático y otros importantes desafíos del siglo XXI.

La protección, la gestión sostenible y la restauración de la naturaleza pueden aportar beneficios sustantivos a la sociedad. Sin embargo, esto solo es posible si alcanzamos una visión compartida de lo que implican tales soluciones, un enfoque coherente de cómo se diseñan y aplican y, lo que es más importante, un marco de aprendizaje que nos ayude a evaluar, adaptar y mejorar, para que las intervenciones futuras sean aún más eficaces.

El Estándar es facilitador, y tiene el objetivo no solo de guiar al usuario en el diseño y la aplicación, sino también de mejorar continuamente la resistencia de la intervención y ayudar a pre- pararse para lo imprevisto. Parte de la premisa de que una solución debe responder inherentemente a un contexto y el resultado puede variar en cada ocasión. El Estándar ofrece un enfoque consistente capaz de tratar y adaptarse a una amplia variedad de circunstancias y contextos particulares con el fin de ofrecer resultados ambientalmente racionales, socialmente justos y económicamente viables, sin dejar a nadie atrás.

Los 8 Criterios y los 28 Indicadores apoyan a los usuarios a 1) evaluar hasta qué punto una solución propuesta reúne los requisitos para convertirse en una SbN e identificar qué medidas pueden tomarse para fortalecer aún más la solidez de la intervención, utilizando una escala de sólida, adecuada, parcial e insuficiente; 2) permitir el diseño a propósito de una solución para que se adhiera a los Criterios e Indicadores, al tiempo que se crean mecanismos de gestión adaptativa para mantener la relevancia y solidez de la solución a lo largo de su vida útil.

El Estándar ha sido desarrollado para una amplia gama de usuarios, en particular los que no pertenecen al sector de la conservación tradicional. Viene acompañado de un conjunto de herramientas de autoverificación accesible y fácil de usar, en tanto que las revisiones y 
mejoras del Estándar son supervisadas por un Comité Internacional de Normas. En consonancia con esto, la UICN respaldará el establecimiento de una comunidad global de usuarios que aprendan colectivamente y ayuden a desarrollar el Estándar.

- El Criterio 1 aborda la importancia de identificar claramente el desafío social al que responderá la solución. A veces, puede extenderse a más de una prioridad clave. El propósito de este criterio es asegurar que haya un diseño deliberado y decidido en términos de satisfacer las necesidades de bienestar humano.

- El Criterio 2 guía el diseño de una SbN en términos de consideraciones espaciales clave, lo que a menudo se conoce como un enfoque de paisaje.

- Los Criterios 3, 4 y 5 corresponden a las tres dimensiones clave del desarrollo sostenible: la sostenibilidad del medio ambiente, la equidad social y la viabilidad económica.

- El Criterio 6 aborda los aspectos prácticos de manejar y equilibrar las compensaciones inherentes a la mayoría de las tomas de decisiones sobre la gestión de los recursos naturales, incluida la conciliación de las necesidades a largo y corto plazo. Destaca que las decisiones de compensación se tomen con plena transparencia, divulgación y consenso entre todos los interesados afectados.

- El Criterio 7 promueve un enfoque de gestión adaptativa, mediante el cual el aprendizaje y la acción se complementan entre sí para que un usuario estándar evolucione y mejore la solución.

- El Criterio 8 promueve la integración de la perspectiva de género en la política nacional, lo cual es fundamental para apoyar la sostenibilidad y durabilidad a largo plazo de una SbN. Esto podría lograrse mediante la convergencia con las políticas, los compromisos nacionales y mundiales, y el intercambio de lecciones que permitan dar forma a otras soluciones.

Este Estándar ha sido desarrollado mientras el mundo lucha por contener y detener la propagación de la COVID-19. En la actualidad se está prestando atención a la recuperación económica posterior a la pandemia. A medida que los líderes mundiales contemplan cómo volver a construir mejor, las soluciones basadas en la naturaleza ofrecen una oportunidad única para invertir en el bienestar social y en economías vibrantes, sin tener que volver a los errores del pasado. 


\section{Reconocimientos}

Además, esta publicación del Estándar es el esfuerzo colectivo de muchas personas, grupos y redes comprometidas. Queremos agradecer a todos los que han contribuido a la preparación de este informe. Un amplio grupo de expertos de la Secretaría de la UICN y de la Comisión de Gestión de ecosistemas (CGE) hizo aportes técnicos. De manera particular, queremos hacer reconocimiento a los aportes de las siguientes personas: Ali Raza Rizvi, Madhav Karki, Barbara Nakangu, Fabrice Renaud, Lucilla Boito, Stephen N. Edwards, Bernal Herrera, Willem Ferwerda, Jonathan Davies, John Waugh, Mike Jones, Birguy Lamizana, Jenny Springer, Kelvin Passfield, Charles Lor, Wendy Atieno, Rebecca Welling, Anita Tzec, Edmund Barrow, Mirjam Kuzee, Leigh Ann Hurt y Jonathan Hughes. Agradecemos a las personas que han formulado comentarios sobre versiones anteriores del documento, incluidos los cientos de participantes de 100 países que participaron en las dos rondas de consultas públicas que enriquecen la calidad y el alcance del Estándar. Agradecemos de manera especial los aportes de grupo del Comité Nacional Francés de la UICN, Conservación Internacional, la Comisión Mundial de Áreas Protegidas de la UICN, el Ministerio Francés de Agricultura, el Centro de Derecho Ambiental de la UICN, la Coalición de Capital Natural y la Comisión Europea.

Este Estándar fue desarrollado con conocimientos técnicos y orientación sobre el establecimiento de normas de Assurance Services International (ASI). También transmitimos nuestra gratitud a Marnie Bammert, de ASI, por llevar a cabo la revisión por pares de esta publicación.

Agradecemos igualmente a nuestra revisora externa Chantal Van Ham por sus comentarios, que han mejorado enormemente la calidad y el alcance de esta publicación.

Agradecemos a Caroline Snow por la edición, a Imre Sebestyén (Unit Graphics) por el diseño, y a Efrat Bronstein por el trabajo gráfico. Del mismo modo agradecemos a IUCN Global Communications Unit y NbS Communication Group por su apoyo en comunicaciones y gráficos.

El informe fue posible gracias a la contribución de la Agencia Francesa de Desarrollo (AFD) a través de la Alianza entre Francia y la UICN por la Naturaleza y el Desarrollo.

Cualquier error sigue siendo responsabilidad de los autores principales. 


\section{Principales colaboradores}

Este Estándar se elaboró de manera consultiva, con base en la experiencia científica, de edición y técnica de numerosas personas de la UICN y de la Comisión de Gestión de Ecosistemas (CGE). Los autores se enumeran en orden alfabético, a continuación.

Andrade, Angela; Cohen-Shacham, Emmanuelle; Dalton, James; Edwards, Stephen; Hessenberger, Daisy; Maginnis, Stewart; Maynard, Simone; McElwee, Pam; Murti, Radhika; Nelson, Cara; Ruiz, Verónica; Siikamäki, Juha; Vasseur, Liette. 


\section{Lista de acrónimos}

\begin{tabular}{|c|c|}
\hline $\mathrm{AbE}$ & Adaptación basada en ecosistemas \\
\hline AFD & Agencia Francesa de Desarrollo \\
\hline ASI & Assurance Services International \\
\hline CDB & Convenio sobre la Diversidad Biológica \\
\hline CDN & Contribuciones determinadas a nivel nacional \\
\hline CGE & Comisión de Gestión de Ecosistemas \\
\hline CLPI & Consentimiento libre, previo e informado \\
\hline CMNUCC & Convención Marco de las Naciones Unidas sobre el Cambio Climático \\
\hline COMPASS & $\begin{array}{l}\text { Community of Protected Areas Sustainability Standards (Comunidad de Estándares de } \\
\text { Sostenibilidad de Áreas Protegidas) }\end{array}$ \\
\hline EPANB & Estrategias y planes de acción nacionales en materia de biodiversidad \\
\hline InVEST & $\begin{array}{l}\text { Integrated Valuation of Ecosystem Services and Trade-offs (Valoración Integrada de } \\
\text { Servicios y Compensaciones de los Ecosistemas) }\end{array}$ \\
\hline IPBES & $\begin{array}{l}\text { Plataforma Intergubernamental Científico-Normativa sobre Diversidad Biológica y } \\
\text { Servicios de los Ecosistemas }\end{array}$ \\
\hline IPCC & Grupo Intergubernamental de Expertos sobre el Cambio Climático \\
\hline ISBN & Número Internacional Normalizado del Libro \\
\hline ISEAL & International Social and Environmental Accreditation and Labeling \\
\hline MyE & Monitoreo y evaluación \\
\hline NDT & Neutralización de la degradación de las tierras \\
\hline NRGF & Marco de Gobernanza de los Recursos Naturales \\
\hline OCDE & Organización de Cooperación y Desarrollo Económicos \\
\hline ODS & Objetivos de Desarrollo Sostenible \\
\hline OIG & Organización intergubernamental \\
\hline OMS & Organización Mundial de la Salud \\
\hline ONU & Naciones Unidas \\
\hline RLTS & Lista Roja de Especies Amenazadas TM \\
\hline RPB & Restauración de los paisajes boscosos \\
\hline RRD-ECO & Reducción del riesgo de desastres basada en los ecosistemas \\
\hline RSE & Responsabilidad social empresarial \\
\hline SbN & Soluciones basadas en la naturaleza \\
\hline SFDRR & Marco de Sendái para la Reducción del Riesgo de Desastres \\
\hline SGAS & Sistema de Gestión Ambiental y Social de la UICN \\
\hline UICN & Unión Internacional para la Conservación de la Naturaleza y de los Recursos Naturales \\
\hline UNCCD & Convención de las Naciones Unidas de Lucha contra la Desertificación \\
\hline UNDRIP & Declaración de las Naciones Unidas sobre los Derechos de los Pueblos Indígenas \\
\hline USD & Dólares de EE. UU. \\
\hline
\end{tabular}





\title{
1. Introducción
}

\author{
"Las soluciones basadas en la naturaleza son acciones \\ dirigidas a proteger, gestionar y restaurar de manera \\ sostenible ecosistemas naturales o modificados, que hacen \\ frente a retos de la sociedad de forma efectiva y adaptable, \\ proporcionando simultáneamente bienestar humano y \\ beneficios de la biodiversidad".
}

(UICN, 2016)

En2020, se reconoce crecientemente el papel que desempeña la naturaleza en nuestra sociedad. Sin embargo, durante la mayor parte del siglo $X X$, los responsables de la toma de decisiones trataron la conservación de la naturaleza como asunto periférico de las agendas nacionales y mundiales. En el mejor de los casos, se considera que se trata de un interés digno; en el peor de los casos, un obstáculo para el desarrollo. Sin embargo, un consenso científico creciente indica que esas opiniones eran profundamente erróneas y que "la naturaleza es esencial para la existencia humana y la buena calidad de vida". El no reconocimiento de este hecho no solo da lugar a un modelo de crecimiento económico que socava las economías futuras y contribuye significativamente a la pérdida de biodiversidad, sino que también pierde la oportunidad de desplegar eficazmente la naturaleza para ayudar a resolver los principales desafíos sociales, como el cambio climático, la salud humana, la seguridad alimentaria, la reducción del riesgo de desastres naturales, etc. Reconocerlo ofrece la posibilidad de incorporar enfoques de conservación en otros sectores, como la agricultura, la infraestructura, los recursos hídricos, la salud, la planificación urbana y el desarrollo rural.

La mayoría de los ecosistemas pueden proporcionar múltiples beneficios a diversos beneficiarios, al tiempo que apoyan la protección de la base de recursos naturales. Esto significa que la gestión de los ecosistemas es a menudo la ruta más prometedora para abordar los desafíos sociales, al asegurar el papel de la biodiversidad en el statu quo de otros sectores.

\subsection{El desarrollo desde el concepto inicial hasta el enfoque global}

Varios enfoques de conservación desarrollados a partir de los años noventa se basan en la gestión decidida de los ecosistemas, incluida la restauración de los paisajes boscosos, la ordenación sostenible de las tierra, la ordenación integrada de los recursos hídricos, la ordenación integrada del paisaje, la ordenación integrada de las zonas costeras, la restauración ecológica y la Iniciativa sobre el Uso Sostenible de la UICN. Esos enfoques operacionales han ofrecido resultados de conservación que proporcionan beneficios tangibles a la sociedad, incluidos empleos, una 
mejor productividad de la tierra, control de la erosión y secuestración de carbono. Detrás de cada uno de estos términos hay una base de investigación y una comunidad de práctica.

Ya sea de manera independiente 0 en combinación con otras formas de soluciones (p. ej., tecnología e ingeniería), los enfoques de conservación (p. ej., protección, restauración y gestión sostenible) también pueden aplicarse con el bienestar humano como objetivo principal. Esta evolución del pensamiento sobre la conservación ha llevado al reconocimiento de dos amplios dominios de las intervenciones de conservación, aquellos cuyo objetivo principal es salvaguardar la biodiversidad por sus propios valores inherentes, y aquellos cuyo propósito principal es salvaguardar la sociedad, lo que ahora se denomina "Soluciones basadas en la naturaleza" (SbN). Ambos dominios se adhieren al mismo conjunto de normas y principios de conservación, y aunque hay ocasiones en las que se superponen en lo operativo, los puntos de partida son a menudo muy distintos.

Además, este cambio de paradigma también llevó al reconocimiento de que varios países tienen una historia de gestión de la naturaleza con formas que generan beneficios para la sociedad, incluso si no utilizaron el término SbN para describir estas intervenciones en ese momento. Si bien todas estas soluciones de conservación han sido útiles, por separado no son suficientes para abordar los desafíos actuales. Las comunidades de práctica e investigación han estado aisladas durante mucho tiempo, a menudo compitiendo por los mismos recursos a pesar de los principios, objetivos y aplicaciones similares de los enfoques de conservación.

Al prestar mayor atención al potencial de las acciones de conservación para el uso sostenible de la naturaleza para las necesidades de las personas, el concepto de SbN se desarrolló como parte de un cambio de paradigma que comenzó

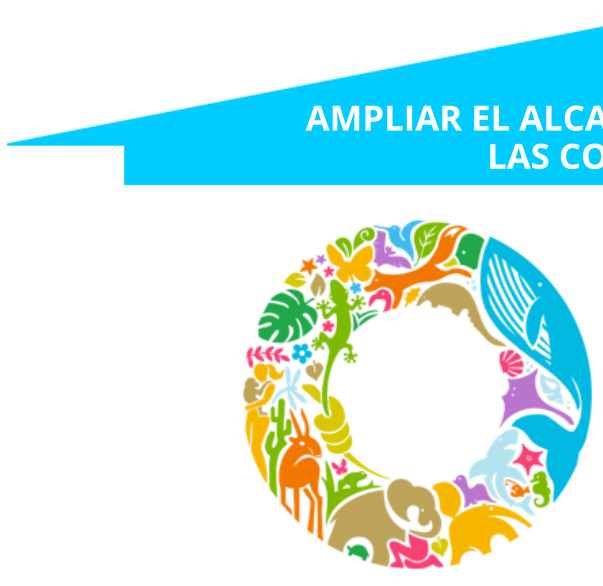

Salvaguardar la naturaleza LAS CONSERVACIONES

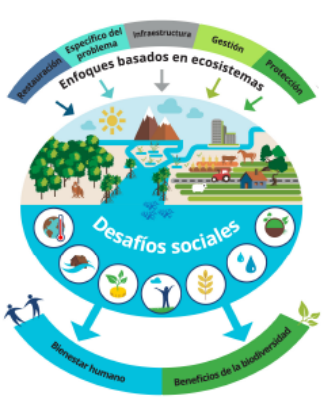

Salvaguardar la sociedad

\section{NORMAS Y CIENCIA DE LA CONSERVACIÓN}

Figura 1: Las intervenciones de conservación se adhieren a las normas y principios de conservación. Existe un ámbito de conservación que se centra en la salvaguardia de la biodiversidad por su valor irremplazable. Otro ámbito se centra en la salvaguardia de la sociedad, siguiendo siempre esas normas y principios de conservación. Estas últimas se conocen como soluciones basadas en la naturaleza. Si bien hay cierta superposición, no todas las intervenciones de conservación son soluciones basadas en la naturaleza. (৫ UICN) 
en los años ochenta, en que las personas son consideradas protectoras, administradoras y restauradoras proactivas de los ecosistemas al abordar una serie de grandes desafíos sociales, en lugar de ser beneficiarias pasivas de la naturaleza (Cohen-Shacham et al., 2019). Las SbN reconocen que la conservación de la biodiversidad y la protección de los servicios de los ecosistemas son esenciales para los diversos aspectos del bienestar humano, incluida la salud humana. Si bien tratan con sistemas complejos, las SbN van más allá de los enfoques mecanicistas tradicionales para la solución de problemas (Rogers et al., 2013). El concepto de SbN tiene su base en el enfoque por ecosistemas (CDB, 2004; Holling, 1973; Holling, 1978; Holling, 1986; Waltner-Toews y Kay, 2005), que sustenta el Convenio sobre la Diversidad Biológica (CDB) (Smith y Maltby, 2003).

Hoy, en 2020, la comunidad conservacionista y los sectores asociados se encuentran en el centro de un movimiento mundial que reconoce, promueve y procura lograr SbN. En los últimos diez años después que la UICN acuñara el término, el enfoque ha cobrado impulso y se ha incorporado a políticas, convocatorias de propuestas, planes económicos, preguntas de investigación y estrategias nacionales para la diversidad biológica y el cambio climático. Con la creciente apreciación e inversión, llegó una exigencia real de que se definiera el término para dar lugar a intervenciones resistentes y rentables.

\subsection{Las soluciones basadas en la naturaleza como marco general para abordar desafíos sociales}

Las soluciones basadas en la naturaleza se consideran un marco general para los enfoques basados en ecosistemas (como los conceptos anteriormente mencionados) que se utilizan para abordar los principales desafíos sociales (Cohen-Shacham et al., 2016) (véase la figura 2). El término "Soluciones basadas en la naturaleza" fue promovido por primera vez por la UICN en 2009, y posteriormente presentado como un término general para destacar una variedad de enfoques de conservación, incluidos los mencionados anteriormente. Los conceptos adicionales que comprende la SbN incluyen: soluciones naturales (el papel de las áreas protegidas en la lucha contra el cambio climático); adaptación basada en ecosistemas (AbE); reducción del riesgo de desastres basada en los ecosistemas (RRD-ECo); infraestructura ecológica (para el crecimiento económico y las inversiones, en el contexto urbano); infraestructura natural (para una gestión integrada sostenible de los recursos hídricos); y ordenación holística o regenerativa del paisaje.

Estos enfoques seguirán siendo muy pertinentes para la aplicación de las SbN. Sirven como enfoques operacionales específicos que pueden desplegarse para ejecutar la solución a un desafío social. También puede ser necesaria una combinación de distintos enfoques dentro de una intervención, y se pueden buscar complementariedades para mejorar la eficiencia y reducir la redundancia.

Para que una intervención sea considerada una SbN, debe abordar uno o varios desafíos sociales de una manera integrada. En la actualidad, la UICN refiere a siete desafíos sociales: la adaptación y mitigación del cambio climático, la reducción del riesgo de desastres naturales, la inversión de la degradación de los ecosistemas y la pérdida de biodiversidad, la salud humana, el desarrollo 


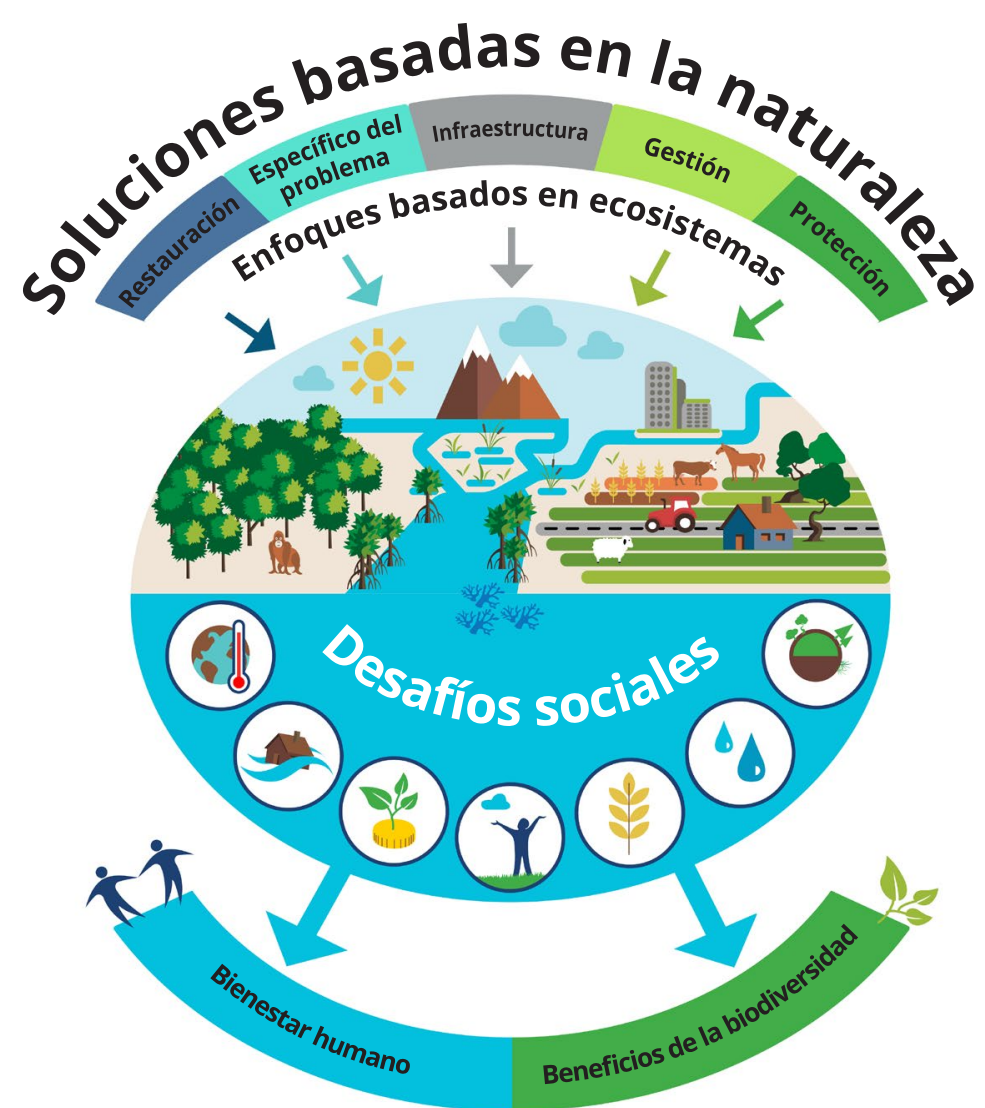

Figura 2: Definición de soluciones basadas en la naturaleza. (৫ UICN)

socioeconómico, la seguridad alimentaria y la seguridad hídrica (véase la figura 3). Si se está abordando el desafío social de la degradación de los ecosistemas, al menos otro desafío social debe ser parte del diseño de la solución, para diferenciar la intervención de la SbN de una pura acción de conservación.
Si bien todavía están evolucionando, actualmente se están poniendo en práctica soluciones a estos desafíos sociales que se basan en conocimientos científicos y buenas prácticas que pueden demostrar el valor de la SbN como respuesta. A medida que el concepto de SbN se desarrolla para su aplicación, se pueden añadir otros desafíos sociales a la lista.

\subsection{Las SbN en el contexto de la crisis de la biodiversidad}

El Informe de Evaluación Global sobre Biodiversidad y Servicios de los Ecosistemas (IPBES, 2019a), de la Plataforma Intergubernamental CientíficoNormativa sobre Diversidad Biológica y Servicios de los Ecosistemas (IPBES) de 2019, presenta un panorama muy sombrío para la biodiversidad, con un millón de especies de plantas y animales clasificados como amenazados o extintos a nivel mundial, y la disminución de los servicios de los ecosistemas debido a la sobreexplotación y el mal uso. La rápida y dramática pérdida de biodiversidad erosiona la capacidad de los ecosistemas para prestar los servicios que son esenciales para el bienestar humano. Las tasas actuales de pérdida de invertebrados y microorganismos del suelo, a través de prácticas 


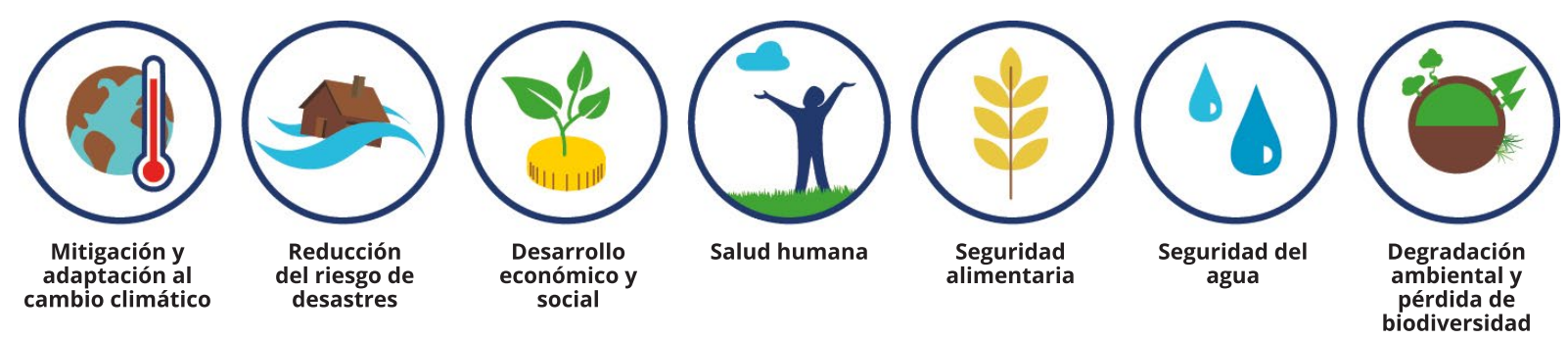

Figura 3: Principales desafíos sociales abordados por la SbN. (@ UICN)

intensivas de uso de la tierra, están socavando los cimientos de los medios de subsistencia humanos. Las contribuciones de la naturaleza a las personas desempeñan un papel vital en apoyo de la existencia humana y la calidad de vida, pero a menudo se distribuyen de manera desigual en el espacio y el tiempo (IPBES, 2019a). La IPBES informa que los efectos negativos son desproporcionados y afectarán especialmente a los pueblos marginados e indígenas y a las comunidades rurales, que dependen directamente de los beneficios de la naturaleza para su supervivencia. La IPBES también destaca que el cambio climático es un motor directo que exacerba el impacto de otros impulsores en la naturaleza y el bienestar humano (IPBES, 2019b); y se está convirtiendo en el principal impulsor de la pérdida de biodiversidad en los próximos años, al afectar a especies, hábitats y ecosistemas.
Para que una solución sea considerada una SbN, es imperativo que proporcione beneficios simultáneos a la biodiversidad y al bienestar humano. Por lo tanto, cada solución debe mantener o mejorar la biodiversidad, sin la cual una acción no puede ser clasificada como SbN. Esto es importante para garantizar que la integridad y la estabilidad del sistema natural no se vean socavadas por prácticas que favorezcan los beneficios a corto plazo, sino que comprometan la capacidad del sistema para servir a las generaciones futuras. Por lo tanto, a diferencia de que la conservación de la biodiversidad es simplemente un producto de una SbN, es un insumo crítico que, si se mantiene o mejora, valida una solución como una SbN (UICN, 2016).

\subsection{Las SbN en el contexto de la crisis climática}

Por otra parte, el informe del Grupo Intergubernamental de Expertos sobre el Cambio Climático (IPCC) sobre el calentamiento global de $1,5^{\circ} \mathrm{C}$ proporciona suficientes pruebas de que las actividades humanas han causado aproximadamente $1,0^{\circ} \mathrm{C}$ de calentamiento global por encima de los niveles preindustriales (IPCC, 2018). Es probable que el calentamiento global alcance los $1,5^{\circ} \mathrm{C}$ entre 2030 y 2052, situándonos así en una situación muy peligrosa, si no logramos el objetivo fijado por el Acuerdo de París: mantener el aumento de la temperatura media mundial "muy por debajo de $2^{\circ} \mathrm{C}$ por encima de los niveles preindustriales" (véase el recuadro 1 para ejemplos de las principales conclusiones). A medida que la humanidad enfrenta un punto de inflexión climático catastrófico, prevalece la necesidad urgente de enfoques innovadores para complementar la conservación de la naturaleza, así como de cambios transformadores inmediatos para reducir las emisiones de carbono y limitar el calentamiento global a $1,5^{\circ} \mathrm{C}$ (IPCC, 2018; Rockström et al., 2009; Steffen et al., 2015). 
El concepto de SbN proporciona un enfoque integrado que puede ayudar a las naciones a cumplir acuerdos y metas internacionales cruciales, como los Objetivos de Desarrollo Sostenible (ODS) de las Naciones Unidas, el Acuerdo de París, las Metas de Aichi, el Desafío de Bonn y el Marco de Sendái para la Reducción del Riesgo de Desastres. El concepto de SbN fue refrendado en la Cumbre de las Naciones Unidas sobre el Clima de 2019 y destacado en el Informe Especial del IPCC sobre el calentamiento global de $1,5^{\circ} \mathrm{C}$ (de Coninck et al., 2018), el Informe sobre el Cambio Climático y la Tierra del IPCC (IPCC, 2019), y el Informe de Evaluación de la Diversidad Biológica Mundial de la IPBES (IPBES, 2019a) por tener el potencial de abordar los principales desafíos sociales y ecológicos mundiales.

A medida que se intensifica la emergencia climática, tanto las personas como la naturaleza serán cada vez más vulnerables a los fenómenos meteorológicos y climáticos extremos, y si bien el impacto será específicamente regional, es probable que las personas y la naturaleza en general sufran impactos negativos más frecuentes e intensos. El Informe Especial del IPCC Cambio Climático y Tierra informa que la mayor frecuencia de fenómenos meteorológicos extremos y los cambios en las pautas de precipitación ya ha afectado la seguridad alimentaria en la tierra (IPCC, 2019), en tanto que el Informe Especial Océanos y Criósfera muestra el modo en que la reducción de la criósfera desde mediados del siglo XX también ha impactado de manera predominantemente negativa la seguridad alimentaria e hídrica (IPCC, 2019). El vínculo entre las personas y la naturaleza es claro de cara al cambio climático. A modo de ejemplo, el cambio climático exacerba la degradación de la tierra, que también afecta a las personas que viven en zonas degradadas (IPCC, 2019). Del mismo modo, el cambio climático plantea un alto riesgo para los ecosistemas costeros, como los prados de algas marinas y los bosques de algas marinas, donde la pérdida de hábitat llevará a la pérdida de especies y diversidad y a la degradación de las funciones de los ecosistemas (IPCC, 2019) de los que dependen las personas.

Esta interrelación entre las personas y la naturaleza ofrece la oportunidad, en forma de SbN, de abordar los desafíos sociales subyacentes (como la seguridad alimentaria), al tiempo que contribuye a la adaptación y mitigación del clima. El Informe del IPCC de 2019 Cambio Climático y Tierra destaca la ordenación sostenible de la tierra, incluida la conservación de los ecosistemas, ya que "puede contribuir a reducir los efectos negativos de múltiples factores estresantes, incluido el cambio climático, sobre los ecosistemas y las sociedades" (IPCC, 2019). Entre los ejemplos de adaptación basada en ecosistemas que pueden eliminar los gases de efecto invernadero y contribuir a la mitigación y adaptación se incluyen la restauración de los ecosistemas naturales y la mejora de la conservación de la diversidad biológica (IPCC, 2019). Para limitar el calentamiento a $1,5^{\circ} \mathrm{C}$ o muy por debajo de $2^{\circ} \mathrm{C}$, la sociedad requiere una combinación de soluciones inspiradas en la naturaleza, derivadas y basadas en la misma, junto con reducciones significativas en las emisiones de combustibles fósiles (figura 4).

La salud de los ecosistemas de los que dependemos nosotros y todas las demás especies se está deteriorando más rápidamente que nunca, amenazando de esa manera la salud del planeta y de las personas. Estamos erosionando los cimientos mismos de nuestras economías, medios de subsistencia, seguridad alimentaria, salud y calidad de vida en todo el mundo. El informe también reconoce que el cambio climático se está convirtiendo en uno de los principales motores de la pérdida de 


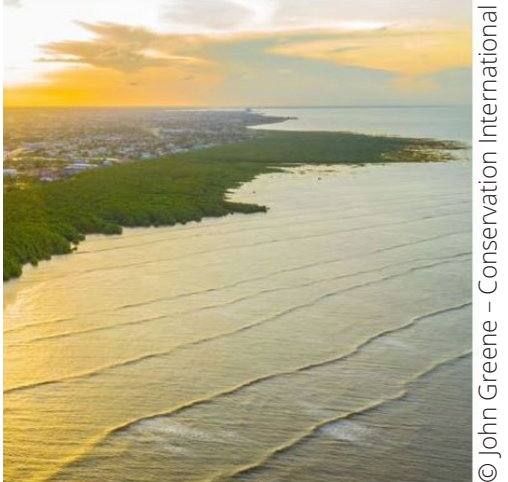

Soluciones basadas en la naturaleza

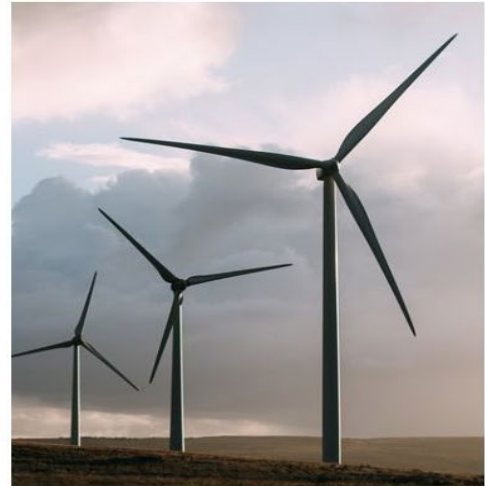

Soluciones derivadas de la naturaleza

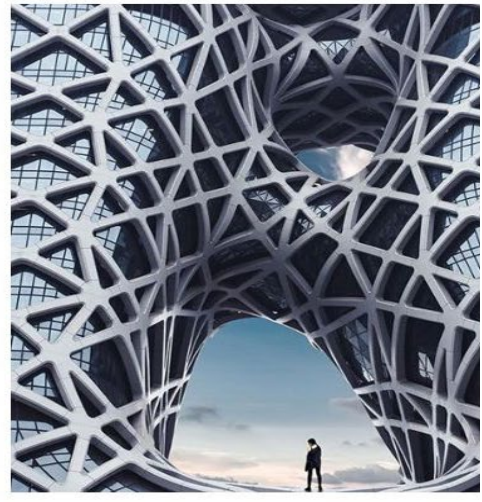

Soluciones inspiradas en la naturaleza

Figura 4: Si bien las soluciones basadas en la naturaleza utilizan el poder de los ecosistemas en funcionamiento como infraestructura para proporcionar servicios naturales en beneficio de la sociedad y el medio ambiente, las soluciones derivadas de la naturaleza e inspiradas en la naturaleza, que también son necesarias para lograr un futuro sostenible y con bajas emisiones de carbono, son distintas. Las soluciones derivadas de la naturaleza incluyen la energía eólica, de las olas y solar, todas ellas derivadas de la naturaleza, y ayudan a cubrir las necesidades de energía con bajas emisiones de carbono mediante métodos de producción derivados de fuentes naturales. Aunque estas fuentes de energía provienen del mundo natural, no se basan directamente en ecosistemas en funcionamiento. Las soluciones inspiradas en la naturaleza incluyen el diseño y la producción innovadores de materiales, estructuras y sistemas que se modelan a partir de procesos biológicos, y que se inspiran en la naturaleza. A manera de ejemplo, el biomimetismo es una práctica que aprende e imita las estrategias que se encuentran en la naturaleza para resolver los desafíos. Estos diseños se inspiran en la naturaleza, como los guantes adhesivos que imitan las adaptaciones de las salamanquesas para escalar paredes. No se basan en ecosistemas en funcionamiento.

biodiversidad posterior a 2020. Esto exige que las crisis de biodiversidad y cambio climático se analicen y aborden simultáneamente a través de SbN, que también desempeñan un papel clave en el logro del cambio transformador necesario para lograr los objetivos de sostenibilidad mundial.

El concepto de SbN puede formar parte del enfoque de jerarquía de mitigación, que es un marco de toma de decisiones que incluye una secuencia de pasos que comienza con la evitación de impactos, seguida de la minimización de mitigación de impactos inevitables, la restauración in situ y, finalmente, cuando sea factible y necesario, las compensaciones de la biodiversidad. La correcta aplicación de la jerarquía de mitigación puede limitar potencialmente los efectos adversos de los proyectos de desarrollo sobre la diversidad biológica además de proporcionar beneficios adicionales para la conservación de la diversidad biológica. Sin embargo, una aplicación inadecuada, especialmente si se efectúa a partir de lagunas de conocimiento fundamentales pero no resueltas, y de una política corporativa, financiera y regulatoria deficiente, puede socavar los enfoques establecidos para la gestión del riesgo de la diversidad biológica. 


\section{Recuadro 1: Ejemplos de los principales resultados de los principales informes mundiales (IPBES, 2019b; IPCC, 2018, PWC \& WWF, 2020):}

- Los ecosistemas naturales han disminuido en un 47 \% en promedio en relación con los primeros estimados.

- Aproximadamente el 25 \% de las especies ya están amenazadas de extinción en la mayoría de los grupos de animales y plantas estudiados, lo que sugiere que alrededor de 1 millón de especies ya se enfrentan a la extinción, muchas de ellas en cuestión décadas, a menos que se tomen medidas para reducir la intensidad de los motores de la pérdida de biodiversidad.

- La integridad biótica (la abundancia de especies presentes de forma natural) ha disminuido en un $23 \%$ en promedio en las comunidades terrestres.

- La biomasa mundial de mamíferos silvestres ha disminuido en un 82 \%. Los indicadores de la abundancia de vertebrados han disminuido rápidamente desde 1970.

- El 72 \% de los indicadores desarrollados por los pueblos indígenas y las comunidades locales muestran un deterioro continuo de los elementos de la naturaleza importantes para ellos.

- La mayoría de los objetivos sociales y ambientales internacionales no pueden alcanzarse mediante las trayectorias actuales, y los objetivos para 2030 y más allá solo pueden lograrse mediante cambios transformadores que abarquen factores económicos, sociales, políticos y tecnológicos.

- Los impulsores directos más impactantes del cambio son los cambios en el uso de la tierra y el mar; la explotación directa de organismos; el cambio climático; la contaminación; y la invasión de especies exóticas.

- Se estima que las actividades humanas han causado aproximadamente $1,0^{\circ} \mathrm{C}$ de calentamiento global por encima de los niveles preindustriales, con un rango probable de $0,8^{\circ} \mathrm{C}$ a $1,2^{\circ} \mathrm{C}$.

- $\quad$ Es probable que el calentamiento global alcance los $1,5^{\circ} \mathrm{C}$ entre 2030 y 2052 si continúa aumentando al ritmo actual.

- El cambio climático crea tensiones adicionales en la tierra, y exacerba los riesgos presentes para los medios de subsistencia, la biodiversidad, la salud humana y de los ecosistemas, la infraestructura y los sistemas alimentarios.

- Los costos de la inacción en lo relativo a la pérdida de la diversidad biológica se estiman en entre USD 4 y USD 20 millones de millones al año en servicios de los ecosistemas entre 1997 y 2011, debido al cambio de la cubierta terrestre y a una estimación de entre USD 6 y USD 11 millones de millones al año debido a la degradación de la tierra.

\subsection{Las SbN en el contexto de la crisis de inclusividad}

Las intervenciones solo pueden tener éxito si se incluyen distintos sistemas de conocimiento y participan grupos afectados, incluidos los pueblos indígenas, las comunidades locales, las mujeres y los jóvenes. Lamentablemente, no siempre ha sido así en la historia de las acciones de conservación, lo que ha llevado a una crisis de inclusión pareja a la de crisis de 
biodiversidad y climática. Gracias a su enfoque interseccional y a la manera integrada en que se aplican, las SbN se benefician significativamente de reunir a los diversos actores que pueden ser directa o indirectamente afectados por la intervención, e incluyen distintos tipos de sistemas de conocimiento y visiones del mundo, como los que se incorporan en el conocimiento ecológico tradicional o indígena. Como ejemplo, los esfuerzos de adaptación presentes en las regiones polares se han beneficiado de la inclusión de los conocimientos indígenas y locales, como aquel en torno a tendencias y patrones de cambio del paisaje terrestre o marino y la salud y las poblaciones de especies (IPCC, 2019).

Cuando se considera la la diversidad de las partes interesadas en una SbN, es fundamental garantizar una participación activa, inclusiva y transparente, independientemente del género, la edad o los antecedentes sociales, económicos - culturales, y que la toma de decisiones respecto de la SbN sea transparente y equitativa para salvaguardar a las personas y la cultura. Esto también es esencial para lograr todos los beneficios que puede ofrecer una SbN. Los aspectos que pueden influir y marginar a los posibles contribuyentes en los procesos de colaboración utilizados en la SbN son el sesgo cultural y las perspectivas elitistas. Cuando los grupos interesados son igualmente importantes (p. ej., rurales y no rurales), tales percepciones pueden llevar a ciertos grupos a desconocer los insumos de las clases sociales inferiores o de los miembros menos educados de la sociedad. Tales situaciones pueden ser limitadas y mejoradas con debates constructivos y colaboraciones facilitadas, procesos que son esenciales para implementar una SbN.

Los pueblos indígenas y las comunidades locales, en particular, ocupan y administran una parte importante de las regiones con mayor biodiversidad de la Tierra y desempeñan un papel vital en la conservación de tierras, mares y recursos y sus usos sostenibles. Cultivan fuertes relaciones económicas, culturales y espirituales con sus entornos naturales y han desarrollado y a menudo mantienen prácticas y conocimientos tradicionales de gestión que contribuyen a la conservación de la biodiversidad y al uso sostenible de los recursos naturales. A modo de ejemplo, las áreas protegidas indígenas, donde se respetan los usos tradicionales y sostenibles de los recursos naturales, pueden representar una SbN que beneficiará la supervivencia de los conocimientos tradicionales y las comunidades indígenas. Asimismo, los administradores de tierras rurales, sean o no indígenas, tendrán un entendimiento más informado de la tierra que están administrando que cualquier otra persona.

Independientemente del grupo de interesados que participe, siempre habrá un componente de género en que la adopción de un enfoque que responda al género sea un requisito previo para el desarrollo sostenible. La participación de las mujeres en la SbN apoya su aplicación, ya que la conservación de la naturaleza y los derechos de las mujeres están inextricablemente vinculados; por ejemplo, la degradación del medio ambiente está exacerbando la violencia contra las mujeres, y adoptar un enfoque que responda a las cuestiones de género en relación con las SbN puede contribuir a abordar tanto a la crisis de la diversidad biológica como a la crisis de inclusividad. Mientras tanto, numerosos estudios demuestran que la participación de las mujeres aporta su conocimiento singular al manejo de los recursos naturales. Un liderazgo más equilibrado en función del género y la participación igualitaria de las mujeres en la SbN dan lugar a más beneficios para la naturaleza y, por lo tanto, para las personas.

Junto con el aumento del impacto y la visibilidad de las SbN en los últimos años, los jóvenes han aumentado y han hecho visible su papel en las acciones de conservación. Los niños y los jóvenes 
tienen una contribución tangible que hacer para resolver desafíos sociales críticos, haciendo hincapié en la equidad intergeneracional que se requiere. Es probable que las intervenciones que prestan mayor atención a los costes y beneficios a corto plazo sin tener en cuenta los costes, beneficios y compensaciones a largo plazo sean menos resistentes; la participación de los jóvenes en una intervención otorga una apreciación y comprensión del impacto intergeneracional a largo plazo, y, por lo tanto, crea resiliencia. Concretamente, al considerar soluciones al cambio climático, no se presta suficiente atención a la protección, la inclusión y el empoderamiento de los jóvenes, ya que solo ocho de las 160 contribuciones determinadas a nivel nacional (CDN) incluyen una referencia directa a la injusticia intergeneracional o a las generaciones futuras. La incorporación de la juventud en el movimiento mundial que apoya las SbN respalda la sostenibilidad de estas intervenciones y aborda los beneficios potenciales que la educación de la juventud aporta a la adaptación y mitigación del clima. 


\section{Presentación del Estándar Global para SbN de la UICN}

\subsection{Necesidad de un Estándar Global}

Con la creciente aceptación del concepto de $\mathrm{SbN}$ se presenta la necesidad correspondiente de asegurar que el concepto se entienda, comunique y aplique claramente, de manera que haga operativos los ocho principios básicos de SbN (UICN, 2016). Los estándares de práctica son un método común para lograr estos objetivos a medida que se desarrollan los campos de práctica. Además, es importante aclarar que, si bien las SbN complementan la conservación de la naturaleza, su objetivo principal es abordar uno o varios desafíos sociales mientras benefician tanto la biodiversidad como el bienestar humano. Esta diferenciación es muy importante para asegurar que 1) la conservación continúe ofreciendo acciones específicas para detener o revertir la pérdida de biodiversidad, según sea necesario, y 2) las acciones de conservación se diseñen deliberada e informativamente como respuestas a uno o más desafíos sociales, y requirieran alianzas innovadoras y la integración de múltiples enfoques (tales como complementariedades con infraestructura gris, es decir, soluciones híbridas).

En consecuencia, con un interés mundial en la SbN en rápido crecimiento, es necesario garantizar que un Estándar relevante y robusto de forma al diseño y ejecución de cada SbN, y que dicho Estándar garantice que:
- exista una comprensión e interpretación comunes del concepto de SbN entre distintos sectores, usuarios y geografías;

- el despliegue de la SbN se lleve a cabo de manera sistemática y coordinada con otros sectores, usuarios y geografías afectadas;

- haya un control de calidad en el diseño y ejecución de las intervenciones a través de procesos estandarizados que permitan la rendición de cuentas;

- los instrumentos, enfoques y métodos pertinentes existentes se aprovechen plenamente para diseñar y ejecutar una solución;

- los riesgos relacionados con el uso no sostenible de la naturaleza se reduzcan al mínimo, y las acciones que puedan ser altamente perjudiciales para la biodiversidad y la sociedad no se clasifiquen como SbN; y.

- múltiples sectores participen en la implementación y tratamiento de los desafíos sociales.

De este modo, la SbN contribuirá al cambio transformador, al convertirse en elemento integral en la planificación y ejecución de las respuestas de la sociedad a tales desafíos. 


\subsection{Alcance del Estándar}

El Estándar Global de la UICN para las SbN es un concepto amplio y definitivo que puede ejecutarse mediante enfoques e instrumentos existentes en materia de ecosistemas, especialmente los que son operativos y participativos. Por lo tanto, la interpretación e implementación del concepto de SbN es muy específica del contexto, y depende de una variedad de factores que influyen en los desafíos sociales que se están abordando, incluidos los tipos de ecosistemas en el paisaje terrestre o marino en que se esté implementando la SbN, el sistema socioeconómicocultural y la composición y las relaciones de los grupos de interesados. En este caso, solo es factible estandarizar los procesos para el diseño y ejecución de SbN, en lugar de esperar un resultado estándar prescrito cada vez que se implemente una solución. Por lo tanto, el Estándar Global para SbN es un Estándar facilitador que tiene por objetivo permitir una mayor aceptación y mejorar el diseño y la ejecución, en lugar de regular los procesos para alcanzar resultados o logros específicos. También se prevé que el proceso de aplicación del Estándar para SbN proporcione pruebas sobre la manera de abordard los cambios ambientales y sociales en el tiempo y contribuir a mejorar el desarrollo de políticas.

El Estándar permitirá a los profesionales estandarizar el diseño e implementación de SbN, mediante: 1) el establecimiento de una base común de entendimiento para lo que es y no es una SbN; 2) la contribución con cambios transformadores, al mejorar la práctica de la SbN, y apoyar la clarificación y desarrollo de normativa relacionada con la SbN.

\subsection{Uso y público objetivo}

El Estándar ha sido creado para que utilice cualquier persona que trabaje en la verificación, diseño y ampliación de SbN. Los usuarios pueden incluir administradores de proyectos del sector público y privado, planificadores de paisaje, profesionales del desarrollo y conservacionistas, Gobiernos o representantes del sector financiero (donantes e inversores), encargados de formular políticas y planificadores. En esta etapa, el Estándar tiene dos funciones: ayudar a guiar el diseño de una SbN y proporcionar un medio para verificar que el diseño cumpla los requisitos del Estándar SbN.

- Diseño: los ocho criterios orientados al proceso responden a los aspectos más importantes de diseño (y ejecución futura) para que una intervención se califique como una SbN. En ese sentido, los criterios responden a un ciclo de gestión de proyectos, al tiempo que destacan los aspectos críticos de la reflexión más allá del espacio geográfico y los plazos del proyecto, y la necesidad de practicar la gestión adaptativa, puesto que el diseño de SbN se basa en una teoría del cambio que inevitablemente contendrá supuestos que deben probarse en el curso de la ejecución.

- Verificación: cuando se diseña una solución, se puede utilizar el Estándar para determinar si se califica como SbN o no. Esta función del Estándar es importante para usuarios tales como financiadores e inversores, que podrían solicitar la presentación de soluciones. Además, las SbN pasadas y en 
curso que preceden la creación de este Estándar también pueden evaluarse a partir de los criterios del mismo, si la intención es que la intervención sea reconocida como una SbN.

- Ampliación: es posible encontrar en línea algunos ejemplos de SbN con una buena parte de los ocho criterios del Estándar en que apenas faltan unos pocos. Muchos de estos serán probablemente pilotos o intervenciones que tienen un plazo limitado o representan un enfoque independiente. El Estándar puede usarse tanto para identificar candidatos sólidos que ampliar, como para identificar lagunas que reparar a fin de transformar la intervención en una SbN sólida.

Además, el Estándar está diseñado para que se utilice como un proceso de autoevaluación o verificación de primera parte. En consonancia con el enfoque del Estándar sobre la facilitación de una mayor aceptación del concepto de SbN, en la actualidad la autoevaluación proporciona un enfoque robusto y flexible para poder diseñar y ejecutar tales soluciones. Ofrece espacio para el aprendizaje y la reflexión iterativos, en lugar de un rígido proceso de certificación normativa, dado que el mundo todavía está entendiendo e interpretando las SbN para distintas necesidades y contextos. 


\section{Proceso de codesarrollo del Estándar Global}

\subsection{Fundación en el marco de definición de la UICN para SbN}

El objetivo principal de las SbN es apoyar el logro de los objetivos de desarrollo de la sociedad y salvaguardar el bienestar humano de manera que refleje los valores culturales y sociales y mejore la resiliencia de los ecosistemas, su capacidad de renovación y la prestación de servicios (UICN, 2016). Junto con el marco de definición de la UICN para las SbN, presentado en 2016, en que se definió las SbN como "acciones dirigidas a proteger, gestionar y restaurar de manera sostenible ecosistemas naturales o modificados, que hacen frente a retos de la sociedad de forma efectiva y adaptable, proporcionando simultáneamente bienestar humano y beneficios de la biodiversidad" (UICN, 2016), los miembros de la UICN adoptaron ocho principios (UICN, 2016), que figuran en la figura 5. Desde entonces, también ha surgido rápidamente una sólida base de literatura publicada que corrobora este papel de las SbN en la conservación.

Un análisis reciente de los principios de las SbN (véase supra) encontró que el marco de las SbN va más allá de otros enfoques similares (p. ej., la restauración de los paisajes boscosos (RPB); la adaptación basada en ecosistemas (AbE); la

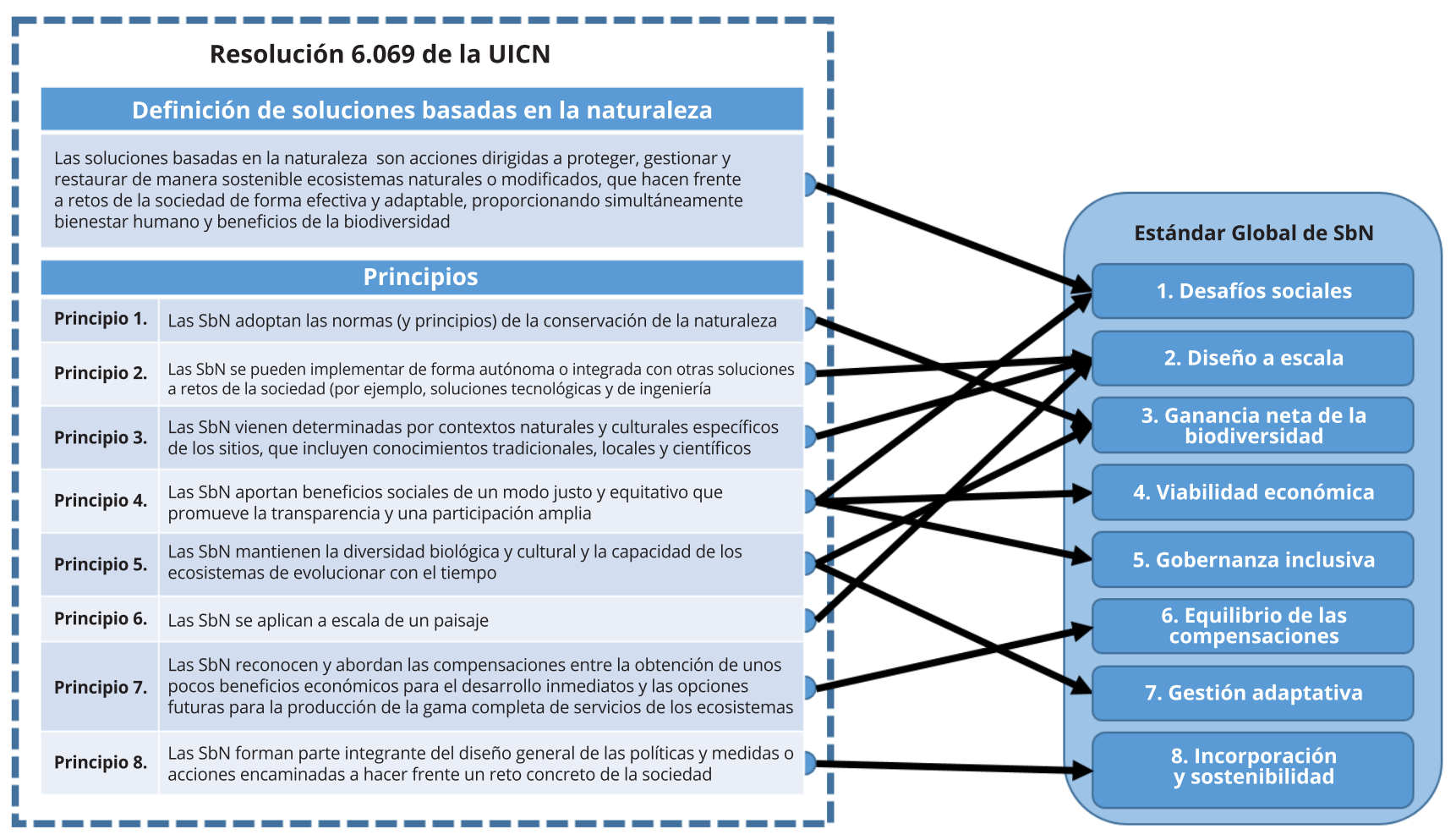

Figura 5: Vínculo entre los principios de SbN y los criterios del Estándar para SbN. (@ UICN) 
restauración ecológica; el enfoque ecosistémico) a través de tres de sus principios $(2,6$ y 8 , es decir, sobre las sinergias de las SbN con otros tipos de soluciones, ejecución a escala de paisaje terrestre o paisaje marino, e integración de políticas). Por lo tanto, el marco de SbN pueden considerarse uno que abarca una serie de enfoques bien establecidos basados en ecosistemas y relacionados con ecosistemas (Cohen-Shacham et al., 2019).

\subsection{Visión general del proceso de codesarrollo}

La UICN facilitó el diseño conjunto de un Estándar para SbN al reunir conocimientos, aptitudes y experiencias de expertos de una amplia gama de partes interesadas. Ese tipo de colaboración masiva en torno al Estándar ha sido importante, dado que las SbN son un tema transversal y, por lo tanto, requieren la integración de múltiples campos de conocimiento (como la ecología, las ciencias sociales, las ciencias políticas, las matemáticas y la economía) y distintas formas de conocimiento (p. ej., conocimiento experimental, conocimiento científico y conocimiento tradicional) para dar forma a buenas prácticas. Hubo dos rondas de consultas públicas, con más de 800 respuestas (sectores público y privado, así como organizaciones no gubernamentales) de 100 países.

Las encuestas de consulta fueron ampliamente difundidas entre los miembros de la UICN y los asociados, incluidas empresas multinacionales, redes de coaliciones y donantes. Además, la Comisión de Gestión de Ecosistemas (CEM) contribuyó al examen científico de los principales conceptos, criterios e indicadores en cuatro reuniones del Comité Directivo, y convocó dos talleres en Washington DC con la participación de varios miembros del equipo directivo. Se recibieron aportes por escrito y a través de discusiones presenciales con grupos focales. Todos los aportes de las consultas de amplio alcance moldearon en gran medida el alcance y el contenido del Estándar. Esta versión final del Estándar fue adoptada en la 98. a reunión del Consejo de la UICN. El Estándar ha sido publicado por la UICN en 2020.

Con respecto al método técnico para elaborar el Estándar, el primer paso fue identificar los ocho principios de SbN, aprobados por los miembros de la UICN mediante la resolución WCC-2016Res-069-ES (UICN, 2016), con trece normas, enfoques y directrices pertinentes vigentes para los marcos de gestión de ecosistemas. Se trazaron los principios y las lagunas comunes entre los marcos para establecer tanto los fundamentos comunes de SbN como los elementos únicos de SbN, a fin de permitir el desarrollo de un Estándar de la UICN. Utilizando este método, se elaboraron originalmente siete criterios para la consulta interna utilizando los conocimientos y la experiencia de la UICN. Sobre la base de exámenes y consultas posteriores, se proporcionan ocho criterios de SbN.

\subsection{Código internacional de normas de sostenibilidad}

Desde el inicio del proceso de elaboración del Estándar, la UICN se comprometió a promover la convergencia, en la medida de lo posible, entre el desarrollo del Estándar Global para SbN de la 
UICN y el Código de buenas prácticas de la Alianza de Acreditación y Etiquetado Social y Ambiental Internacional (ISEAL): el establecimiento de normas sociales y ambientales. Esta versión del Estándar Global para SbN de la UICN ha sido modelada en torno a las lecciones aprendidas durante las consultas públicas mundiales realizadas en 2018 y 2019.

En la parte I del Estándar Global para SbN se enumeran los criterios e indicadores adoptados por la 98. Reunión del Consejo de la UICN en 2020. Este documento, que es la parte II, acompaña este folleto para proporcionar el fundamento científico y la orientación de los usuarios. Un documento adicional, la parte III, servirá posteriormente como guía para el usuario sobre la base de las lecciones de los programas piloto, y vinculado con una herramienta de autoevaluación con sugerencias de medios de verificación y diseño e instrumentos de ejecución. 


\section{Orientación sobre los criterios}

\subsection{Resumen}

El Estándar consta de ocho criterios, y cada uno tiene un conjunto de indicadores. Los criterios se basan firmemente en los principios de SbN, así como en la retroalimentación de las consultas.

El Criterio 1 describe el proceso para determinar los retos sociales que enfrentan las partes interesadas y los titulares de derechos, así como para establecer una comprensión de las oportunidades y desafíos asociados. El diseño de la solución debe tener como objetivo abordar el desafío, teniendo en cuenta los contextos sociales, económicos y ecológicos más amplios en los que existe el desafío y la solución, según el Criterio 2. El Criterio 2 aborda el hecho de que incluso si la ejecución de la solución se realiza a nivel de sitio o a menor escala, las

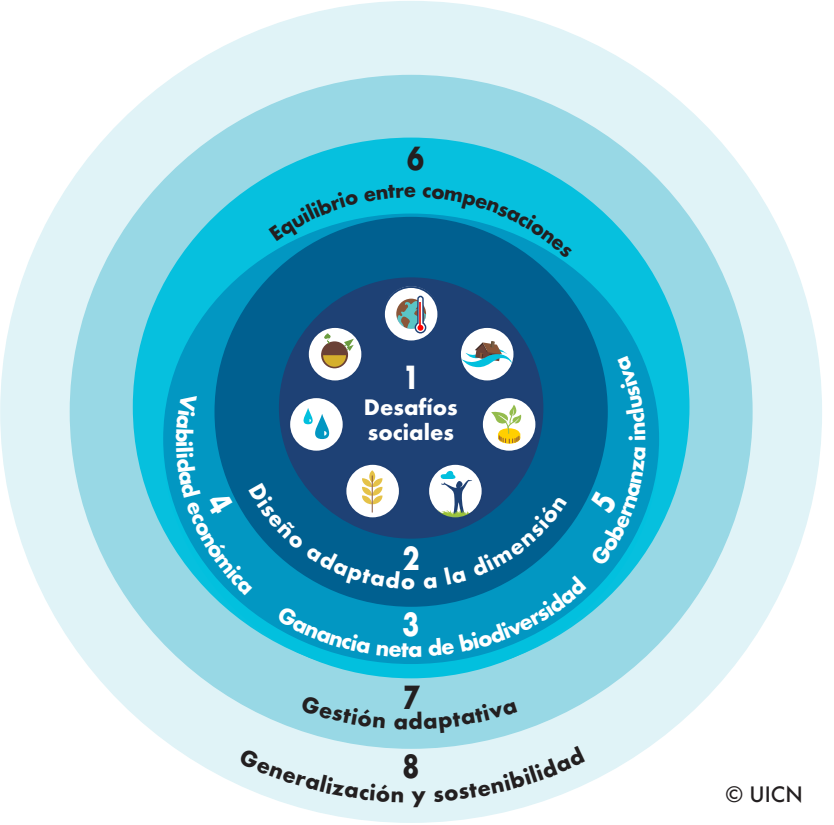

Figura 6. Los ocho criterios que integran el stándar Global de SbN de la UICN están interconectados. (c) UICN consideraciones de nivel de escala mayor pueden en gran medida modelar la solidez y durabilidad de la solución más allá de su ejecución. Los Criterios 3, 4 y 5 esbozan procesos que pueden aumentar las posibilidades de obtener resultados positivos para la biodiversidad, la sociedad y la economía. Sin embargo, para lograr estos tres Criterios con respecto a los resultados inmediatos, a corto y a largo plazo, es necesario determinar y hacer compensaciones, que se enfocan directamente en el Criterio 6, a fin de dar visibilidad e importancia a esta cuestión. Los procesos de adopción de decisiones para cualquier compensación que se haga deben ser transparentes y equitativos, y estar dentro del contexto de uno o más de los Criterios 3, 4 y 5. Además, los principios de la gestión adaptativa, sustentada por una teoría del cambio y procesos de aprendizaje iterativo, según el Criterio 7, también pueden mejorar los logros de la SbN. El Criterio 8 se centra en los procesos para la incorporación de la SbN en escalas espaciales y temporales, mediante los cuales las acciones y los impactos pueden sostenerse más allá de los proyectos independientes, a fin de realizar plenamente el potencial de la naturaleza como herramienta que proporciona solución a los desafíos sociales.

Las siguientes secciones proporcionan orientación sobre los ocho criterios del Estándar SbN y sus indicadores subyacentes. La guía describe los elementos de una SbN sólida e identifica dónde se vinculan entre sí los distintos criterios e indicadores. 


\section{Criterio 1: Las SbN responden eficazmente a los desafíos sociales}

Debe diseñarse una SbN para abordar de manera eficaz y eficiente desafíos sociales específicos, tales como la adaptación y mitigación del cambio climático, la reducción de los riesgos naturales, la degradación de los ecosistemas y la pérdida de biodiversidad, la salud humana, el desarrollo socioeconómico, la seguridad alimentaria y la seguridad hídrica. Se pueden utilizar tres tipos principales de acciones de conservación eficaces (de manera independiente o combinada) para hacer frente a los desafíos sociales: la conservación mediante la protección, la restauración y las actividades restaurativas, y el uso sostenible. El diseño apunta a lograr resultados específicos que directa y explícitamente se dirijan a los desafíos sociales y aporten a una necesidad social, manteniendo al mismo tiempo las funciones de los ecosistemas.

Deben entenderse las condiciones sociales, económicas y ambientales prevalecientes antes de que se inicie la intervención. Esto es importante para que el tipo de desafío que se está abordando y la idoneidad de la SbN propuesta se puedan evaluar y comprender adecuadamente, y para que se midan las mejoras a lo largo del tiempo. La línea de referencia puede consistir en un análisis de la situación, informado por la literatura publicada y/o gris. Además, la línea de referencia debería desarrollarse mediante consultas con los interesados pertinentes, los beneficiarios previstos y otros agentes, como organismos gubernamentales, empresas del sector privado, académicos locales y científicos especializados en el clima y la ecología del sitio, así como las autoridades subnacionales con un mandato específico para el lugar de destino.

Aunque las SbN se centran en abordar desafíos sociales, las actividades definidas también deben apuntar a sostener y mejorar los servicios de los ecosistemas, manteniendo al mismo tiempo la estructura, función y composición de los ecosistemas (véase el criterio 3). Esto preserva la integridad y estabilidad del sistema ecológico y mejora de ese modo la eficacia a largo plazo de la SbN en cuestión para abordar el desafío o retos sociales. Una SbN que simplifique la estructura, función y composición del ecosistema reduce la resiliencia $y$, si bien puede producir resultados de corta duración, eventualmente colapsará. Los enfoques holísticos con una duración de varios años tendrán la mejor oportunidad de éxito.

\section{C-1.1 Se da prioridad a los retos sociales más apremiantes para los titulares de derechos y los beneficiarios}

Aunque que la SbN puede generar múltiples beneficios para una multitud de desafíos sociales, las intervenciones de SbN deben responder a al menos uno (o más) desafíos sociales específicos.

Se debe utilizar un proceso transparente e inclusivo (criterio 5) para identificar el desafío social. Esto se debe a que lo que los interesados externos pudieran percibir como desafíos prioritarios, podrían no ser apreciados por las poblaciones locales como los más apremiantes, y viceversa. Por lo tanto, los procesos descritos en los criterios 5 y 7 deben dar forma a la toma de decisiones. Además, es importante comprender y reconocer que, debido a los impactos interrelacionados de los desafíos sociales sobre los actores locales, resolver un desafío social en particular puede requerir abordar al mismo tiempo otro desafío. A modo de ejemplo, en algunas comunidades puede ser imposible trabajar con los impactos a largo plazo del cambio climático si las comunidades 
carecen de la capacidad para hacer frente a los desastres estacionales, o incluso carecen de un lugar seguro donde vivir. De manera alternativa, si los desafíos sociales y culturales no se abordan bien, como el empleo o la tenencia de la tierra, será difícil alcanzar puntos de inflexión. Se necesita un enfoque de la teoría del cambio para asegurar un cambio transformador que dure para las generaciones venideras. Las referencias y herramientas sobre cómo desarrollar una teoría del cambio estarán disponibles como información complementaria a este Estándar.

\section{C-1.2 Los retos sociales que se abordan se entienden y documentan claramente}

La intervención de SbN debe abordar los retos sociales que afectan directamente a un grupo específico de personas (como una SbN para controlar la erosión costera que pone en peligro a un municipio específico) o impacta indirectamente a la sociedad en su conjunto (como una SbN para secuestrar carbono como opción de mitigación del cambio climático). Sin embargo, una intervención de SbN en torno a un desafío social en particular a menudo produce múltiples beneficios sociales, tales como la creación de empleo, otros beneficios económicos $y$, donde sea apropiado, los desafíos sociales que estos beneficios adicionales abordan deben ser descritos, documentados y contabilizados.

Igualmente, no todas las intervenciones de conservación o restauración pueden afirmar automáticamente ser una SbN. Si bien las intervenciones de conservación pueden generar (directa o indirectamente) beneficios sociales auxiliares, muchas no están explícitamente diseñadas o gestionadas para ofrecer tales beneficios. Para que una intervención de conservación existente se amplíe o se convierta en una SbN, sería necesario modificar el mandato y el plan de gestión a fin de responder a los criterios y objetivos de SbN, junto con el establecimiento de las líneas de referencia necesarias para medir y contabilizar la ejecución. En particular, el criterio 7 (gestión adaptativa) tendría que guiar la transformación de una acción de conservación en una intervención de $\mathrm{SbN}$.

\section{C-1.3 Los resultados del bienestar humano derivados de las SbN se identifican, se comparan y se evalúan periódicamente}

Hay que desarrollar metas para que la intervención ofrezca beneficios para el bienestar humano (véase el glosario para la definición del bienestar humano). Esto es pertinente para diferenciar entre acciones de conservación y SbN (indicador 1.1). Lo ideal sería que se elaboraran metas tanto para la aplicación como para los efectos de la intervención. Si bien los efectos plenos de la SbN pueden alcanzarse más allá del cronograma de intervención, se pueden elaborar metas o hitos indicativos. Tales metas o hitos podrían incentivar la inversión a largo plazo para el mantenimiento de la SbN, y serían útiles para el monitoreo a largo plazo de la intervención. 


\section{Criterio 2: El diseño de las SbN se adapta a la dimensión}

Un buen diseño de SbN es consciente de las interacciones que ocurren en distintas escalas sociales y ecológicas dentro de un paisaje marino o terrestre, y las tiene en cuenta; por ejemplo, la migración estacional de una comunidad de pastores, o la emigración estacional de jóvenes de comunidades rurales para trabajar en una ciudad distante, o bien el flujo de remesas de familiares que viven a distancia. Si no se reconocen en el diseño del proyecto, las interacciones entre las distintas escalas pueden conducir a acciones equivocadas o mal colocadas, duplicación, conflicto y fracaso del proyecto.

Es importante entender cómo se organizan e interactúan los distintos ecosistemas dentro de la misma zona (paisaje). En cada fase del desarrollo y ejecución de la SbN se debe considerar la mayor superficie terrestre/marina.

Las SbN deben ser consideradas dentro de una escala de paisaje terrestre o marino, porque los ecosistemas son afectados por el paisaje terrestre y marino más grande en que están insertos, y tienen efectos sobre estos, por lo cual no pueden ser manejados de manera aislada. Además, debido a que algunos bienes y servicios de los ecosistemas se generan a escala terrestre o marina, las actividades de SbN deben desplegarse estratégicamente en todo el paisaje terrestre o paisaje marino más amplio.

De hecho, la gestión de los procesos ecológicos a nivel del paisaje (p. ej., el reciclado de nutrientes) puede ser tan importante como las decisiones de gestión tomadas a nivel del lugar de intervención, especialmente si la prestación de servicios de los ecosistemas es un objetivo importante.

Por lo tanto, la evaluación, planificación, ejecución y supervisión a largo plazo de las actividades destinadas a influir sobre los bienes y servicios de los ecosistemas que benefician a la sociedad en general (agua, mitigación y adaptación del clima, etc.) requieren enfoques a escala de paisajes terrestres y marinos, así como la aplicación y supervisión integradas de medidas específicas para cada lugar. Por estas razones, en cada fase del desarrollo y ejecución de la SbN debe considerarse el mayor paisaje terrestre/ marino, así como los diversos procesos sociales y económicos que tienen lugar a estas escalas.

\section{C-2.1 El diseño de la SbN reconoce y responde a las interacciones entre la economía, la sociedad y los ecosistemas}

Todas las intervenciones, incluidas las que se realizan en lugares únicos o en pequeñas escalas espaciales, deben desarrollarse en el contexto del gran paisaje terrestre/marino mediante la planificación del paisaje terrestre/marino, a fin de garantizar que las actividades sean estratégicas y aumenten al máximo los beneficios para las personas y los ecosistemas, al mismo tiempo que se minimizan los efectos adversos sobre los ecosistemas y poblaciones humanas adyacentes. La implementación de una SbN innovador a pequeña escala es la base para la ampliación en la medida en que las partes interesadas en el paisaje terrestre/marino aprenden y adoptan las prácticas novedosas iniciadas por quienes están dispuestos a probar algo nuevo. El contexto del paisaje terrestre/marino más amplio incluye perspectivas ecológicas, económicas y socioculturales.

En lugar de centrarse en un ecosistema específico o en un solo conjunto de partes interesadas, la escala del paisaje terrestre/marino considera cómo los ecosistemas y sus funciones están conectados con los valores, derechos y 
beneficios de las distintas partes interesadas. La planificación y la toma de decisiones de la SbN siempre deben emprenderse teniendo en cuenta la escala del paisaje terrestre/ marino, y entendiendo las implicaciones de las intervenciones a escala del paisaje terrestre/ marino. Estas consideraciones podrían ayudar a asegurar que los profesionales de SbN integren las diversas necesidades, los diferentes planes sectoriales, los programas y las políticas, y apoyen el uso de prácticas tradicionales adecuadas para su aplicación, en un único contexto espacial que haya considerado las compensaciones, las opciones y los escenarios. Estas consideraciones sobre el nivel del paisaje terrestre/marino no solo incluirán medidas de los efectos específicos del sitio, sino también de los impactos acumulativos entre los sitios y múltiples partes interesadas.

Dado que las interacciones entre las personas y la naturaleza son complejas e inciertas, el diseño de SbN se puede crear a partir de un modelo cualitativo simple desarrollado en un proceso participativo. Típicamente, esto implicaría la identificación de interacciones primarias entre los interesados y sus usos de la tierra, interacciones entre estos grupos de interesados y el paisaje terrestre o marino en sí, y las interacciones entre el paisaje terrestre o marino y las políticas y disposiciones reglamentarias jurisdiccionales, incluyendo las leyes y políticas nacionales. Este modelo de sistemas simples puede proporcionar la base para el desarrollo participativo de escenarios futuros que guíen la toma de decisiones y permitan la integración adecuada de los temas relacionados con los criterios 3, 4, 6 y 8.

Comprender la influencia de las interacciones a través de escalas jerárquicas (tanto dentro como entre instituciones que participan en la $\mathrm{SbN}$ ) tiene importantes implicaciones para la gobernanza y la consideración de la manera en que las instituciones existentes (tanto formales como informales) pueden apoyar o inhibir diseños alternativos de SbN.

\section{C-2.2 El diseño de SbN está integrado con otras intervenciones complementarias y busca sinergias entre sectores}

Las SbN pueden implementarse de manera independiente, aunque normalmente forman parte de un paquete integrado que incluye otros tipos de soluciones para abordar los retos sociales (p. ej., soluciones tecnológicas y de ingeniería, instrumentos financieros). Las sinergias de SbN con otros tipos de soluciones podrían planificarse de forma explícita. Es importante que todos los aportes tengan sólida base científica e incorporen un enfoque integrador de supervisión como parte del diseño.

Pueden identificarse los vínculos entre una serie de sectores para ampliar el alcance de la respuesta a los desafíos sociales a fin de apoyar las sinergias entre las diferentes soluciones. Estos enfoques conjuntos mejoran la apropiación del enfoque, reducen los riesgos de consecuencias negativas no intencionales y facilitan la incorporación general de las SbN en distintas políticas y sectore. Mientras se planifica la SbN, es importante buscar activamente sinergias potenciales con diversos sectores (p. ej., agricultura, silvicultura, agua, salud, etc.) que contribuyan con el SbN, aborden las necesidades de subsistencia y mejoren la calidad ambiental. Algunos ejemplos ilustrativos de tales vínculos podrían incluir la incorporación en la SbN de: a) los sectores de la agricultura o seguro de cosechas, para abordar mejor la seguridad alimentaria; b) el sector de la salud, para abordar mejor la salud humana en los paisajes urbanos; c) infraestructura, para hacer frente al riesgo de desastres por inundaciones en una 
costa (mediante una mezcla de manglares y rompeolas).

\section{C-2.3 El diseño de SbN incorpora la identificación y la gestión de riesgos más allá del lugar de intervención}

Los procesos de diseño creíbles requieren una evaluación de la influencia de los procesos sociales y ecológicos, y del riesgo de cambios indeseables en el sistema debido a la ocurrencia de un evento externo (p. ej., un riesgo natural)y de cómo esto puede influenciar el resultado previsto de una intervención. Esto es especialmente así para los impactos negativos que surgen fuera de las fronteras de la intervención.

La evaluación de riesgos también considerará la posibilidad de una mayor vulnerabilidad de algunas partes interesadas como consecuencia no intencionada del diseño de la intervención. Esto es importante en el caso de la SbN, donde múltiples fuentes pueden afectar la salud y la integridad a largo plazo de los servicios de los ecosistemas subyacentes. La acción temprana, como la evaluación de riesgos e impactos, así como la gestión proactiva de amenazas, puede marcar la diferencia entre una SbN exitosa y fallida. Las preguntas clave básicas pueden abordarse mediante evaluaciones de vulnerabilidad y resiliencia, como:

- ¿Existen políticas nacionales, subnacionales o locales que puedan socavar los objetivos de gestión de la SbN del sistema socioecológico en cuestión?

- ¿Existen reivindicaciones contrapuestas sobre los sistemas y servicios socioecológicos que sustenten la SbN?

- ¿Existen prácticas de uso de la tierra cercana o corriente arriba que puedan reducir la eficacia de la SbN?

- ¿Es el diseño de la SbN suficientemente robusto para absorber los cambios económicos, demográficos y relacionados con el clima?

- ¿Introduce el propio SbN riesgos potenciales o presiones adicionales en el ecosistema de apoyo (p. ej., riesgo de introducción o propagación de especies invasoras)? 


\section{Criterio 3: Las SbN dan lugar a una ganancia neta en términos de biodiversidad e integridad de los ecosistemas}

La actual crisis de la biodiversidad no solo amenaza con la extinción de especies raras, sino que también está degradando gravemente muchos ecosistemas, socavando tanto la salud planetaria como el bienestar humano en general. Independientemente de los retos sociales que se planteen, todos las SbN deben tener un impacto positivo neto sobre la biodiversidad; en otras palabras, la diversidad biológica y la integridad ecológica del área de intervención y sus alrededores deben mejorar como resultado directo de la SbN.

La SbN debería tratar de conservar o restaurar la integridad de los ecosistemas y evitar simplificar aún más un ecosistema (como al sustituir bosques mixtos naturales con una plantación de monocultivos de árboles). Aunque la diversidad biológica (véase la definición completa en el glosario) es un componente clave de la integridad ecológica, otros componentes igualmente importantes incluyen la estructura y función de los ecosistemas y los paisajes terrestres y marinos, así como la conectividad. Además, la SbN depende de la condición ecológica de los ecosistemas de apoyo; por lo tanto, redunda en interés del profesional de la SbN garantizar que las medidas de aplicación, como mínimo, mantengan la integridad ecológica de la zona meta a largo plazo. Lo que es importante es que los objetivos de conservación sean acordados por los proponentes de la SbN e incorporados en los planes de ejecución, y que se tenga en cuenta el progreso durante el monitoreo de la ejecución, sin perder de vista el desafío social que la SbN pretende abordar.
Es prudente que los profesionales de la SbN evalúen periódicamente los efectos adversos en los ecosistemas meta y adyacentes. El plan operativo de la SbN debería detallar una revisión basada en evidencia de los posibles riesgos e impactos de las principales acciones de la SbN sobre la diversidad biológica de la zona. Además, la primera fase en la planificación de una SbN debería ser la comprensión de la condición de referencia del paisaje terrestre/marino meta con respecto a la diversidad biológica, composición, estructura, función, conectividad y amenazas externas. Esta condición de referencia brinda información sobre el grado de degradación, y puede utilizarse para determinar los objetivos específicos de la SbN, así como para determinar la eficacia y los efectos. Debido a que todos los ecosistemas y los paisajes terrestres y marinos -incluidos los que libres de degradación o que solo tienen mínima degradación- son dinámicos, el grado de degradación no debe evaluarse basándose en el ecosistema histórico o en el paisaje terrestre o marino, sino más bien en la condición en que se habría encontrado el sistema en el momento actual si no se hubiera producido la degradación. Esto puede caracterizarse creando modelos a partir de sitios de referencia existentes o paisajes terrestres y marinos, información teórica o conocimientos tradicionales. Las encuestas y la recopilación de datos pueden ser costosas. No obstante, es necesario que las líneas de referencia caractericen los componentes clave de la integridad ecológica y determinen los factores que impulsan la degradación. 


\section{C-3.1 Las intervenciones con SbN responden directamente a una evaluación basada en datos del estado actual del ecosistema y de los principales impulsores de su degradación y pérdida}

Las encuestas y la recopilación de datos son costosas, por lo que siempre existe el riesgo de que los profesionales de la SbN limiten las evaluaciones de referencia exclusivamente al servicio o servicios de ecosistemas de interés (p. ej., una iniciativa para secuestrar carbono mediante una mejor gestión de las turberas solo evalúa el potencial de captura de carbono). Sin embargo, dado que la prestación de servicios de los ecosistemas se sustenta en la integridad y el estado del propio ecosistema $y$, dado que uno de los principales atractivos de las SbN es que también contribuyen a la conservación de la biodiversidad, es conveniente que las líneas de referencia sean suficientes para orientar estos tipos de decisiones de gestión durante la aplicación.

La información básica de una línea de referencia, como mínimo, debe comprender:

1. información estructural, incluida la dinámica trófica y los estratos de vegetación y su distribución espacial dentro de los ecosistemas, así como la distribución espacial (y los patrones de distribución) de los principales tipos de ecosistemas dentro de los paisajes terrestres y marinos, según la escala requerida en la zona de interés y su estado de conservación actual;

2. la composición de las especies, incluida la abundancia de especies de grupos taxonómicos fundamentales (p. ej., plantas vasculares, mamíferos, aves y microorganismos del suelo) y estado de conservación actual de las especies (riesgo de extinción);

3. información sobre las funciones clave de los ecosistemas (p. ej., tasas de productividad, flujos de agua y nutrientes e interacciones bióticas);

4. Aspectos clave del medio ambiente físico (p. ej., cantidad y calidad del agua e información sobre las propiedades físicas y químicas de los suelos y otros sustratos);

5. conectividad, incluidos los corredores de vegetación natural o seminatural a través de la tierra/paisaje marino que vinculan las áreas protegidas y semiprotegidas con otros refugios para la biodiversidad, y que permiten el intercambio de propágulos, agua y materiales entre ecosistemas;

6. amenazas externas al ecosistema o al paisaje terrestre/marino y el riesgo de colapso de los ecosistemas, cuando sea posible, según lo determinado por la Lista Roja de la UICN de Especies Amenazadas ${ }^{\mathrm{TM}}$ y la Lista Roja de Ecosistemas de la UICN, respectivamente;

7. intervenciones de conservación existentes o en curso para las especies y ecosistemas en riesgo en el paisaje terrestre/marino.

La evaluación de la línea de referencia debe usarse para determinar el grado de degradación y diseñar los objetivos del proyecto, así como para entender los cambios que impulsa la SbN a lo largo del tiempo, lo que puede entonces moldear los objetivos de la gestión, incluida la adaptación de las intervenciones de la SbN para reducir los resultados negativos. Para ello es necesario que las variables evaluadas y la unidad de análisis sean similares o idénticas a la encuesta de referencia. Es necesario realizar un seguimiento periódico para evaluar las mejoras en la integridad de los ecosistemas y la capacidad para prestar los servicios deseados. 


\section{C-3.2 Se identifican resultados claros y cuantificables en términos de conservación de la biodiversidad, se establecen niveles de referencia para ellos y se evalúan periódicamente}

Dado que las SbN dependen de la salud y la condición de los ecosistemas de apoyo, es del interés del profesional garantizar que las medidas de ejecución al menos mantengan, y mejoren como acción ideal, la integridad ecológica y la diversidad de especies de la zona meta a largo plazo. El alcance y las opciones de esas mejoras son específicas del contexto, ya que dependen del acuerdo de otras partes interesadas, las políticas nacionales y subnacionales y los recursos disponibles. En algunas situaciones, la SbN puede incluir actividades de restauración ecológica que eliminan la degradación y permiten que el sistema se recupere a la condición en la que habría estado sin degradación. En otras, la SbN solo puede tratar de diversificar la composición de especies de sitios particulares o mejorar la aplicación de un solo subconjunto de funciones clave de los ecosistemas. Es importante que los objetivos de conservación se acuerden e incorporen en la ejecución, y que la eficacia y los efectos (incluidas las consecuencias no deseadas) se determinen mediante el seguimiento, sin perder de vista el desafío social que la SbN pretende abordar.

Como mínimo, la SbN debe incluir lo siguiente para cada meta de manejo relacionada con la conservación y restauración de la diversidad biológica y la integridad ecológica:

1. variables mensurables específicas asociadas con el objetivo de ordenación (p. ej., número de especies/ha, \% de cubierta de copas);

2. Acción (p. ej., aumentar, disminuir, mantener);

3. Cantidad (p. ej., $50 \%$ );

4. Período (p. ej., 5 años).

\section{C-3.3 El monitoreo incluye evaluaciones periódicas de las consecuencias adversas no deseadas sobre la naturaleza que surgen de la SbN}

En el momento en que se elabore el plan de $\mathrm{SbN}$, se debe elaborar un plan para implementar un programa de monitoreo a fin de determinar la eficacia y los efectos (incluidos los efectos adversos no deseados) de la SbN.

Los ecosistemas son complejos y dinámicos. Si bien un sólido proceso de planificación (criterio 2) ayudará a anticipar y abordar los impactos secundarios negativos, siempre existe el riesgo de que se produzcan resultados no deseados al trabajar con sistemas y procesos naturales. Es prudente que los profesionales de la SbN evalúen periódicamente los efectos adversos en los ecosistemas meta y adyacentes. Hacia el final, el plan operativo de la SbN debería detallar una revisión basada en evidencia de los posibles riesgos e impactos de las principales acciones de la SbN sobre la diversidad biológica de la zona. Esto debe incluir la frecuencia especificada de seguimiento y un marco para responder si se detectan impactos secundarios negativos.

El plan de seguimiento y evaluación debe incluir lo siguiente:

1. la cantidad y las fuentes de financiación de cada componente del programa de monitoreo (que se detallan a continuación);

2. el diseño de la recopilación de datos, incluidas las variables que se han de evaluar, el método de recopilación de datos, la replicación necesaria para determinar los efectos de las intervenciones de gestión, la frecuencia y la duración del monitoreo;

3. los tipos de análisis que se utilizarán para evaluar los efectos de la gestión; 
4. la ubicación y los protocolos para gestionary crear un archivo permanente de datos;

5. La manera en que se compartirán las lecciones aprendidas.

\section{C-3.4 Las oportunidades para mejorar la integridad y la conectividad de los ecosistemas se identifican e incorporan en la estrategia de SbN}

La conectividad de los ecosistemas se refiere a los flujos bidireccionales de componentes bióticos (es decir, vivos) de los ecosistemas que, de otro modo, estarían separados por barreras físicas en un paisaje terrestre/marino. Contribuir a mejorar la conectividad de los ecosistemas suele ser un objetivo de conservación que puede facilitar la SbN. La escala a la que se aborda la conectividad en la planificación depende de los objetivos que se hayan establecido para la intervención de la SbN.

También existe una sólida perspectiva social en torno a la conectividad de los ecosistemas y, en este sentido, algunas de las oportunidades más prometedoras para las intervenciones de SbN se relacionan con la demanda urbana de espacios verdes no solo para oportunidades educativas recreativas $y$ al aire libre, sino también, crecientemente, para la salud pública y la reducción de material particulado y polvo. Las conexiones entre los ecosistemas urbanos y el interior son muy buenos ejemplos del desarrollo de espacios verdes en las zonas urbanas.

Otros ejemplos de formas en que las SbN pueden mejorar la conectividad son los corredores planificados que vinculan pequeños refugios de biodiversidad, como los setos vivos, los humedales y las arboledas en ecosistemas modificados para acomodar el movimiento de especies a través de un paisaje; o la conservación de los vínculos entre los paisajes de aguas de cabecera y las zonas urbanas que aseguran el abastecimiento sostenible de agua para los residentes. Las SbN deben ser diseñadas, ejecutadas y monitoreadas tomando en consideración la conectividad y su efecto sobre la integridad del ecosistema. 


\section{Criterio 4: Las SbN son económicamente viables}

Uno de los desafíos que enfrentan muchos profesionales de SbN hoy en día es la falta de planificación económica o financiera y recursos a largo plazo. Muchas intervenciones cometen el error de invertir muy pronto y no considerar la viabilidad económica y financiera más allá del plazo de la intervención. Esto no solo aumenta el riesgo de que fracase la SbN, sino que también no aprovecha las oportunidades que la SbN ofrece con miras al desarrollo económico sostenible; por ejemplo, la creación de empleos verdes y medios de subsistencia sostenibles se pueden integrar en el ámbito de una intervención de SbN para proporcionar incentivos para un mayor impacto.

Para que la SbN sea sostenible debe haber una fuerte consideración económica (sumada a la de los otros dos pilares del desarrollo sostenible: medioambiental y social). De lo contrario corremos el riesgo de que las ejecuciones se limiten a la vida útil de sus proyectos (p. ej., cinco años) y, al concluir la ejecución, la solución y los múltiples beneficios proporcionados disminuyen $y$, eventualmente, dejan de existir, y esto incluye la posibilidad de dejar el paisaje terrestre/marino peor que antes. Además, las SbN no operan en un vacío en términos de finanzas, por lo que debe haber algún nivel de cohesión e integración con las instituciones financieras y las estructuras de incentivos. Es necesario comprender si la política económica y las estructuras financieras son complementarias para garantizar que la SbN ofrezca toda su gama de beneficios a la naturaleza y a las personas.

La naturaleza sustenta nuestra economía y nuestra sociedad al producir beneficios para las personas, tanto directamente (p. ej., alimentos, maderay fibra) como indirectamente (p. ej., el ciclo de nutrientes, formación de suelos, polinización). Los bienes y servicios que el capital natural proporciona a los seres humanos incluyen una serie de beneficios sociales y ambientales, entre ellos aire y agua limpios, mitigación y adaptación al cambio climático, alimentos, energía, lugares para vivir, materiales para productos, recreación y protección contra los peligros. Si bien algunos de estos beneficios se transponen y cotizan en los mercados, muchos beneficios de la naturaleza son bienes y servicios no comerciales, incluidos algunos aparentemente disponibles de forma gratuita. Al evaluar la SbN, un desafío clave es incorporar sus múltiples beneficios en un marco de evaluación económica común.

Los enfoques centrales para incorporar consideraciones económicas incluyen evaluaciones de coste-efectividad y costebeneficio. Cuando es rentable, la SbN Iogra el conjunto de resultados deseados (p. ej., secuestración de $\mathrm{CO}_{2}$, protección contra inundaciones, filtración de agua y conservación de la biodiversidad) a un coste comparable o inferior al de otras posibles soluciones para los mismos desafíos sociales. La rentabilidad no requiere la monetización de los beneficios; más bien, puede incorporar criterios de valoración de los beneficios monetarios y no monetarios utilizando sus cantidades físicas. La evaluación de la rentabilidad no requiere el uso de una moneda común, lo que ayuda a incorporar beneficios no monetarios, pero limita las opciones disponibles para contrastar los diferentes resultados de beneficios. La evaluación de múltiples criterios puede complementar la evaluación de la rentabilidad agregando distintos criterios de valoración de beneficios en un marco común de evaluación y decisión.

El análisis de rentabilidad integra múltiples resultados de beneficios, privados y sociales, haciéndolos comparables al usar una moneda común. Cuando todos los beneficios pueden ser monetizados, el análisis coste-beneficio ayuda a extenderse más allá de la rentabilidad, no solo 
evaluando el coste de lograr resultados con beneficios específicos (coste-efectividad) sino también determinando qué nivel de inversión en $\mathrm{SbN}$ se justifica en primer lugar (los beneficios exceden los costes).

\section{C-4.1 Se identifican y documentan los beneficios y costos directos e indirectos asociados a las SbN, determinando quién asume los gastos y quién se beneficia de ellas}

El requisito más básico para comprender los aspectos económicos de la SbN consiste en identificar y documentar todos los tipos de beneficios proporcionados (financieros y no financieros; económicos y no económicos), quién los recibe, cuáles son los costes de prestación y quién asume esos costes. Los beneficios y los costes pueden evaluarse en términos no económicos (p. ej., aumento de la calidad del aire) o económicos (p. ej., reducción de los costes de salud), o ambos. Es esencial la consideración de los aspectos de mercado y externos al mercado de la SbN a fin de asegurar una evaluación integral, para identificar quién es el pagador, quién se beneficiará y quién es el ejecutor. Esto servirá de base para el examen de las compensaciones con arreglo al sexto criterio (indicador 6.1).

\section{C-4.2 La elección de SbN se apoya en un estudio de costo-efectividad que incluye los efectos probables de cualquier regulación o de los subsidios pertinentes}

Un marco analítico puede ser un estudio básico de coste-efectividad, una evaluación de costebeneficio o un análisis de múltiples criterios. Hay varios métodos e instrumentos para ayudar a los estudios de rentabilidad y, como mínimo, un intento de hacerlo ayudará en gran medida a moldear el criterio 6 en torno a las compensaciones.

\section{C-La eficacia del diseño de la SbN se justifica en función de las soluciones alternativas disponibles, teniendo en cuenta cualquier externalidad asociada}

El objetivo principal de una SbN es abordar eficazmente al menos un desafío social de una manera económicamente viable. Para identificar la solución más efectiva y asequible, se deben considerar soluciones alternativas. Las soluciones alternativas pueden ser puramente tecnológicas o de ingeniería, soluciones estructurales (soluciones grises). La comparación de varias soluciones puede informar sobre la vía más eficaz para abordar los retos sociales Este indicador está estrechamente vinculado con el indicador 4.2.

\section{C-4.4 El diseño de SbN considera una cartera de opciones de recursos tales como basadas en el mercado, sector público, compromisos voluntarios y acciones para apoyar el cumplimiento de la normativa}

Es necesario contar con recursos suficientes para garantizar su sostenibilidad. Este es el caso independientemente de si la intervención es impulsada por el beneficio o no tiene fines de lucro. En este último caso, la dotación de recursos puede depender en un principio de una subvención, pero debe considerar los medios futuros de dotación de recursos fuera del marco temporal de la acción de intervención. Actualmente, a medida que crece la demanda de SbN, también lo hacen las opciones de recursos, especialmente el financiamiento 
innovador, como el financiamiento combinado. La financiación combinada es el uso estratégico de la financiación para el desarrollo para la movilización de financiación adicional hacia el desarrollo sostenible en los países en desarrollo (OCDE, 2020). Para garantizar que las SbN ofrezcan la solución más eficaz a los desafíos sociales en cada caso, se debe considerar una serie de opciones, entre ellas, por ejemplo, la economía circular, los compromisos voluntarios, los regímenes fiscales, los empleos verdes y las finanzas sociales. La financiación de la SbN por parte del sector privado, ya sea a través de la responsabilidad social corporativa (RSC) o de la financiación benévola, ofrece opciones que también deben tenerse en cuenta.
Se debe considerar un plan financiero/ empresarial a largo plazo para abordar la viabilidad económica/financiera y las limitaciones de la SbN. Este plan iría más allá del cronograma de la fase de planificación y ejecución inicial apoyada por donaciones. Si no se tienen en cuenta las consideraciones financieras a más largo plazo, el costo a corto plazo podría superar los beneficios a largo plazo. Es posible que dicho análisis concluya que la solución deseada no se puede considerar económicamente viable con el paso del tiempo. Por lo tanto, la planificación debe considerar la etapa de ejecución, pero también debe incluir un grado de reflexión prospectiva respecto del criterio anterior. 


\section{Criterio 5: Las SbN se basan en procesos de gobernanza inclusivos, transparentes y empoderadores}

Los procesos de gobernanza apropiados son cruciales para determinar los resultados exitosos de la SbN para las personas y la naturaleza. La participación equitativa, el reparto del poder, el reconocimiento y la seguridad de los derechos y la claridad de las responsabilidades garantizarán el beneficio simultáneo de las personas y la naturaleza a corto y largo plazo. La gobernanza de una intervención de SbN implica oportunidades para participar en procesos de identificación, toma de decisiones, monitoreo y retroalimentación, y quejas para todos los interesados. Todos las SbN deben tener un enfoque inclusivo al identificar y establecer mecanismos de gobernanza, y reconocer y respetar las prácticas culturales y los usos de la tierra preexistentes cuando sea posible, durante el ciclo de vida de la intervención y más allá. Se debe llevar a cabo un riguroso proceso de mapeo de las partes interesadas a fin de identificar la gama de partes interesadas que se verán afectadas por la SbN y de qué manera lo serán. Todos los grupos de interesados deben estar representados, y sus intereses en la intervención se deben considerar al tomar decisiones relativas a la SbN. Hacerlo puede minimizar el riesgo de marginar a un grupo de interesados en particular o, lo que es peor, afectarlos con la intervención de SbN. Por otra parte, la falta de un enfoque inclusivo de este tipo conducirá a la toma de decisiones basadas en perspectivas limitadas, sesgadas y reducidas, lo que podría conducir a mayores desigualdades sociales y/o económicas entre los interesados. Puede conducir a futuros conflictos con las partes interesadas desafectadas, que consideran que debieron haber sido consultadas. Esto es especialmente posible debido a las diferencias de poder inherentes o a la asimetría entre los interesados que pueden estar involucrados - ser afectados. Además, la falta de un enfoque inclusivo puede exacerbar los riesgos destacados en los indicadores 2.3 y 3.3 (cambios indeseables más allá del lugar de intervención y consecuencias adversas) y limitar la medida en que puede practicarse la gestión adaptativa.

La transparencia también es fundamental para garantizar que los recursos (financieros, humanos y naturales) se utilicen de manera justa y eficiente en beneficio del grupo o grupos beneficiarios identificados colectivamente y acordados entre todos los interesados. Se requiere la transparencia de los actores externos que puedan estar impulsando la intervención para que los actores locales y especialmente las comunidades locales entiendan las implicaciones inmediatas y a largo plazo de las intervenciones de SbN, ya sean ecológicas, económicas o sociales (especialmente todo posible impacto negativo sobre la cultura, los derechos y las prácticas locales). Es importante que todas las partes interesadas comprendan y tengan oportunidades equitativas de formar parte de los procesos de toma de decisiones sobre la manera en que se verían afectadas por tales implicaciones, incluso por cualquier compensación que haya que realizar (criterio 6) en la ejecución de la SbN.

La SbN también debe contribuir a abordar las desigualdades estructurales, emocionales y de gobernanza que puedan existir, especialmente las que alejan a los más marginados del poder de toma de decisiones. La gobernanza eficaz ayuda a evitar conflictos y fracasos en la acción de conservación. El uso de herramientas como el Marco para la Gobernanza de los Recursos Naturales (NRGF) puede contribuir directamente al cumplimiento del criterio 5, porque tienen como objetivo guiar el diseño y la implementación de proyectos que logren una consideración 
integral, consistente y sistemática de la inclusión, la equidad y los derechos.

Para lograr una gobernanza participativa, equitativa, transparente y responsable de las intervenciones de $\mathrm{SbN}$, el enfoque debe empoderar a los interesados, especialmente a aquellos que sean pobres, menos influyentes o marginados, al comienzo del proceso, mediante el aumento proactivo de la capacidad y el intercambio de conocimientos. El empoderamiento puede ofrecer las bases para la propiedad a largo plazo, crear autosuficiencia y, en última instancia, sostenibilidad, así como ampliar la intervención.

La comunicación y el compromiso son más eficaces cuando se reconocen y comprenden las necesidades y las culturas del público. Cuando sea pertinente, sería especialmente importante asegurar que las comunidades multiétnicas planificaran y asignaran recursos para la traducción e interpretación de los aportes, de modo que todos los presentes sepan y entiendan lo que todos dicen.

\section{C-5.1 Se pone a disposición de todos los interesados directos un mecanismo de retroalimentacion y solución de reclamaciones definido y plenamente acordado antes de poner en marcha una intervención de SbN}

Un mecanismo de solución de quejas o controversias debe adoptarse pronto (lo ideal sería que se hiciera al planificar la intervención), ya sea en forma de un proceso legal formal o de un sistema informal no legal, y debe tener procedimientos, funciones y reglas acordadas para recibir y adjudicar tales intervenciones. Los exámenes de los mecanismos de reparación existentes en el derecho internacional para las actividades de conservación han demostrado la importancia de incluir métodos contextualmente apropiados para abordar y reparar las reclamaciones. El mecanismo de presentación de reclamaciones debe ser legítimo, accesible, predecible, equitativo, transparente, compatible con los derechos, administrado de forma adaptativa y basado en la participación y el diálogo.

\section{C-5.2 La participación se basa en el respeto mutuo y la igualdad, independientemente del género, la edad o la condición social, y defiende el derecho de los pueblos indígenas al consentimiento libre previo e informado (CLPI)}

La participación debe tener como objetivo asegurar que una diversidad de conocimientos, habilidades e ideas dé forma a la ejecución y evolución de la intervención, por lo que los interesados son propietarios de la SbN y pueden incluso movilizar acciones colectivas y continuas después de la intervención. La plena participación es importante para el éxito de la intervención. La participación pasiva en los casos en que ciertos grupos de interesados puedan simplemente ser informados sobre lo que ha ocurrido u ocurrirá perjudicará la solidez del proceso. De manera similar, la participación no puede ser un ejercicio de extracción de información por parte de uno o más grupos de interesados, ni puede basarse en la coerción o ser incentivada por ganancias materiales. Cuando los pueblos indígenas se ven afectados, el principio de consentimiento libre, previo e informado (CLPI) debe seguirse de manera particular en el diseño y la ejecución de las SbN, pero otros grupos interesados también pueden beneficiarse de los enfoques de CLPI. 


\section{C-5.3 Se han identificado los las partes interesadas afectadas directa e indirectamente afectados de forma directa o indirecta por la SbN, y se les ha implicado en todos los procesos de la intervención}

La SbN debe permitir la participación activa de todas las personas que puedan verse afectadas directa o indirectamente desde el comienzo hasta el final de la intervención. Haciendo uso de una robusta herramienta de mapeo de interesados, es necesario llevar a cabo un análisis de actores a fin de identificar y comprometer a toda la gama de personas que pueden verse afectadas por la SbN. El proceso también debe identificar a las partes interesadas que puedan verse afectadas, y ofrecer oportunidades para su empoderamiento, y reparación, para evitar que queden más marginadas debido a la SbN. Los mecanismos para la toma de decisiones y la ejecución de la intervención de SbN deben reflejar la diversidad y el aporte de los grupos interesados afectados.

\section{C-5.4 Los procesos de toma de decisiones documentan y responden a los derechos e intereses de todas las partes interesadas participantes y afectadas}

Cuando las partes interesadas estén sujetas a la desigualdad, la inequidad y la marginación en términos de su poder, posición social, cultura o situación económica, se deben entender las causas subyacentes y se deben hacer todos los esfuerzos por reducir o evitar tales desigualdades en la medida de lo posible. Hacerlo reducirá la probabilidad de conflictos. En el caso de conflictos potenciales, estos se resuelven en negociaciones respetuosas, que reconocen los derechos de los interesados de acuerdo con contextos culturales y sociales, y la necesidad de un acuerdo para reducir el riesgo de fracaso. Lograrlo contribuirá a moldear la gestión adaptativa de la intervención de la SbN, ya que es imposible prever y reducir todos los impactos e implicaciones de la intervención solo a través del proceso de planificación. Además, si no pueden resolverse los conflictos entre los interesados, será necesario utilizar el mecanismo de reclamación y reparación.

\section{C-5.5 Cuando la dimensión de las SbN trasciende los límites jurisdiccionales, se establecen mecanismos para posibilitar la toma de decisiones conjunta de los interesados directos en las jurisdicciones afectadas}

Los ecosistemas a menudo trascienden las fronteras políticas o administrativas. Por lo tanto, es importante asegurar enfoques holísticos que involucren a los interesados e instituciones más allá de los límites de la escala geográfica de una SbN que se esté implementando. El establecimiento de organizaciones y reglas de colaboración, o la construcción de las ya existentes, es importante para las intervenciones que implican intervenciones transjurisdiccionales tales como ríos y especies migratorias. Tales organismos pueden evitar objetivos de gestión contradictorios en jurisdicciones adyacentes que forman parte del mismo sistema ecológico. Un desajuste de las escalas sociales y ecológicas aumenta el riesgo de fracaso, por lo que los enfoques de gobernanza participativa deben reconocer explícitamente estas conexiones (véase también el criterio 2 sobre las escalas ecológicas).

Cuando proceda, las SbN eficaces a veces requieren coordinación en materia de cooperación transfronteriza, transnacional o 
regional. En tales casos, será necesario obtener acuerdos de cooperación de las autoridades nacionales pertinentes que enmarcan una visión compartida y un enfoque coherente de la planificación, el monitoreo, la toma de decisiones y la aplicación compartidas de las SbN. El acuerdo debe ir acompañado de una revisión jurídica para garantizar el cumplimiento de los respectivos acuerdos de cooperación internacional (es decir, que las autoridades nacionales de ejecución tienen el mandato necesario y existe un procedimiento de recurso establecido que puede utilizarse en caso de controversias o consecuencias imprevistas) y las leyes y reglamentos de las distintas jurisdicciones involucradas. A menudo se puede pedir a una organización intergubernamental que facilite el proceso. 


\section{Criterio 6: Las SbN ofrecen un equilibrio equitativo entre el logro de sus objetivos principales y la provisión constante de múltiples beneficios}

Aunque se espera que una SbN individual priorice explícitamente uno de los desafíos sociales más específicos (criterio 1), los ecosistemas de apoyo seguirán ofreciendo una gama de beneficios que importantes para la sociedad en su conjunto (criterio 3). De hecho, la capacidad de ofrecer múltiples beneficios simultáneamente es un atributo importante de SbN. En algunos casos, la "acumulación" de los beneficios clave (p. ej., la protección del agua, la secuestración de carbono y la salud pública a través de la recreación) es un factor determinante importante en cuanto a si una SbN es económicamente viable (criterio 4).

Sin embargo, este atributo fundamental de los ecosistemas también puede ser un desafío para el profesional de SbN. Maximizar la provisión de múltiples beneficios de cualquier SbN corre el riesgo de dar lugar a una reducción proporcional del beneficio clave del ecosistema, que es fundamental para abordar el desafío social que se está tratando. Por el contrario, maximizar el suministro del beneficio fundamental del ecosistema casi con certeza dará lugar a una reducción de la calidad y la cantidad de otros beneficios del ecosistema. Estas compensaciones son muy a menudo una característica inherente de la gestión de los recursos naturales, y surgen cuando se favorece un determinado servicio del ecosistema o preferencia de las partes interesadas (p. ej., agua potable limpia) a expensas de otro (p. ej., producción agrícola). Además, no todas las partes interesadas se ven afectadas por igual y la SbN debe ser explícita acerca de qué beneficios y costos se abordarán. Algunas compensaciones son el resultado de decisiones deliberadas, mientras que otras ocurren sin planificación o conocimiento de los impactos. Las compensaciones se convierten en un problema importante cuando la misma opción se repite varias veces, de modo que los conjuntos de importantes beneficios del ecosistema desaparecen u ocurren de otra manera a niveles inferiores a los óptimos en todo el paisaje terrestre/marino.

Sin embargo, las compensaciones pueden ser manejadas con éxito si las consecuencias probables son evaluadas adecuadamente, divulgadas en su totalidad y acordadas por las partes interesadas más afectadas (véase el estudio de caso del criterio 6 en la parte I). La negociación justa y transparente de las compensaciones y solución de compromiso entre las partes potencialmente afectadas por cualquier pérdida como resultado de la SbN, incluidos los medios de subsistencia, proporciona la base para el éxito de los resultados a largo plazo de la SbN. Es fundamental reconocer que las compensaciones tienen límites, lo que significa que se necesitarán salvaguardias para garantizar que no se superen las propiedades estabilizadoras a largo plazo de los servicios de regulación y apoyo de los ecosistemas, como es el caso de las prácticas intensivas de uso industrial de la tierra. Más recientemente, también se dispone de instrumentos como la valoración integrada de los servicios de los ecosistemas y los beneficios derivados de la inversión (Sharp et al., 2020) y estudios de casos sobre las lecciones de la gestión de los beneficios derivados de la venta. Se dispondrá de una compilación de estudios de casos útiles y herramientas sugeridas como complemento de esta orientación.

\section{C-6.1 Se reconocen explícitamente los costos y beneficios potenciales de las compensaciones asociadas a la intervención de SbN, y se utiliza esta información para adoptar salvaguardias y cualquier otra medida correctora que resulte adecuada}

Los profesionales de la SbN identifican y documentan los beneficios y costes de la SbN, y 
quién los recibe y quién los paga (criterio 4), y los resultados modelan las acciones y la distribución equitativa de los beneficios y costes entre los interesados. Dicho análisis no debe limitarse a la fase de planificación, sino que también debe ser incorporado en todo el ciclo de vida de las SbN, incluida la iniciación, planificación, ejecución y cierre, reconociendo que las intervenciones de SbN pueden ser implementadas a perpetuidad.

Las compensaciones tienen una dimensión espacial, temporal y de reversibilidad. La dimensión espacial se refiere a si los efectos de las compensaciones se sienten localmente o en un lugar lejano. La dimensión temporal se refiere a si los efectos se producen relativamente rápido o lentamente. La reversibilidad expresa la probabilidad de que un servicio de ecosistema interrumpido pueda regresar a su estado original si cesa el evento perturbador. Además, deben establecerse acuerdos de distribución de beneficios que se hayan acordado mutuamente para asegurar un equilibrio equitativo de los beneficios y las compensaciones de las políticas y las inversiones.

\section{C-6.2 Se reconocen y respetan los derechos, el uso y el acceso a la tierra y los recursos de las diferentes partes interesadas directos, junto con sus responsabilidades respectivas}

Hay que defender los derechos legales y de uso de los grupos vulnerables y marginados. Los derechos, el uso, las responsabilidades y la rendición de cuentas de los grupos de interesados deben analizarse y evaluarse utilizando las herramientas apropiadas, basándose en los resultados del análisis o la cartografía de los interesados. En particular, al tratar con los pueblos indígenas y las comunidades locales, se debe utilizar el consentimiento libre, previo e informado (CLPI) (en convergencia con el criterio 5). Además, todos los interesados se ven afectados por igual y la SbN debe contar con mecanismos para equilibrar las compensaciones entre los grupos mediante el uso de enfoques como la transparencia, los incentivos y las alternativas sostenibles.

\section{C-6.3 Las salvaguardias establecidas se revisan periódicamente para garantizar que se respetan los límites mutuamente acordados de las compensaciones y que dichos límites no desestabilizan las SbN en su totalidad}

Muchas políticas pertinentes en el campo de la conservación tienen políticas explícitas de salvaguardia (véase, por ejemplo, el Apéndice 1 del Acuerdo de Cancún de la CMNUCC). Los proyectos voluntarios de carbono han seguido con frecuencia las normas sobre el clima, la comunidad y la biodiversidad. Se han establecido otras salvaguardias para las inversiones del Banco Mundial. Estos sistemas de salvaguardia están en vigor para anticipar y evitar las consecuencias adversas de las intervenciones, y pueden utilizarse como base para una salvaguardia de la SbN apropiada a los contextos locales. 


\section{Criterio 7: Las SbN se gestionan de forma adaptativa, con base en datos}

Este criterio está estrechamente vinculado a los indicadores 2.3 y 3.3 .

Las SbN aprovechan los servicios de los ecosistemas, que son sistemas complejos, dinámicosydeautoorganización. Losecosistemas pueden responder de maneras deseables a una intervención de SbN. Sin embargo, la intervención también podría crear consecuencias no deseadas, imprevistas e indeseables. Por lo tanto, las SbN son intentos de influir en un ecosistema para que cambie de manera que satisfaga las necesidades sociales a largo plazo, y no pueden considerarse como intervenciones que puedan predecir completamente los resultados en un sentido absoluto de resolución de problemas. En consecuencia, la SbN debe basarse en una teoría del cambio, que se pruebe y se adapte sobre la base de la evidencia. La teoría del cambio debe reconocer las propiedades de autoorganización de los ecosistemas y basarse en una evaluación del proceso y la función en la medida en que estas se relacionan con los desafíos sociales. Los supuestos críticos con respecto al riesgo de fracaso sistémico deben ser claramente establecidos en la teoría del cambio y probados de cara a la evidencia, o a través de la experimentación. La teoría del cambio también debe identificar las condiciones propicias para la SbN.

Por lo tanto, debe incorporarse la gestión adaptativa al proceso de ejecución de la SbN. La gestión adaptativa se define como: "un proceso estructurado e iterativo de... toma de decisiones frente a la incertidumbre, con el objetivo de reducir la incertidumbre con el tiempo". Además, para responder a este enfoque de gestión, es necesario que todos los interesados aprendan continuamente acerca de los procesos de todo el sistema, y adapten la SbN de acuerdo con los cambios sistémicos. Esto también puede incluir consideraciones sobre los impactos a largo plazo de la sostenibilidad del sitio inmediato de la SbN, cambios que pueden desencadenarse en paisajes terrestres/marinos adyacentes y paisajes terrestres/marinos aguas abajo, e impactos que pueden ocurrir a escalas más grandes, tanto a lo largo del tiempo como en el espacio geográfico.

Por otro lado, los impactos indeseables de paisajes terrestres/marinos adyacentes y paisajes terrestres/marinos aguas abajo, así como sistemas a mayor escala, pueden estar fuera del control de los interesados. Esto subraya la necesidad de gestión adaptativa, flexibilidad y procesos de aprendizaje iterativo al implementar la SbN. El reconocimiento de las interacciones entre los componentes sociales y ecológicos de todo el sistema dentro de un paisaje terrestre/marino, así como las interacciones que se producen a través de los distintos niveles de escala social y ecológica, sustentarían dichos enfoques de aprendizaje y gestión. El éxito de esto depende en gran medida del criterio 5, procesos de gobernanza inclusivos, transparentes y empoderadores. La gestión adaptativa también puede contribuir a medir la cantidad de carbono almacenado en los suelos, la vegetación y su permanencia a través del tiempo, así como los cambios en la composición de la biodiversidad.

\section{C-7.1 La estrategia de SbN se establece y utiliza como base para la vigilancia continua y la evaluación periódica de la intervención}

En una SbN, la teoría del cambio no es estática; es dinámica y reconoce la incertidumbre de 
los sistemas bioeconómicos y las condiciones cambiantes. Los supuestos y los facilitadores identificados en la teoría del cambio deben revisarse regularmente con respecto a la línea de referencia establecida. Junto con la línea de referencia también deben considerarse otras pruebas sociales, económicas y ecológicas pertinentes y nuevas que podrían mejorar los impactos de la SbN, así como reducir los riesgos de resultados negativos no deseados. Un plan de seguimiento y evaluación también permitirá la revisión sistemática de la intervención de la SbN frente a la línea de referencia y otras nuevas pruebas.

\section{C-7.2 Se elabora un plan de vigilancia continua y evaluación, y se aplica a lo largo de todo el ciclo de vida de la intervención}

Un plan de seguimiento y evaluación (MyE), preferiblemente un plan participativo de MyE que incluya a los interesados en la verificación de los resultados y el aprendizaje, garantizará que la intervención de la SbN se encamine hacia la implementación y la ejecución y ayude a gestionar los impactos positivos y negativos a largo plazo. Si bien a veces se puede percibir como una carga administrativa, es un enfoque poderoso para entender si la intervención de la SbN aborda efectivamente los desafíos sociales. Para garantizar que las consideraciones de supervisión no se vean comprometidas debido a las medidas de reducción de costos, todos los planes de supervisión deben establecerse antes de la aplicación. Cuando sea necesario, el MyE puede ser independiente y dirigido por un tercero. En el caso de la autoverificación o de la verificación por parte de terceros, se recomienda encarecidamente que se lleve a cabo un examen o evaluación externos de la iniciativa, como momentos ideales a mitad de periodo y al final
Cuando se hace bien, el MyE no solo puede ayudar a evaluar los cambios a lo largo de la intervención, sino también captar los impactos inmediatos y a corto plazo sobre la naturaleza y la vida de las personas. Apoyará las intervenciones de SbN en la defensa de la rendición de cuentas y el cumplimiento.

Este plan de MyE también es importante para identificar respuestas en condiciones cambiantes descritas en el indicador 7.1, y para manejar las desviaciones resultantes. Estas respuestas servirán como medidas de gestión adaptativa que emprenderá la comunidad de interesados. Las acciones deben desarrollarse y ejecutarse de manera inclusiva y participativa, manteniendo así el criterio 5. La información sobre los procesos para identificar las acciones, así como la ejecución de las acciones, debe estar disponible para su inspección, con las atribuciones apropiadas, respetando la privacidad y seguridad de los informantes. El MyE debe reflejar escalas ecológicas y sociales adecuadas, ya que la SbN puede tener influencias a distintas escalas, y las acciones pueden requerir un compromiso a escalas diferentes de la escala original de la SbN. Sin ese enfoque adaptativo, las acciones pueden tener un impacto marginal o nulo.

\section{C-7.3 Se aplica un marco de aprendizaje iterativo que posibilita la gestión adaptativa a lo largo de todo el ciclo de vida de la intervención}

El aprendizaje es el proceso de desarrollar una comprensión basada en la evidencia, y la adaptación es el ajuste de la gestión de acuerdo con la nueva información. El aprendizaje basado en la evidencia debe impulsar la gestión de la SbN. Además, el aprendizaje iterativo, la aplicación y el aprendizaje son esenciales para modelar las acciones de gestión adaptativa, a fin 
de responder a los factores que influyen sobre las intervenciones de la SbN. Para este Criterio los Indicadores 7.1 y 7.2 proporcionan un circuito de retroalimentación continuo que permite aprender y adaptar la intervención de la SbN. Estos procesos de retroalimentación pueden ser incorporados como parte del plan de monitoreo y evaluación de la intervención, y habilitan un cronograma consistente para análisis repetidos.
También se pueden introducir en el proceso de aprendizaje iterativo pruebas adicionales, producidas a partir de fuentes de conocimientos tradicionales y científicos. Esto es especialmente importante dado el impacto del cambio climático que sufren los ecosistemas. De manera ideal, el aprendizaje iterativo se institucionaliza de modo que se lleve a cabo incluso después de que cese la intervención de la SbN. 


\section{Criterio 8: Las SbN son sostenibles y se integran en un contexto jurisdiccional adecuado}

Dado que la SbN es un concepto relativamente nuevo y emergente, la información sobre la SbN debe circular libre y abiertamente, y aumentar la demanda y la oferta de SbN. Esto permite a las personas extraer las lecciones aprendidas y determinar si es necesario ajustar los procesos de SbN y cómo hacerlo. En cuanto se conozca mejor, debería ser posible ampliar y/o replicar la SbN en cuestión. Tanto la ampliación como la replicación aportarán pruebas y conocimientos del enfoque de SbN, lo que permitirá aún más el diseño de una SbN aún más eficaz, asequible y sostenible.

Las SbN están diseñadas y gestionadas para complementar las estructuras, políticas, planes institucionales, las leyes, los reglamentos y las intervenciones cercanas (véanse el criterio 2 de diseño a escala y el criterio 7 de gestión adaptativa, respectivamente). Sin embargo, si bien una intervención de la SbN puede estar limitada en el tiempo (p. ej., cuando se limitan a cinco años ciertas acciones específicas, como la plantación de manglares), la SbN en general, incluido el marco y el impacto resultantes, se mantiene fuera de estos límites. El propósito de este criterio es asegurar que las SbN permitan que su propia integración de soluciones persista en el tiempo.

Al apoyar la captación y ampliación de la SbN en el tiempo y mucho más allá del cronograma de la intervención, los profesionales de la SbN deben asegurar que esta tenga una trayectoria a largo plazo de varias décadas. Existen diversos enfoques para la incorporación de la SbN, sin embargo, todos dependen de las comunicaciones estratégicas y la divulgación. Los públicos que se deben considerar comprenden personas particulares (el público en general, académicos), instituciones (Gobierno nacional, empresas emergentes, organizaciones no gubernamentales) y redes globales (Objetivos de Desarrollo Sostenible, Acuerdo de París).

\section{C-8.1 El diseño, la aplicación y las lecciones extraídas de las SbN se comparten para impulsar un cambio transformador}

Para que se amplíe (generalice) o se replique (amplíe a nivel geográfico, sectorial o de objetivos) un enfoque basado en la SbN, es importante que el proceso de diseño e implementación, además de las lecciones aprendidas, estén disponibles y accesibles a las personas relevantes o a petición de cualquier parte interesada directamente afectada o bien parte muy interesada en replicar el proceso. Los públicos para esta comunicación comprenden a personas tales como encargados de la toma de decisiones en sectores donde la SbN puede ser una solución, inversionistas, usuarios de la SbN de los sectores público y privado, y el público en general. Entre los ejemplos se incluyen boletines informativos sobre las lecciones aprendidas, comunicados de prensa sobre asociaciones formadas, capacitaciones sobre diseño o implementación, informes sobre políticas y cabildeo. Las lecciones aprendidas deben incluir tanto consecuencias positivas como negativas (incluidas las no deseadas) y posibles maneras de superarlas en el futuro.

Para que estas comunicaciones sean accesibles, se deben considerar los públicos que puedan encontrar barreras en términos de tecnología, cultura o contexto económico. Los profesionales de SbN pueden considerar apropiado publicar los resultados en una editora de acceso abierto. Además, se pueden considerar la visibilidad 
específica del sitio y la sensibilización, digamos mediante vallas y carteles.

\section{C-8.2 Las SbN aportan información a los marcos normativos y reglamentarios facilitadores y ayudan a perfeccionarlos con el fin de respaldar su adopción y generalización}

Las SbN ya están sujetas a una serie de políticas, planes, leyes y reglamentos preexistentes que en algunos casos las restringen y en otros las respaldan. La SbN debe abordar y ser compatible con el contexto proporcionado por las políticas, planes, leyes y reglamentos actuales para poder ofrecer los resultados deseados (criterio de diseño a escala 2), o sugerir nuevas políticas y reglamentos necesarios para garantizar su correcta aplicación; de otro modo podría amenazar la durabilidad y viabilidad de la SbN a largo plazo si, por ejemplo, requiere acciones o intervenciones que contravengan o sean incompatibles con las políticas y prácticas establecidas en torno a la estrategia de uso de la tierra. También podría haber situaciones en las que las políticas existentes de uso de la tierra se socaven mutuamente $y$, por lo tanto, presenten desafíos adicionales para la aplicación de la SbN. En estas circunstancias, la SbN puede brindar la oportunidad de destacar estas incompatibilidades a los responsables de la formulación de políticas y actuar como un factor desencadenante para modificar los reglamentos a fin de garantizar la sostenibilidad y la durabilidad.

En ocasiones, pueden encontrarse contradicciones entre los objetivos o requisitos de las diferentes políticas sectoriales o de uso de la tierra que tienen el potencial de reducir la eficacia y/o eficiencia de la aplicación de las SbN. Estos deben estar plenamente documentados junto con opciones para resolver o solucionar esos obstáculos, tanto para fines de supervisión como para la consideración de los encargados de formular políticas. A fin de mejorar el diseño y facilitar la efectiva convergencia de las políticas futuras de SbN, se deben mantener los resultados de la supervisión y evaluación, así como otras formas de aprendizaje de lecciones, y deben seguir siendo fácilmente accesibles dentro del dominio público.

\section{C-8.3 Cuando resulte pertinente, las $\mathrm{SbN}$ contribuyen a los objetivos nacionales y mundiales en las esferas del bienestar humano, el cambio climático, la biodiversidad y los derechos humanos, incluida la Declaración de las Naciones Unidas sobre los Derechos de los Pueblos Indígenas}

El objetivo de la SbN es abordar los desafíos sociales mundiales. Las SbN particulares parten de ese impulso al registrar su progreso con miras al aumento del bienestar humano (incluidas la salud, la riqueza, etc.) y enfrentar la crisis climática y de biodiversidad. Cuando los impactos de la SbN contribuyan a las metas nacionales y globales pertinentes (que se identifican en el criterio 2 de Diseño a escala), deben informar a los organismos responsables de esas metas para que se documente este impacto. Las metas que se deben considerar son, entre otras:

- las políticas, reglamentos y leyes nacionales y subnacionales;

- los Objetivos de Desarrollo Sostenible (ODS) de las Naciones Unidas;

- el Decenio de las Naciones Unidas sobre la Restauración de los Ecosistemas;

- los objetivos de la Convención de las Naciones Unidas de Lucha contra la Desertificación 
(CNULD), como la neutralización de la degradación de las tierras (NDT);

- aquellas específicas de un desafío social (Acuerdo de París, Metas mundiales de Nutrición de la Organización Mundial de la Salud [OMS], el Marco de Sendái para la Reducción del Riesgo de Desastres);

- aquellas específicas de la crisis de la biodiversidad (Metas de Aichi para la Diversidad Biológica o su sucesora, el Protocolo de Nagoya sobre acceso y participación en los beneficios o su sucesora, las Estrategias y planes de acción nacionales en materia de biodiversidad [EPANDB]).

La entrega de información a los responsables de las metas se puede lograr mediante la transferencia de conocimientos, informes sobre políticas, reuniones con los encargados de formular políticas o la presentación de informes a los distintos mecanismos normativos. 


\section{Cómo utilizar el estándar}

El Estándar ha sido creado para utilizarlo en aplicaciones de diseño, ampliación y verificación como una herramienta práctica simple pero robusta que refuerza las mejores prácticas, aborda y corrige las deficiencias y permite que las intervenciones converjan con principios de SbN internacionalmente aceptados (WCC2016-Res-069). Los usuarios pueden aplicar el Estándar tanto a las intervenciones en curso como a las propuestas, utilizando la herramienta de autoevaluación que se ha diseñado para que usarla junto con las herramientas de gestión de proyectos y los enfoques técnicos existentes. Los indicadores y sus escalas de orientación y puntuación pueden vincularse fácilmente con los sistemas de presentación de informes y gestión de operaciones existentes para reducir al mínimo el trabajo adicional necesario.

Para la fase inicial de despliegue del Estándar para $\mathrm{SbN}$, se ha desarrollado una herramienta de autoevaluación (que se puede descargar aquí) para permitir a los usuarios del Estándar calcular el porcentaje de su intervención con respecto a los ocho criterios y determinar si su intervención se adhiere al Estándar Global para SbN de la UICN. La hoja de autoevaluación, en forma de hoja de cálculo de Excel, permite a los usuarios identificar hasta qué punto su intervención se adhiere a los indicadores individuales: sólida, adecuada, parcial e insuficiente. Luego se proporciona a los usuarios un sistema de semáforos para cada uno de los criterios, que les permite identificar áreas de mejora y les ofrece un nivel general de correspondencia, para así determinar si la intervención se adhiere al Estándar Global para SbN de la UICN.
Para cada indicador se registra una puntuación de cuatro, dependiendo de si la intervención aborda el indicador de forma sólida, adecuada, parcial e insuficiente. El resultado se utiliza para calcular el nivel de cumplimiento de cada criterio particular, y da por igual un resultado sólido, adecuado, parcial e insuficiente para puntuaciones superiores a 75, entre 50 y 75, entre 25 y 50 e inferiores al $25 \%$, respectivamente (Tabla 1). Estas puntuaciones de indicadores se normalizan de modo que cada criterio tenga el mismo peso. Después de la normalización, las puntuaciones de criterio se combinan para dar el correspondiente porcentaje general. Independientemente de la correspondencia porcentual general, si una intervención logra una calificación "insuficiente" con respecto a cualquier criterio, entonces no se adhiere al Estándar Global para SbN de la UICN. El porcentaje de correspondencia se puede utilizar para describir si tal adhesión es sólida, adecuada o parcial.

Si bien el Estándar evalúa si el diseño de una intervención cumple los requisitos de calificación de una SbN, su ejecución requerirá otros estándares, herramientas y enfoques operativos. A modo de ejemplo, si se manejara una cuenca hidrográfica para la reducción del riesgo de inundaciones, se requerirían herramientas como las directrices para el Manejo Integral de los Recursos Hídricos para poner en funcionamiento la SbN, después de haberla diseñado de acuerdo con los ocho criterios (figura 7). En este sentido, el Estándar Global para SbN complementa antes que sustituir el uso de otras normas. 


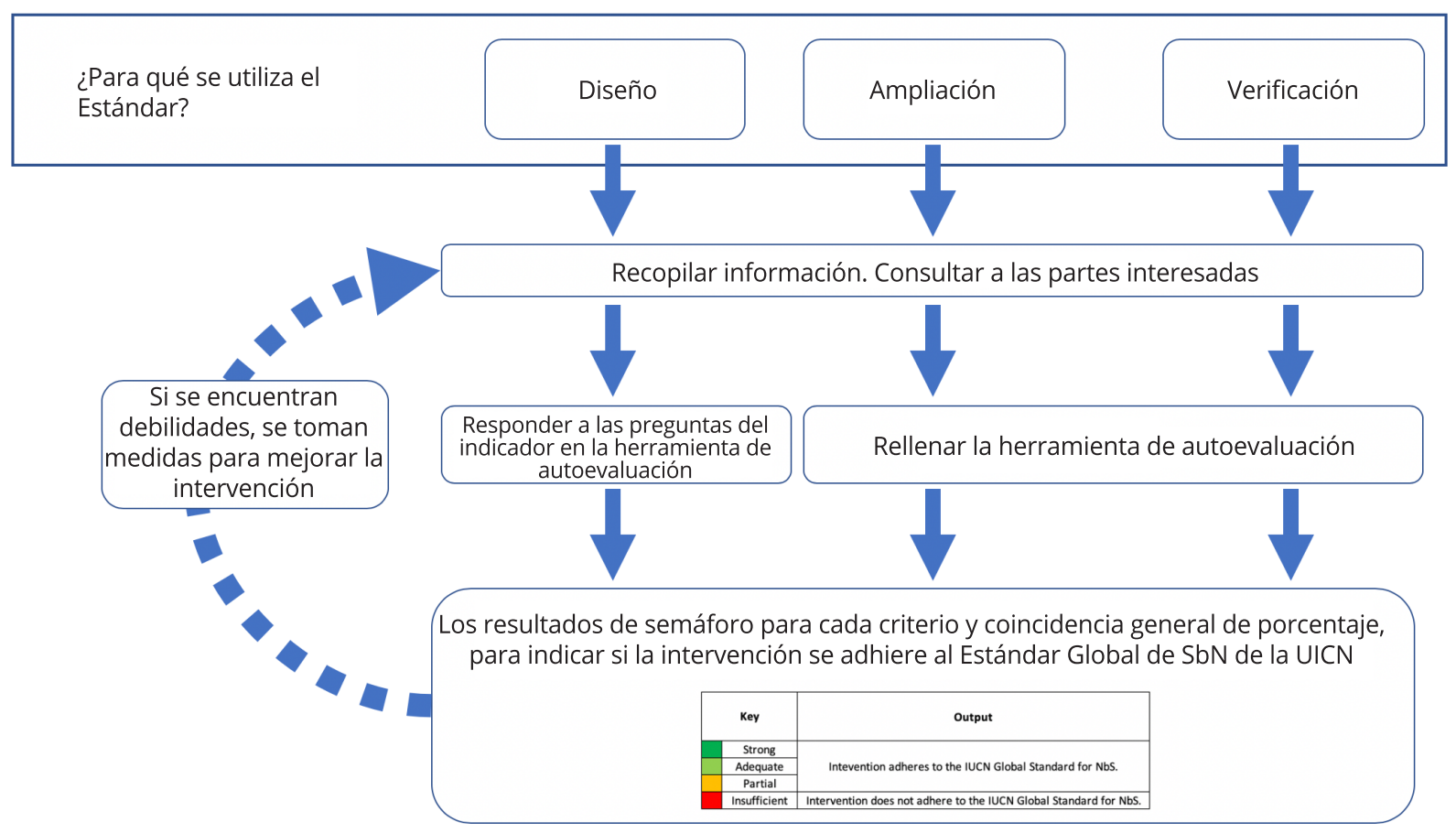

Figura 7: Cómo utilizar el estándar y cómo se vincula con la autoevaluación. (@ UICN)

\subsection{Cómo autoevaluarse}

La autoevaluación de cara al Estándar para SbN debería llevarse a cabo en distintas etapas del ciclo del proyecto, para ayudar a identificar los productos, debilidades y fortalezas no anticipadas a fin de mejorarlas o aliviarlas. Por lo tanto, la autoevaluación no debe considerarse una valoración de un proyecto de SbN. Más bien tiene como objetivo garantizar la prestación de los beneficios sociales previstos sin comprometer con ello la naturaleza, y viceversa. La autoevaluación utilizará un sistema de semáforos para indicar el estado de los distintos indicadores enumerados, en que el verde expresa que se cumple completamente un indicador, el naranja ilustra el logro parcial, y el rojo, la ausencia de logros.

La autoevaluación debe llevarse a cabo de la siguiente manera:

- revisar los indicadores, la orientación y los ejemplos que figuran en la parte II, y considerar los medios de verificación sugeridos;

- identificar los medios de verificación más adecuados para demostrar hasta qué punto

Tabla 1: Resultado de la hoja de autoevaluación.

\begin{tabular}{ccc}
\hline Clave (\%) & Producto \\
\cline { 1 - 2 }$\geq 75$ & Sólida & \\
\cline { 1 - 2 }$\geq 50 y<75$ & Adecuado & La intervención se adhiere al Estándar Global para SbN de la UICN. \\
\cline { 1 - 2 }$\geq 25 y<50$ & Parcial & \\
\cline { 1 - 2 }$<25$ & Insuficiente & La intervención no se adhiere al Estándar Global para SbN de la UICN. \\
\hline
\end{tabular}


su SbN cumple lo que requiere un indicador respectivo utilizando la guía de escala para sólida, adecuada, parcial e insuficiente proporcionada en la herramienta de autoevaluación;

- describir cómo y hasta qué punto su SbN cumple lo que requiere el indicador en las celdas correspondientes de la herramienta de autoevaluación;

- proporcionar enlaces a los medios de verificación utilizados (si están disponibles en línea) o adjuntarlos a su autoevaluación para corroborar sus conclusiones;

- consultar en la hoja general los resultados de los semáforos, el porcentaje de correspondencia general y si la intervención se adhiere al Estándar Global para SbN de la UICN;
- compartir, informar y debatir las conclusiones según sea necesario para mejorar o implementar soluciones;

- ser flexibles y reiterar el proceso según sea necesario según cambien algunos aspectos.

Las partes I y || del Estándar se complementarán posteriormente con una guía del usuario (parte III) y enfoques e instrumentos de intercambio de plataformas. Mientras tanto, los usuarios del Estándar pueden conectar aquí con la comunidad de práctica global, donde también encontrarán ayuda y preguntas frecuentes. Las preguntas también pueden dirigirse a NbSStandard@iucn.org para comunicarlas al Grupo de SbN en la UICN. 


\section{Glosario de definiciones}

Término

\begin{tabular}{l} 
Acción \\
\hline Plan de acción \\
\hline Adaptación \\
\hline Gestión adaptativa
\end{tabular}

Definición

Fuente

Enlace

Las acciones no se consideran comportamientos reactivos o cambios en el estilo de vida, sino más bien un ejercicio activo de participación democrática en la sociedad. La acción debe emprenderse consciente, intencional y voluntariamente

Un plan escrito de implementación que a menudo detalla los plazos, etapas, roles y/o responsabilidades de los proyectos relacionados con los objetivos de la estrategia.

Iniciativas y medidas para reducir la vulnerabilidad de los sistemas naturales y humanos frente a los efectos reales o previstos del cambio climático. Existen diversos tipos de adaptación, por ejemplo, anticipada y reactiva, privada y pública, y autónoma y planificada.

Un proceso sistemático de mejora continua de las políticas y prácticas de gestión aprendiendo de los resultados de los programas existentes.

El análisis y revisión de la información derivada de la investigación con el fin de ayudar a alguien en un puesto de responsabilidad a evaluar posibles acciones o pensar en un problema. La evaluación

Evaluación significa reunir, resumir, organizar, interpretar $y$, posiblemente, reconciliar elementos de conocimiento existentes y comunicarlos para que sean relevantes y útiles para un encargado de la adopción de decisiones inteligente pero inexperto.

Referencia para cantidades mensurables a partir de las cuales se puede medir un resultado alternativo,

Línea de referencia por ejemplo, un escenario de no intervención

IPCC

Glosario de

terminología de mapeo y evaluación de servicios de los ecosistemas herramientas de la CDB

https://www.cbd.int/cepal

Glosario de toolkit/2008/doc/CDB-ToolkitGlossaries.pdf

https://www.cbd.int/cepa/ toolkit/2008/doc/CDB-ToolkitGlossaries.pdf

Glosario de la UICN

https://www.iucn.org/sites/ dev/files/iucn-glossary-ofdefinitions en.pdf

Glosario de la UICN

https://www.iucn.org/sites/ dev/files/iucn-glossary-ofdefinitions en.pdf utilizado como referencia en el análisis de

https://www.ipcc.ch/pdf/ assessment-report/ar4/syr/ ar4 syr appendix.pdf escenarios de intervención.

Cualquier persona, grupo de personas o entidad que utilice o pueda utilizar los beneficios obtenidos de la naturaleza proporcionados por la unidad de manejo. Los ejemplos incluyen, entre otros, personas, grupos de personas o entidades ubicadas en la cercanía de la unidad de manejo. Los usuarios finales, como los consumidores o los beneficiarios indirectos de la mitigación del carbono, no se consideran beneficiarios.

Beneficiarios

del servicio de ecosistemas

\section{Beneficios/} impacto
Beneficios: Cambio positivo en el "bienestar" desde el cumplimiento de las necesidades y deseos. En términos de impacto: efecto positivo sobre las personas, la sociedad y los recursos ambientales como resultado del cambio ambiental.
Procedimiento de

servicios del ecosistema: https://fsc.org/es/documentdemostración del centre/documents/ impacto y herramientas resource/316 de mercado

Glosario de

terminología de mapeo https://oneecosystem.pensoft. y evaluación de servicios net/articles.php?id=27110 de los ecosistemas 
Término

\section{Definición}

Fuente

Enlace

Biodiversidad (abreviatura de diversidad biológica)

significa la diversidad de la vida en todas sus

formas: la diversidad de las especies, de las

variaciones genéticas dentro de una especie, y de

los ecosistemas. La importancia de la diversidad

Biodiversidad biológica para la sociedad humana no es una noción que se pueda exagerar. Se estima que el $40 \%$ de la economía mundial se basa en productos y procesos biológicos. Los pobres, especialmente los que viven en zonas de baja productividad agrícola, dependen de manera especial de la diversidad genética del medio ambiente.

Desde el momento en que los seres humanos ocuparon la Tierra por primera vez y comenzaron a cazar animales, recolectar alimentos y cortar madera, han ejercido impacto sobre la biodiversidad. En los dos últimos siglos, el crecimiento de la población humana, la sobreexplotación de los recursos naturales y la degradación del medio ambiente han dado lugar a una disminución

Pérdida de biodiversidad

\section{Captación \\ Servicios de adaptación climática} cada vez más acelerada de la diversidad biológica mundial. Las especies están disminuyendo en número y se están extinguiendo, y los ecosistemas están sufriendo daños y van desapareciendo. Se estima que el $80 \%$ del bosque original que cubría la Tierra hace 8.000 años ha sido despejado, dañado o fragmentado. Algunos expertos evalúan la tasa de extinción de las especies entre 1.000 y 10.000 veces superior a la tasa natural.

El área drenada por un río o un cuerpo de agua. El término se usa a menudo indistintamente con cuenca hidrográfica. Véase la definición de cuenca.

Beneficios para las personas de una mayor capacidad social para responder al cambio, proporcionados por la capacidad de los ecosistemas para moderar y adaptarse al cambio y la variabilidad climáticas.
Glosario de

herramientas de la CDB https://www.cbd.int/cepa/ toolkit/2008/doc/CBD-ToolkitGlossaries.pdf
Glosario de herramientas de la CDB https://www.cbd.int/cepa/ toolkit/2008/doc/CDB-ToolkitGlossaries.pdf

Cambio climático. El cambio climático se refiere a cualquier cambio en el clima a lo largo del tiempo, ya sea debido a la variabilidad natural o como resultado de la actividad humana. Este uso difiere del de la Convención Marco de las Naciones Unidas sobre el

Cambio climático Cambio Climático, que define el "cambio climático" como: "un cambio en el clima que se atribuye directa o indirectamente a la actividad humana que altera la dev/files/iucn-glossary-ofdefinitions en.pdf

Glosario de la UICN dev/files/iucn-glossary-ofdefinitions en.pdf

Publicación de la

UICN de 2016 sobre soluciones basadas en la naturaleza - (Lavorel et al., 2015) https://portals.iucn.org/ library/sites/library/files/ documents/2016-036.pdf composición de la atmósfera mundial y que se suma a la variabilidad climática natural observada durante un periodo comparable".

\begin{tabular}{|c|c|c|c|}
\hline Cierre & $\begin{array}{l}\text { El cierre del proyecto tiene como objetivo recoger } \\
\text { las lecciones del proyecto para su uso futuro. }\end{array}$ & PAAS de la UICN & $\begin{array}{l}\text { https://www.iucn.org/ } \\
\text { resources/project- } \\
\text { management-tools/project- } \\
\text { guidelines }\end{array}$ \\
\hline Composición & $\begin{array}{l}\text { El conjunto de organismos dentro de un ecosistema. } \\
\text { En un plan de restauración o vigilancia que suele } \\
\text { incluir una lista de especies o géneros (para plantas } \\
\text { y fauna de vertebrados) o al menos de orden (para } \\
\text { invertebrados y microorganismos). }\end{array}$ & $\begin{array}{l}\text { International standards } \\
\text { for the practice of } \\
\text { ecological restoration } \\
\text { - including principles } \\
\text { and key concepts } \\
\text { (Normas internacionales } \\
\text { para la práctica de la } \\
\text { restauración ecológica, } \\
\text { incluidos principios y } \\
\text { conceptos clave) }\end{array}$ & $\begin{array}{l}\text { http://seraustralasia. } \\
\underline{\text { com/wheel/image/SER }} \\
\underline{\text { nternational_Standards.pdf }}\end{array}$ \\
\hline
\end{tabular}




\begin{tabular}{|c|c|c|c|}
\hline Término & Definición & Fuente & Enlace \\
\hline Concepto & $\begin{array}{l}\text { Unidad de conocimiento creada por una } \\
\text { combinación única de características. Los conceptos } \\
\text { son resúmenes abstractos, nociones generales, } \\
\text { conocimientos, etc., de todo un conjunto de } \\
\text { comportamientos, actitudes o características que se } \\
\text { considera que tienen algo en común. Los conceptos } \\
\text { se utilizan para ayudar a presentar/transmitir } \\
\text { un significado preciso, categorizar, interpretar, } \\
\text { estructurar y dar sentido a los fenómenos. }\end{array}$ & $\begin{array}{l}\text { Glosario de términos } \\
\text { de clasificación de } \\
\text { las Naciones Unidas, } \\
\text { preparado por el } \\
\text { Grupo de Expertos } \\
\text { en Clasificaciones } \\
\text { Económicas y Sociales } \\
\text { Internacionales }\end{array}$ & $\frac{\text { http://data.un.org/Glossary. }}{\text { aspx?q=scientific+knowledge }}$ \\
\hline
\end{tabular}

Conflicto

\section{Conectividad}

\section{Conservación}

\section{Consulta}

Una incompatibilidad entre opiniones, principios, etc. el conflicto no es necesariamente malo, anormal o disfuncional, sino más bien un elemento inherente de la interacción humana. Al pensar en las direcciones tomadas por la sociedad, lo que
Intercambios externos, los flujos bidireccionales que ocurren entre unidades ecológicas dentro del paisaje o el medio acuático, e incluyen flujos de energía, agua, fuego, material genético, animales y semillas. Los intercambios se ven facilitados por los vínculos con el hábitat.
International standards for the practice of ecological restoration - including principles and key concepts (Normas internacionales para la práctica de la restauración ecológica, incluidos principios y conceptos clave) http://seraustralasia. com/wheel/image/SER International Standards.pdf https://www.iucn.org/es/ node/29888

\begin{tabular}{|c|c|c|c|}
\hline Conservación & $\begin{array}{l}\text { La conservación de los ecosistemas y los hábitats } \\
\text { naturales y el mantenimiento y recuperación de } \\
\text { poblaciones viables de especies en sus entornos } \\
\text { naturales y, en el caso de las especies domesticadas } \\
\text { y cultivadas, en los entornos en los que han } \\
\text { desarrollado sus características específicas. }\end{array}$ & Glosario de la UICN & $\frac{\text { dev/files/iucn-glossary-of- }}{\underline{\text { definitions en.pdf }}}$ \\
\hline Consulta & $\begin{array}{l}\text { La consulta es un proceso bidireccional de diálogo } \\
\text { entre la empresa del proyecto y sus partes } \\
\text { interesadas. La consulta con los interesados directos } \\
\text { se refiere realmente a iniciar y mantener relaciones } \\
\text { externas constructivas a lo largo del tiempo. Las } \\
\text { empresas que inician el proceso temprano y } \\
\text { asumen una visión estratégica a largo plazo están, } \\
\text { en esencia, creando su "licencia social para operar" } \\
\text { al nivel local. }\end{array}$ & $\begin{array}{l}\text { Corporación Financiera } \\
\text { Internacional }\end{array}$ & $\begin{array}{l}\frac{\text { https://www.ifc.org/wps/ }}{\text { wcm/connect/multilingual }} \\
\text { ext_content/ifc external } \\
\text { corporate site/home es }\end{array}$ \\
\hline
\end{tabular}

La protección, cuidado, gestión y mantenimiento de los ecosistemas, los hábitats, las especies y poblaciones silvestres, dentro o fuera de sus entornos naturales, con el fin de salvaguardar las condiciones naturales para su permanencia a largo plazo. Conservación ex situ. La conservación de los componentes de la diversidad biológica fuera de sus hábitats naturales. Conservación in situ. La conservación de los ecosistemas y los hábitats naturales y el mantenimiento y recuperación de poblaciones viables de especies en sus entornos y cultivadas, en los entornos en los que han desarrollado sus características específicas.

\section{de Derec} $\underline{\text { nde/2988 }}$ $-$ mediante los cuales manejamos el conflicto. Cuando hay conflicto, las partes pueden estar menos
inclinadas o ser menos capaces de participar plena o constructivamente en las negociaciones hasta que se reconozca adecuadamente el conflicto.

La consulta es un proceso bidireccional de diálogo entre la empresa del proyecto y sus partes interesadas. La consulta con los interesados directos se refiere realmente a iniciar y mantener relaciones externas constructivas a lo largo del tiempo. Las asumen una visión estratégica a largo plazo están, al nivel local. 
Gareis, R., Huemann, M.,

y Martinuzzi, A., 2010.

Relating sustainable

development and

project management:

a conceptual model.

(Relacionando el

https://www.pmi.org/learning/ que surgen en el curso de un proyecto Se pueden

Coste calcular para paquetes de trabajo individuales, para objetos individuales de consideración, para asignaciones internas y para todo el proyecto.

desarrollo sostenible y development-project-

management-6497 la gestión de proyectos:

Un modelo conceptual.)

Análisis de coste-
beneficio

Un instrumento de decisión que juzga la

conveniencia de los proyectos comparando sus costos y beneficios.

Glosario de la UICN

https://www.iucn.org/sites/ dev/files/iucn-glossary-ofdefinitions en.pdf

"Cultural(es)" se refiere al conjunto de los rasgos distintivos espirituales y materiales, intelectuales y afectivos que caracterizan a una sociedad o a un

Cultural grupo social y que abarca, además de las artes y

UNESCO

http://portal.unesco.org/es/ las letras, los modos de vida, las maneras de vivir juntos, los sistemas de valores, las tradiciones y las creencias.

Variedad o multiformidad de estructuras sociales humanas, sistemas de creencias y estrategias para adaptarse a situaciones en distintas partes
Glosario de

herramientas de la CDB

\section{del mundo. El idioma es un buen indicador de la diversidad cultural, en la actualidad se hablan más de 6.000 idiomas. \\ Diversidad cultural}

Los beneficios no materiales que las personas obtienen de los ecosistemas a través del enriquecimiento espiritual, el desarrollo cognitivo, la reflexión, la recreación y la experiencia estética, incluidos, por ejemplo, los sistemas de conocimiento, relaciones sociales y valores estéticos.
Millennium

Ecosystem Assement - MEA (Evaluación de Ecosistemas del Milenio) https://www.cbd.int/cepa/ toolkit/2008/doc/CDB-ToolkitGlossaries.pdf $\mathrm{DO}=\mathrm{DO}$ TOPIC\&URL SECTION=201.html

\section{culturales de los ecosistemas}

Encargado(a) de la toma de decisiones
Una persona cuyas decisiones, y las acciones que las siguen, pueden influir sobre una condición, proceso o asunto bajo consideración.
Millennium

Ecosystem Assement - MEA (Evaluación de Ecosistemas del Milenio) https://www.

millenniumassessment.org/ documents/document.776. aspx.pdf https://www.

millenniumassessment.org/ documents/document.776 aspx.pdf
Una grave interrupción del funcionamiento de una comunidad o una sociedad que causa pérdidas humanas, materiales, económicas o ambientales generalizadas que exceden la capacidad de la comunidad o sociedad afectada para hacer frente con sus propios recursos (EIRD 2004). Reducción del riesgo de desastres. Personas e instituciones que participan en la preparación, mitigación (p. ej., reforzamiento de las estructuras de construcción, sensibilización pública sobre los riesgos de desastres) y actividades de prevención (p. ej., plantar árboles para estabilizar las riberas fluviales) asociadas con acontecimientos extremos. Entre ellas figuran la previsión de peligros y las actividades inmediatas de socorro en caso de desastres importantes como resultado de inundaciones, ciclones y, en algunos casos, de contaminación (adaptado de IISD/UICN/SEI 2003). https://www.iucn.org/sites/ dev/files/iucn-glossary-ofdefinitions en.pdf 
Término

Riesgo de
desastres

La pérdida potencial de vidas, lesiones, bienes destruidos o dañados que podrían ocurrir en un sistema, sociedad o comunidad en un periodo específico, determinado probabilísticamente como una función de los peligros, la exposición, la vulnerabilidad y la capacidad.

Gestión de sistemas de autodiseño humano y ambiental o gestión liviana, que une el diseño humano y el autodiseño ambiental de modo que sean simbióticos. Es el diseño de ecosistemas
Fuente

Enlace

Monty, F., Murti,

R., Miththapala, S.

y Buyck, C., 2017.

Ecosystems protecting

infrastructure and

communities: lessons

learned and guidelines

for implementation

(Ecosistemas

que protegen la

infraestructura y

las comunidades:

Lecciones aprendidas

y pautas para la

implementación). sostenibles que integren a la sociedad humana con su entorno natural en beneficio de ambos.

Un recurso controlado por donantes (presa, detritus, nutrientes) desde un hábitat hasta un receptor (planta o consumidor) desde un segundo hábitat, que aumenta la productividad de la población del receptor, y altera potencialmente la dinámica de los recursos de consumo en el sistema receptor.
Publicación de la

UICN de 2016 sobre

soluciones basadas en

la naturaleza - (Odum,

1996) y (Mitsch, 2012) https://portals.iucn.org/ library/sites/library/files/ documents/2017-045.pdf
Subsidios ecológicos

Ecosistema

Enfoque por ecosistema

Salud del
ecosistema

Ecosistema. Según el Convenio de Diversidad Biológica, un ecosistema se entiende como un complejo dinámico de comunidades vegetales, animales y microorganismos y su entorno no vivo que interactúan como una unidad funcional. Los ecosistemas pueden ser pequeños y simples, como un estanque aislado, o grandes y complejos, como una selva tropical específica o un arrecife de coral en mares tropicales.

\section{Polis et al., 1997}

https://www.annualreviews. org/doi/pdf/10.1146/annurev. ecolsys.28.1.289 https://portals.iucn.org/

library/sites/library/files/ documents/2016-036.pdf

El enfoque por ecosistemas es una estrategia para la ordenación integrada de la tierra, el agua y los recursos vivos que promueve la conservación y el uso sostenible de manera equitativa. El enfoque por ecosistemas sitúa las necesidades humanas en el centro de la gestión de la biodiversidad. Su objetivo es manejar el ecosistema, basándose en las múltiples funciones que desempeñan los ecosistemas y en los múltiples usos que se hacen de estas funciones. El enfoque por ecosistemas no tiene como objetivo obtener beneficios económicos a corto plazo, sino optimizar el uso de un ecosistema sin dañarlo.

Glosario de

herramientas de la CDB https://www.cbd.int/cepa/ toolkit/2008/doc/CDB-ToolkitGlossaries.pdf
El tamaño, la biodiversidad, la estabilidad, el grado de organización, los intercambios internos de materiales, la energía y la información entre diferentes piscinas, y otras propiedades que caracterizan un ecosistema. Comprende funciones y procesos de los ecosistemas.

\section{Millennium}

Ecosystem Assement

- MEA (Evaluación de

Ecosistemas del Milenio)

millenniumassessment.org/ documents/document.776. aspx.pdf
Condición de un ecosistema: es la capacidad de un ecosistema para producir servicios, en relación con su capacidad potencial. Condición de un servicio ecosistémico: es la capacidad de un servicio ecosistémico de producir beneficios a las personas, en relación con su capacidad potencial.
Millennium

Ecosystem Assement

- MEA (Evaluación de

Ecosistemas del Milenio) https://www.

millenniumassessment.org/ documents/document.776. aspx.pdf 


\section{Gestión de ecosistemas}

La gestión (de un ecosistema) es una categorización amplia que puede incluir el mantenimiento y la reparación de los ecosistemas (incluida la restauración).
International standards

for the practice of ecological restoration

- including principles and key concepts

(Normas internacionales para la práctica de la restauración ecológica, incluidos principios y conceptos clave) http://seraustralasia. $\mathrm{com} /$ wheel/image/SER International Standards.pdf

\begin{tabular}{|c|c|c|c|}
\hline $\begin{array}{l}\text { Proceso del } \\
\text { ecosistema }\end{array}$ & $\begin{array}{l}\text { Cualquier cambio o reacción física, química o } \\
\text { biológica que se produzca dentro de un ecosistema. } \\
\text { Los procesos de los ecosistemas incluyen } \\
\text { descomposición, producción, ciclo de nutrientes y } \\
\text { flujos de nutrientes y energía. }\end{array}$ & $\begin{array}{l}\text { Glosario de } \\
\text { terminología de mapeo } \\
\text { y evaluación de servicios } \\
\text { de los ecosistemas }\end{array}$ & $\begin{array}{l}\text { https://oneecosystem.pensoft. } \\
\text { net/articles.php?id=27110 }\end{array}$ \\
\hline $\begin{array}{l}\text { Propiedades del } \\
\text { ecosistema }\end{array}$ & $\begin{array}{l}\text { Atributos que caracterizan a un ecosistema, como } \\
\text { su tamaño, biodiversidad, estabilidad, grado de } \\
\text { organización, así como sus funciones y procesos } \\
\text { (es decir, los intercambios internos de materiales, } \\
\text { energía e información entre diferentes grupos). }\end{array}$ & $\begin{array}{l}\text { Glosario de } \\
\text { terminología de mapeo } \\
\text { y evaluación de servicios } \\
\text { de los ecosistemas }\end{array}$ & $\begin{array}{l}\text { https://oneecosystem.pensoft. } \\
\underline{\text { net/articles.php?id=27110 }}\end{array}$ \\
\hline $\begin{array}{l}\text { Servicios de los } \\
\text { ecosistemas }\end{array}$ & $\begin{array}{l}\text { Los beneficios que obtienen las personas de los } \\
\text { ecosistemas. Estos incluyen servicios de provisión, } \\
\text { como alimentos y agua; servicios de regulación, } \\
\text { como control de inundaciones y enfermedades; } \\
\text { servicios culturales, como beneficios espirituales, } \\
\text { recreativos y culturales; y servicios de apoyo, como } \\
\text { el ciclo de nutrientes que mantienen las condiciones } \\
\text { para la vida en la Tierra. El concepto de "bienes } \\
\text { y servicios de los ecosistemas" es sinónimo de } \\
\text { servicios de los ecosistemas. }\end{array}$ & $\begin{array}{l}\text { Millennium } \\
\text { Ecosystem Assement } \\
\text { - MEA (Evaluación de } \\
\text { Ecosistemas del Milenio) }\end{array}$ & $\begin{array}{l}\frac{\text { https://www. }}{\text { millenniumassessment.org/ }} \\
\frac{\text { documents/document.776. }}{\text { aspx.pdf }}\end{array}$ \\
\hline
\end{tabular}

La gestión eficaz de los ecosistemas es un marco orientado a la acción que tiene por objeto fomentar la sostenibilidad socioecológica de un planeta que cambia rápidamente. Su objetivo central es mantener la capacidad de proporcionar servicios de los ecosistemas que apoyen el bienestar humano en condiciones de incertidumbre y cambio.

Gestión eficaz del La gestión eficaz de los ecosistemas integra tres ecosistema enfoques de sostenibilidad que se superponen ampliamente:

(i) reducir la vulnerabilidad a los cambios previstos; (ii) fomentar la resiliencia para mantener condiciones deseables frente a perturbaciones e incertidumbre; y

(iii) transformar las trayectorias indeseables cuando surjan oportunidades [de cambio].

\begin{tabular}{|c|c|c|c|}
\hline $\begin{array}{l}\text { Estructura del } \\
\text { ecosistema }\end{array}$ & $\begin{array}{l}\text { Característica estática de un "ecosistema"' que se } \\
\text { mide como un inventario o volumen de materiales } \\
\text { o de energía, o la composición y distribución de } \\
\text { elementos biofísicos. }\end{array}$ & $\begin{array}{l}\text { Glosario de } \\
\text { terminología de mapeo } \\
\text { y evaluación de servicios } \\
\text { de los ecosistemas }\end{array}$ & $\begin{array}{l}\text { https://oneecosystem.pensoft. } \\
\text { net/articles.php?id=27110 }\end{array}$ \\
\hline $\begin{array}{l}\text { Adaptación basada } \\
\text { en los ecosistemas }\end{array}$ & $\begin{array}{l}\text { El uso de la biodiversidad y los servicios de } \\
\text { los ecosistemas como parte de una estrategia } \\
\text { general de adaptación para ayudar a las personas } \\
\text { a adaptarse a los efectos adversos del cambio } \\
\text { climático. }\end{array}$ & $\begin{array}{l}\text { Publicación de UICN } \\
2016 \text { sobre soluciones } \\
\text { basadas en la } \\
\text { naturaleza - (CDB, 2009) }\end{array}$ & $\frac{\frac{\text { https://portals.iucn.org/ }}{\text { library/sites/library/files/ }}}{\underline{\text { documents/2016-036.pdf }}}$ \\
\hline $\begin{array}{l}\text { Reducción del } \\
\text { riesgo de desastres } \\
\text { basada en los } \\
\text { ecosistemas }\end{array}$ & $\begin{array}{l}\text { La gestión sostenible, la conservación y la } \\
\text { restauración de los ecosistemas para proporcionar } \\
\text { servicios que reduzcan el riesgo de desastres, } \\
\text { mitigando los peligros y aumentando la resiliencia de } \\
\text { los medios de subsistencia. }\end{array}$ & $\begin{array}{l}\text { Publicación de UICN } \\
2016 \text { sobre soluciones } \\
\text { basadas en la } \\
\text { naturaleza - (PEDRR, } \\
\text { 2010) }\end{array}$ & $\frac{\frac{\text { https://portals.iucn.org/ }}{\text { library/sites/library/files/ }}}{\underline{\text { documents/2016-036.pdf }}}$ \\
\hline
\end{tabular}

Ecosystem Stewardship: Sustainability Strategies for a Rapidly Changing Planet (Gestión de http://dx:doi.org/10.1016/i ecosistemas: Estrategias tree.2009.10.008 de sostenibilidad para un planeta que cambia rápidamente)

\section{.}


Enfoque integrado y basado en la ciencia para la gestión de los recursos naturales que tiene

Gestión basada en los ecosistemas como objetivo mantener la salud, la resiliencia y la diversidad de los ecosistemas, al tiempo que permite el uso sostenible por parte de los seres humanos de los bienes y servicios que proporcionan.
Publicación de UICN

2016 sobre soluciones basadas en la

naturaleza - (Kappel et al., 2006) y (Garcia et al., 2003)

\section{Mitigación basada
en los ecosistemas}

Mejorar los beneficios para la reducción de las emisiones y evitar los impactos negativos sobre la diversidad biológica, teniendo en cuenta la necesidad de asegurar la participación plena y efectiva de las comunidades indígenas y locales en los procesos pertinentes de formulación de políticas y ejecución, según proceda. Mejorar la conservación, el uso sostenible y la restauración de los hábitats marinos y costeros vulnerables a los efectos del cambio climático o que contribuyen a la mitigación del cambio climático.
Publicación de UICN

2016 sobre soluciones

basadas en la

naturaleza - (CDB, 2010) https://portals.iucn.org/

library/sites/library/files/

documents/2016-036.pdf ttps://portals.iucn.org/ library/sites/library/files/ documents/2016-036.pdf
Participar/ involucrarse

Atraer o involucrar el interés o la atención de alguien. Participar en/con: participar o involucrarse.
Glosario de Derecho Ambiental de la UICN https://www.iucn.org/

theme/environmental-law/ our-work/water/water-lawand-governance-supportplatform/learning-resources/ glossary\#PStext

Se refiere a todos los componentes vivos y no vivos y a todos los factores, como el clima, que rodean a un organismo. Con frecuencia se confunde con la palabra ecología, que es la ciencia que estudia las

Medio ambiente relaciones de los seres vivos entre sí, así como con todas las partes no vivas de un medio ambiente. El medio ambiente podría ser concebido como una fila de fichas de dominó. En este sentido, la ecología sería el estudio del efecto sobre cada una de las piezas de dominó al caer.
Glosario de la UICN

https://www.iucn.org/sites/ dev/files/iucn-glossary-ofdefinitions en.pdf

\section{Se refiere al impacto final de los esfuerzos de} desarrollo en ambos sexos. Implica que los resultados deben ser igualmente accesibles y

Glosario de la UICN

https://www.iucn.org/sites/ dev/files/iucn-glossary-ofdefinitions en.pdf utilizados por hombres y mujeres. La igualdad de oportunidades no implica necesariamente que ambos sexos gocen de los mismos beneficios.

\section{equitativos}

\begin{tabular}{ll}
\hline Busca el acceso de las personas a la igualdad de \\
oportunidades y el desarrollo de capacidades \\
básicas; esto significa que se deben eliminar las \\
barreras que obstaculizan las oportunidades \\
económicas y políticas, así como el acceso a la \\
educación y a los servicios básicos, para que \\
las personas (mujeres y hombres de todas las \\
edades, condiciones y posiciones) puedan disfrutar \\
de esas oportunidades y beneficiarse de ellas. \\
Significa justicia; es decir, dar a cada uno lo que es \\
legítimamente suyo, reconocer las condiciones o \\
características específicas de cada persona o grupo \\
humano (sexo, género, clase, religión, edad); es el \\
reconocimiento de la diversidad, sin dar razón a la \\
discriminación.
\end{tabular}

Equidad
La calidad de ser justo e imparcial. // Principio en virtud del cual todas las personas que se encuentren en la misma situación deben acatar las mismas leyes, sin ningún tipo de distinción ni discriminación.
Glosario de Derecho Ambiental de la UICN https://www.lucn.org/ theme/environmental-law/ our-work/water/water-lawand-governance-supportplatform/learning-resources/ glossary\#PStext 


\begin{tabular}{|c|c|c|c|}
\hline Término & Definición & Fuente & Enlace \\
\hline Proceso evolutivo & $\begin{array}{l}\text { Una serie de eventos que producen cambios en } \\
\text { las frecuencias genéticas dentro de una población. } \\
\text { Tales cambios pueden dar lugar a la aparición } \\
\text { de nuevas especies (especiación) o nuevos taxa } \\
\text { intraespecíficos. }\end{array}$ & $\begin{array}{l}\text { Glosario de } \\
\text { terminología de mapeo } \\
\text { y evaluación de servicios } \\
\text { de los ecosistemas }\end{array}$ & $\begin{array}{l}\text { https://oneecosystem.pensoft. } \\
\text { net/articles.php?id=27110 }\end{array}$ \\
\hline $\begin{array}{l}\text { Flujo (servicio de } \\
\text { ecosistema) }\end{array}$ & $\begin{array}{l}\text { La cantidad de un servicio ecosistémico que se } \\
\text { moviliza realmente en un área y tiempo específicos }\end{array}$ & $\begin{array}{l}\text { Glosario de } \\
\text { terminología de mapeo } \\
\text { y evaluación de servicios } \\
\text { de los ecosistemas }\end{array}$ & $\begin{array}{l}\text { https://oneecosystem.pensoft. } \\
\text { net/articles.php?id }=27110\end{array}$ \\
\hline $\begin{array}{l}\text { Seguridad } \\
\text { alimentaria }\end{array}$ & $\begin{array}{l}\text { La seguridad alimentaria, es decir, la disponibilidad } \\
\text { de alimentos accesibles para todos, seguros y } \\
\text { localmente apropiados, y confiables a través del } \\
\text { tiempo y el espacio, es uno de los principales } \\
\text { problemas que enfrenta el mundo hoy en día. }\end{array}$ & $\begin{array}{l}\text { Publicación de UICN } \\
2016 \text { sobre soluciones } \\
\text { basadas en la } \\
\text { naturaleza }\end{array}$ & $\begin{array}{l}\frac{\text { https://portals.iucn.org/ }}{\text { library/sites/library/files// }} \\
\text { documents/2016-036.pdf }\end{array}$ \\
\hline $\begin{array}{l}\text { Restauración } \\
\text { de los paisajes } \\
\text { boscosos }\end{array}$ & $\begin{array}{l}\text { Un proceso planificado que busca recuperar } \\
\text { la integridad ecológica y mejorar el bienestar } \\
\text { humano en paisajes deforestados o degradados. La } \\
\text { restauración de los paisajes boscosos es el proceso } \\
\text { a largo plazo de recuperar la funcionalidad ecológica } \\
\text { y mejorar el bienestar humano en los paisajes } \\
\text { forestales deforestados o degradados. }\end{array}$ & $\begin{array}{l}\text { Publicación de } \\
\text { UICN } 2016 \text { sobre } \\
\text { soluciones basadas } \\
\text { en la naturaleza - } \\
\text { (Mansourian et al., } \\
\text { 2005) y Maginnis et al., } \\
\text { 2014) }\end{array}$ & $\begin{array}{l}\frac{\text { https://portals.iucn.org/ }}{\text { library/sites/library/files/ }} \\
\text { documents/2016-036.pdf }\end{array}$ \\
\hline Marco & $\begin{array}{l}\text { Marco. Una estructura de alto nivel que establece un } \\
\text { propósito y una dirección comunes para los planes } \\
\text { y programas. }\end{array}$ & Glosario de la UICN & $\begin{array}{l}\frac{\text { https://www.iucn.org/sites/ }}{\text { dev/files/iucn-glossary-of- }} \\
\text { definitions en.pdf }\end{array}$ \\
\hline Género & $\begin{array}{l}\text { Los géneros son grupos biosocioculturales } \\
\text { históricamente construidos a partir de la } \\
\text { identificación de características sexuales que } \\
\text { clasifican a los seres humanos. Una vez clasificados, } \\
\text { se les asigna un conjunto diferenciado de funciones, } \\
\text { actividades, relaciones sociales, formas y normas } \\
\text { de comportamiento. Es un conjunto complejo de } \\
\text { determinaciones y características económicas, } \\
\text { sociales, jurídicas, políticas y psicológicas, es decir, } \\
\text { culturales, creando lo que en cada periodo, sociedad } \\
\text { o cultura constituye el contenido específico de ser } \\
\text { hombre o mujer. }\end{array}$ & Glosario de la UICN & $\frac{\frac{\text { https://www.iucn.org/sites/ }}{\text { dev/files/iucn-glossary-of- }}}{\underline{\text { definitions en.pdf }}}$ \\
\hline
\end{tabular}

El aumento estimado de la temperatura media global en superficie promediada durante un periodo de 30 años, o el periodo de 30 años centrado en un año o década en particular, expresado en relación con los niveles preindustriales, a menos que se especifique lo contrario. Para periodos de 30 años que abarquen años pasados y futuros, se supone que se mantiene la tendencia actual al calentamiento multidecenal.

https://www.ipcc.ch/ site/assets/uploads/ sites/2/2019/05/SR15 SPM version report LR.pdf
La acción o la manera de gobernar; el sistema de controlar, dirigir o regular la influencia. Comprende cuatro aspectos: social, político, económico y

Gobernanza jurídico. Más que el gobierno, la gobernanza se refiere al complejo de procesos e instituciones por medio de los cuales la sociedad cuestiona, toma y administra decisiones.
Glosario de Derecho Ambiental de la UICN

Glosario del Global Reporting Institute https://www.iucn.org/ theme/environmental-law/ our-work/water/water-lawand-governance-supportplatform/learning-resources/ glossary\#PStext

https://www.globalreporting org/standards/media/1913/gristandards-glossary.pdf
Comité o junta responsable de la orientación estratégica de la organización, la supervisión eficaz de la gestión y la rendición de cuentas de la gestión ante la organización en general y sus partes interesadas

\section{gobernanza}


La infraestructura verde comprende todas las redes naturales, seminaturales y artificiales de sistemas ecológicos multifuncionales dentro, alrededory entre áreas urbanas, a todas las escalas espaciales. El concepto de infraestructura verde hace hincapié en la calidad y la cantidad de espacios verdes urbanos y periurbanos, su papel multifuncional y la importancia de las interconexiones entre
Infraestructura

\section{verde}

Mecanismo de reclamación

Salud humana

Bienestar humano

\begin{tabular}{|c|c|}
\hline Bienestar humano & $\begin{array}{l}\text { potable; las buenas relaciones sociales, incluyendo } \\
\text { la cohesión social, el respeto mutuo, y la capacidad } \\
\text { de ayudar a otros y proveer a los niños; la seguridad, } \\
\text { incluido el acceso seguro a los recursos naturales } \\
\text { y de otro tipo, la seguridad personal y la seguridad } \\
\text { frente a los desastres naturales y provocados por el } \\
\text { hombre, y la libertad de elección y acción, incluida } \\
\text { la oportunidad de lograr lo que un individuo valora } \\
\text { hacer y ser". }\end{array}$ \\
\hline
\end{tabular}

Impacto planificada con otras características ambientales diseñadas y manejadas para ofrecer una amplia gama de servicios ecosistémicos. Incorpora espacios verdes (o azules si se trata de ecosistemas acuáticos) y otras características físicas en las zonas terrestres (incluidas las costeras) y marinas. En tierra, la infraestructura verde está presente en entornos rurales y urbanos. fuente de aprendizaje continuo. Se espera por igual

"Se supone que el bienestar humano tiene múltiples componentes, incluido el material básico para una buena vida, como medios de subsistencia seguros y adecuados, alimentos suficientes en todo momento, vivienda, ropa y acceso a los bienes; la salud, incluyendo sentirse bien y tener un ambiente físico saludable, como el aire limpio y el acceso al agua potable; las buenas relaciones sociales, incluyendo la cohesión social, el respeto mutuo, y la capacidad de ayudar a otros y proveer a los niños; la seguridad, de otro tipo, la seguridad personal y la seguridad frente a los desastres naturales y provocados por el la oportunidad de lograr lo que un individuo valora hacer y ser".
Efecto positivo o negativo sobre las personas, la sociedad y los recursos ambientales como resultado del cambio ambiental.
Publicación de UICN 2016 sobre soluciones basadas en la naturaleza - (Tzoulas et al., 2007) y (Comisión Europea, 2013)

\section{https://portals.iucn.org/} library/sites/library/files/ documents/2016-036.pdf
Sistema del mecanismo de reclamación que consta de procedimientos, funciones y reglas para recibir quejas y proveer remedio. Nota: se espera que los mecanismos de reclamación eficaces sean legítimos, accesibles, predecibles, equitativos, transparentes, compatibles con los derechos y constituyan una que, para que los mecanismos a nivel operativo sean eficaces, se basen en el compromiso y el diálogo. Para ver una descripción de cada uno de estos criterios, véase el Principio Rector 31 de las Naciones Unidas.

Un estado de pleno bienestar físico, mental y social, no simplemente la ausencia de dolencias o enfermedades. La salud de toda una comunidad o población se refleja en las mediciones de la incidencia y prevalencia de enfermedad, las tasas de mortalidad específicas por edad y la esperanza de vida. Componentes del bienestar: los aspectos vivenciales del bienestar, como la salud, la felicidad y la libertad de ser y de hacer, y, en términos más generales, las libertades básicas. Determinantes del bienestar: son insumos para la producción de bienestar, como alimentos, ropa, agua potable y acceso a conocimientos e información.
Glosario del Global Reporting Institute https://www.globalreporting org/standards/media/1913/gristandards-glossary.pdf
Millennium

Ecosystem Assement

- MEA (Evaluación de

Ecosistemas del Milenio) https://www.

millenniumassessment.org/ documents/document.776. aspx.pdf
Millennium

Ecosystem Assement

- MEA (Evaluación de

Ecosistemas del Milenio) https://www.

millenniumassessment.org/ aspx.pdf documents/document.776.

\section{Glosario de}

terminología de mapeo https://oneecosystem.pensoft. y evaluación de servicios net/articles.php?id=27110 de los ecosistemas 


\begin{tabular}{|c|c|c|c|}
\hline Término & Definición & Fuente & Enlace \\
\hline $\begin{array}{l}\text { Impacto } \\
\text { (ambiental) }\end{array}$ & $\begin{array}{l}\text { El efecto mensurable de la acción humana sobre } \\
\text { un determinado ecosistema. Un instrumento de } \\
\text { medición es la manifestación del impacto ambiental, } \\
\text { a través del cual se revela el impacto ambiental } \\
\text { significativo y potencial generado por una actividad } \\
\text { o trabajo, así como el modo en que podría evitarse o } \\
\text { mitigarse en caso de que sea un impacto negativo. }\end{array}$ & Glosario de la UICN & $\begin{array}{l}\frac{\text { https://www.iucn.org/sites/ }}{\text { dev/files/iucn-glossary-of- }} \\
\underline{\text { definitions en.pdf }}\end{array}$ \\
\hline
\end{tabular}

La aplicación describe las medidas adoptadas para cumplir los compromisos contraídos en virtud de un tratado, y abarca fases jurídicas y eficaces. La aplicación legal se refiere a la legislación, reglamentos, decretos judiciales, incluidas otras acciones, tales como los esfuerzos para administrar Aplicación los avances, que toman los Gobiernos para trasladar los acuerdos internacionales a la legislación y la normativa nacionales. La aplicación eficaz requiere políticas y programas que induzcan cambios en el comportamiento y las decisiones de los grupos destinatarios. Los grupos destinatarios toman entonces medidas eficaces de mitigación y adaptación. Véase también Cumplimiento.

\begin{tabular}{|c|c|c|c|}
\hline Indicador & $\begin{array}{l}\text { Factor o variable cuantitativa o cualitativa que } \\
\text { proporciona un medio simple y confiable para } \\
\text { medir el logro de resultados, para reflejar los } \\
\text { cambios relacionados con un sistema de normas, } \\
\text { o para contribuir a evaluar el desempeño de una } \\
\text { organización. }\end{array}$ & $\begin{array}{l}\text { Glosario de términos } \\
\text { de ISEAL - adaptado del } \\
\text { Glosario de la OCDE, } \\
2002 \text {. }\end{array}$ & $\begin{array}{l}\frac{\text { https://www. }}{\text { sustainabilityxchange.info/ }} \\
\text { filesagri/ISEAL Glosario de } \\
\text { términos v1 - 16 Jan 2015.pdf }\end{array}$ \\
\hline $\begin{array}{l}\text { Conocimiento } \\
\text { indígena }\end{array}$ & $\begin{array}{l}\text { El conocimiento que es único a una cultura o } \\
\text { sociedad dada. Véase conocimientos tradicionales. }\end{array}$ & $\begin{array}{l}\text { Millennium } \\
\text { Ecosystem Assement } \\
\text { - MEA (Evaluación de } \\
\text { Ecosistemas del Milenio) }\end{array}$ & $\begin{array}{l}\frac{\text { https://www. }}{\text { millenniumassessment.org/ }} \\
\text { documents/document.776. } \\
\text { aspx.pdf }\end{array}$ \\
\hline Pueblos indígenas & $\begin{array}{l}\text { Los descendientes existentes de los pueblos que } \\
\text { habitaban el territorio actual de un país total o } \\
\text { parcialmente en el momento en que personas } \\
\text { de una cultura u origen étnico distinto llegaron } \\
\text { allí de otras partes del mundo, los vencieron y, } \\
\text { por conquista, asentamiento u otros medios } \\
\text { los redujeron a una situación no dominante o } \\
\text { colonial; que hoy viven más de conformidad con } \\
\text { sus costumbres y tradiciones sociales, económicas } \\
\text { y culturales particulares que con las instituciones } \\
\text { del país del que ahora forman parte, bajo la } \\
\text { estructura del Estado que incorpora principalmente } \\
\text { características nacionales, sociales y culturales de } \\
\text { otros segmentos de la población que predominan. } \\
\text { (Definición de trabajo adoptada por el Grupo de } \\
\text { Trabajo de las Naciones Unidas sobre Pueblos } \\
\text { Indígenas). }\end{array}$ & Glosario de la UICN & $\begin{array}{l}\frac{\text { https://www.lucn.org/sites/ }}{\text { dev/files/iucn-glossary-of- }} \\
\text { definitions en.pdf }\end{array}$ \\
\hline Infraestructura & $\begin{array}{l}\text { El equipo, servicios públicos, empresas productivas, } \\
\text { instalaciones y servicios esenciales básicos para } \\
\text { el desarrollo, operación y crecimiento de una } \\
\text { organización, ciudad o nación. }\end{array}$ & IPCC & $\begin{array}{l}\frac{\text { https://www.ipcc.ch/pdf/ }}{\text { assessment-report/ar4/syr/ }} \\
\underline{\text { ar4 syr appendix.pdf }}\end{array}$ \\
\hline Instituciones & $\begin{array}{l}\text { Las instituciones son acuerdos, leyes, procesos o } \\
\text { costumbres persistentes y previsibles que sirven } \\
\text { para estructurar las transacciones y relaciones } \\
\text { políticas, sociales, culturales o económicas en } \\
\text { una sociedad. Pueden ser informales o formales, } \\
\text { y facilitan los esfuerzos organizados y colectivos } \\
\text { en torno a preocupaciones comunes. Si bien } \\
\text { son persistentes, las instituciones evolucionan } \\
\text { constantemente. }\end{array}$ & $\begin{array}{l}\text { Glosario de Derecho } \\
\text { Ambiental de la UICN }\end{array}$ & $\begin{array}{l}\text { https://www.iucn.org/ } \\
\text { theme/environmental-law/ } \\
\text { our-work/water/water-law- } \\
\text { and-governance-support- } \\
\text { platform/learning-resources/ } \\
\text { glossary\#PStext }\end{array}$ \\
\hline
\end{tabular}


Término integrada introducidas

Especies invasoras especies exóticas se vuelven problemáticas. Son estas especies las que se denominan "especies exóticas invasoras". "Una especie extraña invasora es una especie que se establece fuera de su distribución natural pasada o presente, y cuya introducción y/o propagación amenazan la diversidad biológica".

El uso de la tierra se refiere a la forma en que se asigna una parte específica de la tierra: Su propósito, necesidad o uso (p. ej., para agricultura, la industria, para fines residenciales o para la naturaleza).

Uso de la tierra

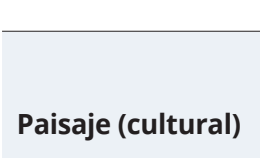

\section{Paisaje (cultural)}

Propiedades culturales que representan las obras combinadas de la naturaleza y de las personas.
El nivel de integración dentro de las "evaluaciones de ecosistemas" existentes varía, pero generalment
cae dentro de i) combinación, ii) interpretación y iii) comunicación de conocimientos de diversas disciplinas.

Las especies introducidas son aquellas presentes fuera de su entorno natural (pasado o presente) y potencial de dispersión (es decir, fuera del entorno que ocupan naturalmente o que no podrían ocupar

Una especie exótica es una especie introducida por los seres humanos, ya sea intencional o pasada o presente; sin embargo, no todas las especies exóticas tienen impactos negativos, y se estima que entre el $5 \%$ y el $20 \%$ de todas las
Fuente

Enlace

Un método de análisis que combina resultados

y modelos de las ciencias físicas, biológicas, estos componentes, en un marco coherente a fin de aluar la situación y las consecuencias del cambio modelos utilizados para llevar a cabo dicho análisis se denominan modelos de evaluación integrada. IPCC $\quad \frac{\text { https://www.ipcc.ch/pdf/ }}{\text { assessment-report/ar4/syr/ }}$ ar4 syr appendix.pdf

\section{Glosario de}

terminología de mapeo https://oneecosystem.pensoft. y evaluación de servicios net/articles.php?id=27110 de los ecosistemas

Glosario de la RLTS

http://www.iucnredlist. org/initiatives/mammals/ description/glossary chas Glosario de la RLTS

http://www.iucnredlist. org/initiatives/mammals/ description/glossary

Un área, tal como la perciben las personas, cuyo carácter es el resultado de la acción y la interacción de factores naturales y/o humanos. El término "paisaje" se define así como una zona o área tal como la perciben la población local o los visitantes, cuyas características visuales y su carácter son el resultado de la acción de factores naturales

Paisaje (geográfico) y/o culturales. Se reconoce el hecho de que los paisajes evolucionan con el paso del tiempo y son el resultado de actividades naturales y humanas. El paisaje debe ser considerado como un todo; los componentes naturales y culturales forman parte de ese grupo complejo, no son elementos por separado.
Glosario de

herramientas de la CDB

Glosario de

terminología de mapeo https://oneecosystem.pensoft. y evaluación de servicios net/articles.php?id $=27110$ de los ecosistemas https://www.cbd.int/cepa/ toolkit/2008/doc/CDB-ToolkitGlossaries.pdf

El enfoque del paisaje se basa en un conjunto emergente de principios que hacen hincapié en la gestión adaptativa, la participación de las partes

Enfoque de paisaje interesadas y los múltiples objetivos para abordar las preocupaciones de la sociedad acerca de las compensaciones respecto del medio ambiente y el desarrollo.

Glosario de

terminología de mapeo https://oneecosystem.pensoft. y evaluación de servicios net/articles.php?id=27110 de los ecosistemas
Sayer et al., 2013.

https://www.pnas.org/ content/110/21/8349 


\begin{tabular}{|c|c|c|c|}
\hline Término & Definición & Fuente & Enlace \\
\hline $\begin{array}{l}\text { Conectividad } \\
\text { horizontal }\end{array}$ & $\begin{array}{l}\text { La medida en que un paisaje facilita los movimientos } \\
\text { de los organismos y sus genes, enfrenta amenazas } \\
\text { críticas tanto de la fragmentación como de la } \\
\text { pérdida de hábitat. }\end{array}$ & Rudnick et al., 2012 & $\begin{array}{l}\text { https://www.fs.fed.us/rm/ } \\
\text { pubs other/rmrs 2012 } \\
\text { rudnick d001.pdf }\end{array}$ \\
\hline Flujos del paisaje & $\begin{array}{l}\text { Flujos de paisaje son intercambios que ocurren a } \\
\text { un nivel mayor que el sitio (incluidos los entornos } \\
\text { acuáticos) e incluyen flujos de energía, agua, fuego } \\
\text { y material genético. Los intercambios se ven } \\
\text { facilitados por los vínculos con el hábitat (Wiens } \\
\text { 1992). }\end{array}$ & $\begin{array}{l}\text { International standards } \\
\text { for the practice of } \\
\text { ecological restoration } \\
\text { - including principles } \\
\text { and key concepts } \\
\text { (Normas internacionales } \\
\text { para la práctica de la } \\
\text { restauración ecológica, } \\
\text { incluidos principios y } \\
\text { conceptos clave) }\end{array}$ & $\begin{array}{l}\frac{\text { http://seraustralasia. }}{\text { com/wheel/image/SER }} \\
\text { International Standards.pdf }\end{array}$ \\
\hline
\end{tabular}

No existe una sola definición aceptada de la :escala horizontal"; más bien se trata de un término que se usa comúnmente para referirse a una acción que cubre una gran escala espacial y usualmente aborda una gama de procesos de ecosistemas, objetivos de conservación y usos de la tierra. La "escala adecuada" podría tener en cuenta el interés particular de los implicados en las características locales, estéticas o culturales, las características naturales, como las cuencas fluviales o determinados hábitats, o las zonas reconocidas como las 159 zonas de carácter nacional. La conservación a escala horizontal se caracteriza por

Escala horizontal la búsqueda de múltiples beneficios en una esfera definida (p. ej., calidad del agua, biodiversidad y acceso). Los mejores ejemplos también establecen vínculos con prioridades económicas y sociales más amplias, en las que mejorar la naturaleza puede proporcionar beneficios a la economía local y a la calidad de vida. Existen fuertes vínculos entre el enfoque a escala horizontal y un "enfoque por ecosistemas", que fomenta un enfoque integrado de la ordenación de la tierra, considerando los costos y beneficios de las decisiones sobre el uso de la tierra y persiguiendo aquellos que minimizan los riesgos y maximizan las oportunidades para las personas, para la naturaleza y para la economía.

Landscape scale towards an integrated approach; The Natural Choice, Natural Environment White Paper, 2011 https://www.banc.org.uk/wpcontent/uploads/2015/05/ ECOS-33-3-4-6-Landscapescale-integrated-approach.pdf Etapas consecutivas e interrelacionadas de un
producto (bien o servicio), desde la extracción de recursos naturales hasta su eliminación fina.
Glosario del PNUD

- Adaptado de ISO

14040:2006 https://www.unenvironment. org/explore-topics/resourceefficiency/why-does-resourceefficiency-matter/glossary

El cabildeo o los asuntos públicos son una forma especializada de relaciones públicas. Se refiere a las actividades destinadas a establecer y mantener relaciones informales con los responsables de la toma de decisiones formales. Las relaciones informales se utilizan para influir en los procesos de

Glosario de herramientas de la CDB https://www.cbd.int/cepa/ toolkit/2008/doc/CDB-ToolkitGlossaries.pdf toma de decisiones en interés de la organización, su programa y/u objetivos.

Conocimiento local Véanse Conocimientos indígenas o tradicionales.

Es incorporar una preocupación específica, por
ejemplo, el uso sostenible de los ecosistemas, en las políticas y acciones

\section{Millennium} Ecosystem Assement - MEA (Evaluación de Ecosistemas del Milenio) https://www.

millenniumassessment.org/ documents/document.776. aspx.pdf 
Mantenimiento de ecosistemas (actividades en curso) aplicadas después de la recuperación total, destinadas a contrarrestar los procesos de degradación ecológica para mantener los atributos

\section{Mantenimiento} de un ecosistema. Es probable que se requiera un mayor mantenimiento continuo en los sitios restaurados donde persisten los niveles más altos de amenazas, en comparación con los sitios donde se han controlado las amenazas (McDonald et al 2016)
International standards for the practice of ecological restoration - including principles and key concepts (Normas internacionales para la práctica de la

http://seraustralasia. $\mathrm{com} /$ wheel/image/SER International Standards.pdf restauración ecológica incluidos principios y conceptos clave)
Medidas que permiten una actividad con un impacto negativo en la biodiversidad, pero reducen el impacto en el sitio al considerar cambios en la escala, diseño, ubicación, proceso, secuencia, gestión y/o monitoreo de la actividad propuesta. Requiere un esfuerzo conjunto de planificadores, ingenieros, ecologistas, otros expertos y, a menudo, partes interesadas locales para llegar a la mejor opción ambiental práctica. Un ejemplo es el impacto inaceptable sobre la biodiversidad de la construcción de un camino determinado, que se ve mitigado por la construcción de un viaducto de vida silvestre.

\section{Glosario de}

herramientas de la CDB https://www.cbd.int/cepa/ toolkit/2008/doc/CDB-ToolkitGlossaries.pdf

\begin{tabular}{|c|c|c|c|}
\hline Monitoreo & $\begin{array}{l}\text { Recuentos periódicos estadísticamente diseñados } \\
\text { de una población para observar su número, } \\
\text { composición y distribución }\end{array}$ & Glosario de la UICN & $\begin{array}{l}\text { https://www.iucn.org/sites/ } \\
\text { dev/files/iucn-glossary-of- } \\
\text { definitions en.pdf }\end{array}$ \\
\hline
\end{tabular}
composición y distribución definitions en.pdf

Un proceso continuo mediante el cual una organización extrae conclusiones sobre su contribución a los resultados e impactos previstos. Un sistema de supervisión y evaluación consiste en un conjunto de funciones, procesos y actividades interconectados, incluida la recopilación sistemática de datos de supervisión sobre determinados indicadores y la realización de evaluaciones de resultados y efectos.

Monitoreo evaluación

\begin{tabular}{|c|c|c|c|}
\hline $\begin{array}{l}\text { Compromisos } \\
\text { nacionales }\end{array}$ & $\begin{array}{l}\text { Estrategia y plan de acción nacional sobre } \\
\text { diversidad biológica. El Convenio sobre la Diversidad } \\
\text { Biológica pide a cada una de sus partes que } \\
\text { elabore una Estrategia y plan de acción nacional } \\
\text { sobre diversidad biológica (Artículo 6a) que defina } \\
\text { actividades y fije metas específicas para alcanzar } \\
\text { los objetivos del Convenio. Estos planes son } \\
\text { ejecutados principalmente por una asociación } \\
\text { de organizaciones de conservación. Las especies } \\
\text { o hábitats que son objeto de la EPANDB son las } \\
\text { prioridades de acción establecidas por los Gobiernos } \\
\text { y, por lo tanto, suscitan mayor preocupación cuando } \\
\text { están amenazados. Las EPANDB no tienen estatus } \\
\text { legal, y las especies y tipos de hábitat incluidos en la } \\
\text { lista no necesariamente están protegidos (aunque } \\
\text { algunos están cubiertos por otra legislación). }\end{array}$ & $\begin{array}{l}\text { Glosario de } \\
\text { herramientas de la CDB }\end{array}$ & $\begin{array}{l}\text { https://www.cbd.int/cepa/ } \\
\text { toolkit/2008/doc/CDB-Toolkit- } \\
\text { Glossaries.pdf }\end{array}$ \\
\hline
\end{tabular}


Término

Un ecosistema nativo local es un ecosistema que comprende especies o subespecies (con la exclusión de especies no nativas invasoras) que se sabe que han evolucionado localmente o que han migrado recientemente de localidades vecinas debido a los cambios en el clima. Cuando faltan

Nativo pruebas locales, la información regional e histórica puede ayudar a moldear los ecosistemas nativos locales más probables. Estos se diferencian de los "ecosistemas culturales" (p. ej., agroecosistemas) si los ecosistemas han sido sustancialmente modificados en extensión y configuración más allá de sus análogos naturales, o están fuera del rango de variación natural de ese ecosistema.
International standards

for the practice of

ecological restoration

- including principles

and key concepts

(Normas internacionales

para la práctica de la

restauración ecológica

incluidos principios y

conceptos clave) http://seraustralasia. com/wheel/image/SER International_Standards.pdf

El medio ambiente natural comprende todas las cosas vivas y no vivas que se presentan naturalmente en la Tierra. En su sentido más puro, es un ambiente que no es resultado de la actividad o la intervención humanas. El entorno natural puede

Glosario de

herramientas de la CDB https://www.cbd.int/cepa/ toolkit/2008/doc/CDB-ToolkitGlossaries.pdf contrastarse con el "entorno construido", y también contrasta con el concepto de paisaje cultural.

La infraestructura natural se define como una "red de tierras naturales planificada y gestionada estratégicamente, como bosques y humedales,

Infraestructura natural paisajes de trabajo y otros espacios abiertos que conserva o mejora los valores y funciones de los ecosistemas y proporciona beneficios asociados a las poblaciones humanas".
Publicación de UICN

2016 sobre soluciones https://portals.iucn.org/ basadas en la library/sites/library/files/ naturaleza - Benedict \& documents/2016-036.pdf McMahon, 2006)

\section{Concepto}

Desarrollo

Ejecución y seguimiento

Evaluación

Cierre

Son las posibilidades de desarrollar habilidades intelectuales, físicas y emocionales, de perseguir y alcanzar las metas establecidas en la vida. https://www.lucn.org/

resources/project-

management-tools/projectguidelines

https://www.iucn.org/sites/ dev/files/iucn-glossary-ofdefinitions en.pdf

Condiciones ecológicas o sociales sobre el terreno que son consecuencia directa de los productos y contribuyen a lograr impacto propuesto. A manera de ejemplo, el cuerpo de agua que se protege del ganado, el cambio en el área de bosque manejada de manera sostenible (como resultado de un mejor conocimiento a través de la formación), la reducción de la erosión y la sedimentación (como resultado de la replantación en pendientes).

Consecuencias inmediatas y directas de las actividades de gestión realizadas en la unidad de gestión; por ejemplo, metros de valla construidos, número de personas formadas y cantidad de hectáreas de pendiente replantadas, proporción de la unidad de manejo donde se han eliminado especies exóticas.

Procedimiento de servicios del ecosistema: https://ic.fsc.org/file-download. demostración del impacto y herramientas de mercado ecosystem-servicesprocedure.a-7433.pdf
Procedimiento de servicios del ecosistema: demostración del impacto y herramientas de mercado https://ic.fsc.org/file-download. ecosystem-servicesprocedure.a-7433.pdf

\section{Productos}


La investigación de acción participativa es un enfoque de investigación que se ha utilizado desde la década de 1940. Involucra a investigadores y participantes que trabajan juntos para entender una situación problemática y cambiarla a fin de mejorarla. Hay muchas definiciones del enfoque, y comparten algunos elementos comunes. La
Investigación de acción participativa

\begin{tabular}{|l} 
\\
\hline Aprendizaje \\
y acción \\
participativas
\end{tabular}
investigación de acción participativa se centra en el cambio social que promueve la democracia y desafía la desigualdad; es específico del contexto, a menudo orientado a las necesidades de un grupo en particular; es un ciclo iterativo de investigación, acción y reflexión; y a menudo busca "liberar" a los participantes para que tengan una mayor conciencia de su situación con el fin de tomar medidas. La investigación de acción participativa utiliza una gama de métodos distintos, tanto cualitativos como cuantitativos.

El aprendizaje y la acción participativas es una familia de enfoques, métodos, actitudes, comportamientos y relaciones que permiten a las personas compartir, analizar y mejorar sus conocimientos sobre su vida y sus condiciones, y planificar, actuar, supervisar, evaluar y reflexionar.
Instituto de Estudios de https://www. Desarrollo participatorymethods.org/ glossary-terms
Instituto de Estudios de Desarrollo

https://www.

participatorymethods.org/ glossary-terms

\begin{tabular}{|c|c|c|c|}
\hline Política & $\begin{array}{l}\text { Principios generales que guían a un Gobierno en } \\
\text { su gestión de los asuntos públicos. Es un curso o } \\
\text { principio de acción adoptado o propuesto por una } \\
\text { organización o persona. }\end{array}$ & $\begin{array}{l}\text { Glosario de Derecho } \\
\text { Ambiental de la UICN }\end{array}$ & $\begin{array}{l}\text { https://www.iucn.org/ } \\
\text { theme/environmental-law/ } \\
\text { our-work/water/water-law- } \\
\text { and-governance-support- } \\
\text { platform/learning-resources/ } \\
\text { glossary\#PStext }\end{array}$ \\
\hline Preindustrial & $\begin{array}{l}\text { El periodo de varios siglos anterior al inicio de la } \\
\text { actividad industrial a gran escala alrededor de } 1750 . \\
\text { El periodo de referencia (1850-1900) se utiliza como } \\
\text { aproximación de la temperatura media global en } \\
\text { superficie en la etapa preindustrial. }\end{array}$ & Informe del IPCC & $\begin{array}{l}\frac{\text { https://www.ipcc.ch/ }}{\text { site/assets/uploads/ }} \\
\text { sites/2/2019/05/SR15_SPM } \\
\text { version report_LR.pdf }\end{array}$ \\
\hline Proyecto & $\begin{array}{l}\text { Un proyecto es un conjunto de actividades con un } \\
\text { plazo limitado que han sido diseñadas para lograr } \\
\text { resultados e impactos. }\end{array}$ & PAAS de la UICN & $\begin{array}{l}\text { https://www.iucn.org/ } \\
\text { resources/project- } \\
\text { management-tools/project- } \\
\text { guidelines }\end{array}$ \\
\hline $\begin{array}{l}\text { Diseño del } \\
\text { proyecto }\end{array}$ & $\begin{array}{l}\text { El diseño de la organización adecuada de un } \\
\text { proyecto determinado puede considerarse como un } \\
\text { factor central de éxito del proyecto. Los proyectos } \\
\text { requieren diseños organizativos adecuados, } \\
\text { incluidos roles tales como el de propietario del } \\
\text { proyecto, director del proyecto, miembros del } \\
\text { equipo del proyecto, equipos y subequipos del } \\
\text { proyecto. Además, la organización del proyecto } \\
\text { debe estar relacionada con la empresa o empresas } \\
\text { ejecutoras del proyecto. Los métodos centrales } \\
\text { de gestión de proyectos son el organigrama del } \\
\text { proyecto y las descripciones de funciones del } \\
\text { proyecto. }\end{array}$ & $\begin{array}{l}\text { Relating sustainable } \\
\text { development and } \\
\text { project management: } \\
\text { a conceptual model } \\
\text { (Relacionando el } \\
\text { desarrollo sostenible y } \\
\text { la gestión de proyectos: } \\
\text { Un modelo conceptual) } \\
\text { - (Gareis, 2005) }\end{array}$ & $\begin{array}{l}\frac{\text { https://www.pmi.org/learning/ }}{\text { library/relating-sustainable- }} \\
\frac{\text { development-project- }}{\text { management-6497 }}\end{array}$ \\
\hline Proyección & $\begin{array}{l}\text { Una posible evolución futura de una cantidad } \\
\text { o conjunto de cantidades, a menudo calculada } \\
\text { con la ayuda de un modelo. Las proyecciones se } \\
\text { distinguen de las predicciones para subrayar que } \\
\text { las proyecciones entrañan supuestos relativos, por } \\
\text { ejemplo, futuros desarrollos socioeconómicosy y } \\
\text { tecnológicos que bien podrían o no hacerse realidad } \\
\text { y, por lo tanto, están sujetas a una incertidumbre } \\
\text { sustancial. }\end{array}$ & IPCC & $\begin{array}{l}\frac{\text { https://www.ipcc.ch/pdf/ }}{\text { assessment-report/ar4/syr/ }} \\
\text { ar4 syr_appendix.pdf }\end{array}$ \\
\hline
\end{tabular}


Término

\begin{tabular}{l} 
Área protegida \\
\hline Servicios de \\
aprovisionamiento
\end{tabular}

\section{Definición}

La UICN define un área protegida como: "Un espacio geográfico claramente definido, reconocido, dedicado y gestionado, por medios legales u otros medios eficaces, para lograr la conservación a largo plazo de la naturaleza con los servicios de los ecosistemas y los valores culturales asociados" (Dudley, 2008). La protección efectiva también puede tener lugar en otros lugares, y la UICN dirige un proceso para definir "otros mecanismos efectivos de conservación basados en áreas" en reconocimiento de esto (Jonas et al., 2014).

Los productos obtenidos de los ecosistemas, incluidos, por ejemplo, los recursos genéticos, los alimentos y las fibras, y el agua dulce. Áreas protegidas de la $\frac{\text { https://www.lucn.org/es/ }}{\text { node/236 }}$
UICN
Millennium

Ecosystem Assement

- MEA (Evaluación de

Ecosistemas del Milenio) https://www.

millenniumassessment.org/ documents/document.776.

aspx.pdf
Regulación de los servicios
Los beneficios obtenidos de la regulación de los procesos de los ecosistemas, incluidas, por ejemplo, la regulación del clima, el agua y algunas enfermedades humanas.
Millennium

Ecosystem Assement

- MEA (Evaluación de Ecosistemas del Milenio) https://www.

millenniumassessment.org/ documents/document.776. aspx.pdf

\begin{tabular}{|c|c|c|c|}
\hline $\begin{array}{l}\text { Resiliencia } \\
\text { (ecosistema) }\end{array}$ & $\begin{array}{l}\text { La resiliencia de los ecosistemas es la capacidad } \\
\text { de un sistema de absorber perturbaciones y } \\
\text { reorganizarse, manteniendo al mismo tiempo } \\
\text { una función, estructura y retroalimentaciones } \\
\text { similares. En las comunidades de plantas y animales, } \\
\text { esta propiedad depende en gran medida de } \\
\text { las adaptaciones por especies individuales a las } \\
\text { perturbaciones o tensiones experimentadas durante } \\
\text { la evolución de la especie. }\end{array}$ & $\begin{array}{l}\text { International standards } \\
\text { for the practice of } \\
\text { ecological restoration } \\
\text { - including principles } \\
\text { and key concepts } \\
\text { (Normas internacionales } \\
\text { para la práctica de la } \\
\text { restauración ecológica, } \\
\text { incluidos principios y } \\
\text { conceptos clave) }\end{array}$ & $\begin{array}{l}\text { http://seraustralasia. } \\
\text { com/wheel/image/SER } \\
\text { International Standards.pdf }\end{array}$ \\
\hline $\begin{array}{l}\text { Resiliencia } \\
\text { (general) }\end{array}$ & $\begin{array}{l}\text { La capacidad de un sistema social o ecológico } \\
\text { para absorber perturbaciones, manteniendo al } \\
\text { mismo tiempo la misma estructura básica y las } \\
\text { mismas formas de funcionamiento, la capacidad } \\
\text { de autoorganización y la capacidad de adaptarse al } \\
\text { estrés y al cambio. }\end{array}$ & IPCC & $\begin{array}{l}\text { https://www.ipcc.ch/pdf/ } \\
\text { assessment-report/ar4/syr/ } \\
\underline{\text { ar4 syr appendix.pdf }}\end{array}$ \\
\hline $\begin{array}{l}\text { Recursos } \\
\text { (biológicos) }\end{array}$ & $\begin{array}{l}\text { Recursos biológicos. Los recursos genéticos, } \\
\text { organismos o partes de los mismos, poblaciones } \\
\text { o cualquier otro componente biótico de los } \\
\text { ecosistemas con valor o utilidad real o potencial } \\
\text { para los seres humanos. Acceso: se define como la } \\
\text { posibilidad de participación, utilización y beneficio. }\end{array}$ & Glosario de la UICN & $\begin{array}{l}\frac{\text { https://www.iucn.org/sites/ }}{\text { dev/files/iucn-glossary-of- }} \\
\text { definitions en.pdf }\end{array}$ \\
\hline
\end{tabular}


Los recursos naturales suelen clasificarse en recursos renovables y no renovables. Los recursos renovables son generalmente recursos vivos (pescado, café y bosques, por ejemplo), que pueden reabastecerse (renovarse) si no se sobreexplotan. Los recursos renovables pueden reabastecerse y usarse indefinidamente si se utilizan de manera sostenible. Una vez que los recursos renovables se consumen a un ritmo que supera su tasa natural de sustitución, la población permanente disminuirá y eventualmente se agotará. La tasa de utilización sostenible de un recurso renovable está determinada por la tasa de sustitución y la cantidad de población permanente de ese recurso en particular. Los recursos naturales renovables no vivos incluyen el suelo, así como el agua, el viento, pueden clasificarse en función de su origen como bióticos y abióticos. Los recursos bióticos se derivan básico como su refinación en una forma más pura refinados) se consideran generalmente actividades

\begin{tabular}{|c|c|c|c|}
\hline Restauración & $\begin{array}{l}\text { Recuperación de la estructura, función y procesos } \\
\text { del ecosistema original. }\end{array}$ & Glosario de la UICN & $\begin{array}{l}\text { https://www.iucn.org/sites/ } \\
\text { dev/files/iucn-glossary-of- } \\
\text { definitions en.pdf }\end{array}$ \\
\hline Resultados & $\begin{array}{l}\text { Los productos e impactos resultantes de la } \\
\text { aplicación de un sistema de normas (adaptado del } \\
\text { Glosario de la OCDE, 2002). }\end{array}$ & Glosario de la ISEAL & $\begin{array}{l}\text { https://www. } \\
\text { sustainabilityxchange.info/ } \\
\text { filesagri/ISEAL\%20Glossary\%20 } \\
\frac{\text { of\%20Terms } \% 20 \mathrm{v} 1 \% 20-\% 20}{16 \% 20 \mathrm{Jan} \% 202015 . \mathrm{pdf}}\end{array}$ \\
\hline Riesgo & $\begin{array}{l}\text { Un riesgo de proyecto puede describirse como } \\
\text { "posibilidad de una desviación negativa o positiva de } \\
\text { un objetivo del proyecto". Por lo tanto, los riesgos } \\
\text { pueden afectar el éxito de un proyecto y deben } \\
\text { gestionarse adecuadamente. }\end{array}$ & $\begin{array}{l}\text { Relating sustainable } \\
\text { development and } \\
\text { project management: } \\
\text { a conceptual model } \\
\text { (Relacionando el } \\
\text { desarrollo sostenible y } \\
\text { la gestión de proyectos: } \\
\text { Un modelo conceptual) } \\
\text { - (Gareis, 2005) }\end{array}$ & $\begin{array}{l}\text { https://www.pmi.org/learning/ } \\
\text { library/relating-sustainable- } \\
\underline{\text { development-project- }} \\
\underline{\text { management-6497 }}\end{array}$ \\
\hline
\end{tabular}

Glosario de herramientas de la CDB https://www.cbd.int/cepal toolkit/2008/doc/CDB-ToolkitGlossaries.pdf las mareas y la radiación solar, en comparación con la energía renovable. Los recursos también de animales y plantas (es decir, del mundo vivo). Los recursos abióticos se derivan del mundo no vivo, por ejemplo, la tierra, el agua y el aire. Los recursos minerales y de energía son también recursos abióticos, algunos de ellos derivados de la naturaleza. Tanto la extracción del recurso y directamente utilizable (p. ej., metales, aceites de recursos naturales, aunque este último no se produzca necesariamente cerca del primero. Los recursos naturales son capital natural convertido en insumos básicos para procesos de capital infraestructural.

Recursos
(naturales)

Un riesgo de proyecto puede describirse como un objetivo del proyecto". Por lo tanto, los riesgos pueden afectar el éxito de un proyecto y deben gestionarse adecuadamente. a conceptual model Relacionando el Un modelo conceptual) (Gareis, 2005) 
Término

The concept of

scalability: increasing

the scale and potential

A través de este proceso, la "escalabilidad" se definió como: la capacidad de [una] intervención que demostró ser eficaz a pequeña escala y/o bajo condiciones controladas para expandirse bajo condiciones del mundo real a fin de alcanzar una mayor proporción de la población elegible, mientras mantiene la eficacia. adoption of health promotion interventions into policy and practice (El concepto de escalabilidad: aumentar la escala y la adopción potencial de las intervenciones de promoción de la salud en la política y la práctica).

Las dimensiones mensurables de fenómenos u observaciones. Se expresa en unidades físicas, como metros, años, tamaño de la población o cantidades trasladadas o intercambiadas. En la observación, la escala determina la finura y grosor relativos de los distintos detalles y la selectividad entre los patrones que estos datos pueden formar.

\begin{tabular}{|c|c|c|c|}
\hline Ampliación & $\begin{array}{l}\text { La ampliación se logra mediante: la participación en } \\
\text { los procesos y la acción de toma de decisiones; el } \\
\text { aprendizaje de qué cambio es necesario y factible; la } \\
\text { relación y las redes que difunden ideas e inspiran la } \\
\text { acción. La participación, el aprendizaje y la relación } \\
\text { generan intervenciones viables que satisfacen las } \\
\text { necesidades locales y la apropiación por parte de } \\
\text { los interesados. Esto conduce a la sostenibilidad y la } \\
\text { ampliación de los resultados. }\end{array}$ & $\begin{array}{l}\text { Burns, D.y Worsley, } \\
\text { S., 2015. Navigating } \\
\text { Complexity in } \\
\text { International } \\
\text { Development } \\
\text { (La complejidad } \\
\text { de la navegación } \\
\text { en el desarrollo } \\
\text { internacional), Rugby, } \\
\text { UK: Practical Action } \\
\text { Publishing }\end{array}$ & $\begin{array}{l}\text { http:// dx.doi.org/ 10.3362/ } \\
\underline{\underline{9781780448510}}\end{array}$ \\
\hline $\begin{array}{l}\text { Conocimiento } \\
\text { científico }\end{array}$ & $\begin{array}{l}\text { El Programa para la Evaluación Internacional de } \\
\text { Alumnos define la alfabetización científica como } \\
\text { la capacidad de utilizar el conocimiento científico, } \\
\text { identificar preguntas y extraer conclusiones basadas } \\
\text { en evidencia para entender y ayudar a tomar } \\
\text { decisiones sobre el mundo natural y los cambios } \\
\text { producto de la actividad humana. }\end{array}$ & OCDE & https://stats.oecd.org/glossary/ \\
\hline Sectores & $\begin{array}{l}\text { Subdivisión de una economía, sociedad o esfera } \\
\text { de actividad, definida sobre la base de alguna } \\
\text { característica común }\end{array}$ & $\begin{array}{l}\text { Glosario del Global } \\
\text { Reporting Institute }\end{array}$ & $\begin{array}{l}\text { https://www.globalreporting. } \\
\text { org/standards/media/1913/gri- } \\
\text { standards-glossary.pdf }\end{array}$ \\
\hline
\end{tabular}

https://www.usaid.gov/sites/ default/files/documents/1865/ v5web R4D MSIBrookingsSynthPaper0914-3. $\underline{\mathrm{pdf}}$
La ampliación se define como "expandir, replicar, adaptar y mantener políticas, programas o proyectos exitosos en el espacio geográfico y a lo largo del tiempo para llegar a un mayor número de personas. "Es importante definir por adelantado la escala final a la que debe o puede tomarse una intervención, dadas las necesidades de la población objetivo y la naturaleza de la intervención. También es importante considerar de manera realista el horizonte temporal sobre el que debe extenderse el proceso de ampliación para lograr la escala final deseada. Hartmann y Linn encontraron que la ampliación exitosa de los programas a escala nacional puede llevar de diez a quince años, o más.
Taking Innovations to Scale: Methods, Applications and Lessons (Cómo llevar las innovaciones a escala: Métodos, aplicaciones y lecciones)
(1)

\section{Ecosystem Assement Ecosistemas del Milenio) \\ Millennium}

Ampliación

La ampliación se logra mediante: la participación en los procesos y la acción de toma de decisiones; el relación y las redes que difunden ideas e ictible, acción. La participación, el aprendizaje y la relación generan intervenciones viables que satisfacen las necesidades locales y la apropiación por parte de los interesados. Esto conduce a la sostenibilidad y la

El Programa para la Evaluación Internacional de Alumnos define la alfabetización científica como la capacidad de utilizar el conocimiento científico, en evidencia para entender y ayudar a tomar decisiones sobre el mundo natural y los cambios de actividad, definida sobre la base de alguna Reporting Institute

Burns, D.y Worsley,

Complexity in

International

velopment

de la navegación

http:// dx.doi.org/ $10.3362 /$ 9781780448510 dia/1913/gristandards-glossary.pd https://www.ncbi.nlm.nih.gov/ pubmed/22241853

https://www.

millenniumassessment.org/ documents/document.776. aspx.pdf 
International standards for the practice of ecological restoration - including principles and key concepts n área o ubicación discreta. Puede presentarse en Sitio distintas escalas, pero generalmente se encuentra en la escala de la parcela o finca (es decir, más pequeña que el paisaje).
(Normas internacionales

para la práctica de la restauración ecológica, incluidos principios y conceptos clave) http://seraustralasia. com/wheel/image/SER International Standards.pdf

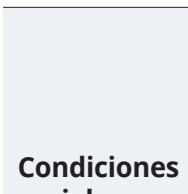

sociales

Especies

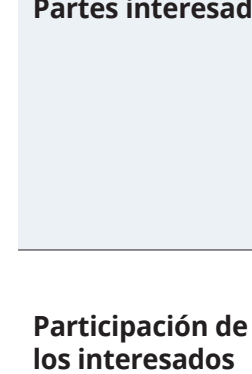

Capital social. Consiste, en sentido estricto, de redes sociales y normas asociadas que tienen efecto sobre la productividad de la comunidad. Tiene sus raíces en la confianza, y es lo que facilita la cooperación y la coordinación en beneficio mutuo de los miembros del grupo. En un sentido más amplio, el término capta asociaciones verticales y horizontales, entre comunidades y otros grupos, como agencias forestales, grupos de certificación forestal, consejos municipales, etc.

\section{Glosario de la UICN}

https://www.iucn.org/sites/ dev/files/iucn-glossary-ofdefinitions en.pdf

Es un grupo de individuos que se reproducen entre sí con características comunes que producen descendencia fértil (capaz de reproducirse) y que no pueden reproducirse con otros grupos de ese tipo, es decir, una población que, en términos reproductivos, está aislada de otras; las especies relacionadas se agrupan en géneros, que es una designación en letra o número después del nombre genérico, por ejemplo, Squatina sp.

Las partes interesadas son personas o grupos que se ven afectados directa o indirectamente por un proyecto, así como aquellos que pueden tener intereses en un proyecto y/o la capacidad de influir positiva o negativamente en su resultado. Las partes interesadas pueden incluir comunidades o personas afectadas localmente y sus representantes formales e informales, autoridades gubernamentales nacionales o locales, políticos, líderes religiosos, organizaciones de la sociedad civil y grupos con intereses especiales, la comunidad académica u otras empresas. El "interés" que cada una de estas personas o grupos tenga en un proyecto o inversión variará.

https://www.lucn.org/sites/ dev/files/iucn-glossary-ofdefinitions en.pdf

\section{los interesados}

La participación de los interesados es un término general que abarca una serie de actividades e interacciones durante la vida de un proyecto. https://www.ifc.org/wps/wcm/

CFI connect/938f1a0048855805b eacfe6a6515bb18/IFC Stakeho IderEngagement.pdf
Una estrategia es un plan a largo plazo con un alcance definido que identifica: objetivos mensurables; actores clave y grupos destinatarios para el logro de resultados que convergen con su visión declarada.

Servicios ecosistémicos necesarios para la producción de todos los demás servicios ecosistémicos. Algunos ejemplos incluyen Servicios de apoyo la producción de biomasa, la producción de oxígeno atmosférico, la formación y retención del suelo, el ciclo de nutrientes, el ciclo del agua y el abastecimiento del hábitat.
Estrategia
Glosario de

herramientas de la CDB toolkit/2008/doc/CDB-ToolkitGlossaries.pdf https://www.ifc.org/wps/wcm/ connect/938f1a0048855805b eacfe6a6515bb18/IFC Stakeho IderEngagement. pdf?MOD=AIPERES 


\begin{tabular}{|c|c|c|c|}
\hline Término & Definición & Fuente & Enlace \\
\hline Sostenibilidad & $\begin{array}{l}\text { Se refiere al acceso, la utilización y la gestión } \\
\text { adecuadas de los recursos naturales, para } \\
\text { garantizar que los hombres y las mujeres de las } \\
\text { generaciones presentes y futuras puedan satisfacer } \\
\text { sus necesidades básicas de manera ininterrumpida. } \\
\text { Patrón de comportamiento que garantiza para } \\
\text { cada una de las generaciones futuras la opción } \\
\text { de disfrutar, como mínimo, del mismo nivel de } \\
\text { bienestar que disfrutó la generación precedente. Se } \\
\text { hace hincapié en la equidad intergeneracional del } \\
\text { desarrollo. }\end{array}$ & Glosario de la UICN & $\frac{\frac{\text { https://www.iucn.org/sites/ }}{\text { dev/files/iucn-glossary-of- }}}{\underline{\text { definitions en.pdf }}}$ \\
\hline Sostenible & $\begin{array}{l}\text { Relativo a, o que guarda relación con, o que designa } \\
\text { formas de actividad y cultura económica humana } \\
\text { que no conducen a la degradación ambiental, y que } \\
\text { especialmente evitan el agotamiento a largo plazo } \\
\text { de los recursos naturales. }\end{array}$ & $\begin{array}{l}\text { Glosario de Derecho } \\
\text { Ambiental de la UICN }\end{array}$ & $\begin{array}{l}\text { https://www.iucn.org/ } \\
\text { theme/environmental-law/ } \\
\text { our-work/water/water-law- } \\
\text { and-governance-support- } \\
\text { platform/learning-resources/ } \\
\text { glossary\#PStext }\end{array}$ \\
\hline Gestión sostenible & $\begin{array}{l}\text { Gestión a través de la cual el potencial actual de los } \\
\text { recursos se utiliza de la mejor manera posible, y no } \\
\text { reduce su disponibilidad. }\end{array}$ & Glosario de la UICN & $\begin{array}{l}\text { https://www.iucn.org/sites/ } \\
\text { dev/files/iucn-glossary-of- } \\
\text { definitions en.pdf }\end{array}$ \\
\hline Uso sostenible & $\begin{array}{l}\text { Uso de los componentes de la diversidad biológica } \\
\text { de manera y a un ritmo que no conduzcan a la } \\
\text { disminución a largo plazo de la diversidad biológica, } \\
\text { manteniendo así su potencial de satisfacción de } \\
\text { las necesidades y aspiraciones de las generaciones } \\
\text { presentes y futuras. }\end{array}$ & Glosario de la UICN & $\frac{\frac{\text { https://www.lucn.org/sites/ }}{\text { dev/files/iucn-glossary-of- }}}{\underline{\text { definitions en.pdf }}}$ \\
\hline Sinergias & $\begin{array}{l}\text { Resultado de actividades conjuntas que van más allá } \\
\text { de la suma de las actividades individuales, de modo } \\
\text { que los esfuerzos resulten más eficaces y eficientes. }\end{array}$ & $\begin{array}{l}\text { Glosario de términos } \\
\text { del UNEP para } \\
\text { negociadores de } \\
\text { acuerdos ambientales } \\
\text { multilaterales (2007) }\end{array}$ & $\begin{array}{l}\text { http://wedocs.unep.org/ } \\
\text { handle/20.500.11822/7569 }\end{array}$ \\
\hline Teoría del cambio & $\begin{array}{l}\text { Descripción e ilustración íntegras de cómo y por } \\
\text { qué se espera que ocurra un cambio deseado en un } \\
\text { contexto particular. }\end{array}$ & $\begin{array}{l}\text { Ecosystem Services } \\
\text { Procedure: Impact } \\
\text { Demonstration and } \\
\text { Market Tools - adapted } \\
\text { The Centre for Theory } \\
\text { of Change } 2016 \\
\text { (Procedimiento de } \\
\text { servicios del ecosistema: } \\
\text { Demostración de } \\
\text { impacto y herramientas } \\
\text { de mercado - } \\
\text { adaptación del Centro } \\
\text { de Teoría del Cambio } \\
\text { 2016) }\end{array}$ & $\begin{array}{l}\frac{\text { https://ic.fsc.org/file-download. }}{\text { ecosystem-services- }} \\
\text { procedure.a-7433.pdf }\end{array}$ \\
\hline Compensación & $\begin{array}{l}\text { Una elección que implica perder una calidad o } \\
\text { servicio (de un ecosistema) a cambio de obtener } \\
\text { otra calidad o servicio. Muchas decisiones que } \\
\text { afectan a los ecosistemas implican compensaciones, } \\
\text { a veces principalmente de largo plazo. }\end{array}$ & Glosario de la UICN & $\begin{array}{l}\frac{\text { https://www.iucn.org/sites/ }}{\text { dev/files/iucn-glossary-of- }} \\
\text { definitions en.pdf }\end{array}$ \\
\hline
\end{tabular}


El conocimiento ecológico tradicional es un complejo de conocimiento-práctica-creencia oral intergeneracionalmente transmitido (Berkes, 2008), que captura una fuerte memoria ambiental cultural y sensibilidad al cambio, y depende de la supervivencia de las culturas vivas en sus tierras aborígenes. El conocimiento ecológico tradicional es complementario de la ciencia occidental y la gestión de los recursos en las zonas protegidas, especialmente en esta era de rápidos cambios ambientales. Esto es reconocido por los ecologistas en la revista Frontiers in Ecology: "El conocimiento local explícito desde el punto de vista espacial es particularmente importante para la identificación de umbrales o puntos de inflexión... los pueblos nativos tienen un conocimiento íntimo de las variaciones espaciales y temporales como indicadores observables, que cuando se combinan con una comprensión científica...pueden utilizarse para elaborar descripciones fiables de las condiciones de referencia para las evaluaciones [ambientales]...." (Herrick et al., 2010). Las prácticas culturales tradicionales han sido, en su mayor parte, ecológicamente sostenibles. Parks Canada y el Canadian Parks Council (2008) reconocen que las prácticas de larga data, probadas y ecológicamente apropiadas son valores ecológicos que deben restaurarse o mantenerse.
Ecological Restoration for Protected Areas (Restauración ecológica para áreas protegidas) https://portals.iucn.org/library/ sites/library/files/documents/ PAG-018.pdf
Explotación de los recursos naturales por usuarios indígenas o por residentes no indígenas mediante métodos tradicionales. El uso local se refiere a la explotación por parte de los residentes locales.
Millennium

Ecosystem Assement

- MEA (Evaluación de

Ecosistemas del Milenio) https://www.

millenniumassessment.org/ documents/document.776. aspx.pdf

La transparencia se refiere a un entorno en el que los objetivos de la política, su marco jurídico, institucional y económico, las decisiones de política y sus fundamentos, datos e información relacionados con las políticas monetarias y financieras, y los términos de la rendición de cuentas de las agencias, detail.asp?!D=4474 se proporcionan al público de una manera comprensible, accesible y oportuna.

\begin{tabular}{|c|c|c|c|}
\hline Incertidumbre & $\begin{array}{l}\text { Expresión del grado en que se desconoce una } \\
\text { condición futura (p. ej., de un ecosistema). La } \\
\text { incertidumbre puede ser el resultado de la falta } \\
\text { de información o del desacuerdo sobre lo que se } \\
\text { conoce o incluso se sabe. Puede tener muchos } \\
\text { tipos de fuentes, desde errores cuantificables en } \\
\text { los datos hasta terminología claramente definida } \\
\text { o proyecciones inciertas del comportamiento } \\
\text { humano. Por lo tanto, la incertidumbre puede estar } \\
\text { representada por medidas cuantitativas (p. ej., una } \\
\text { gama de valores calculados por varios modelos) o } \\
\text { por declaraciones cualitativas (p. ej., que reflejen el } \\
\text { juicio de un equipo de expertos). }\end{array}$ & $\begin{array}{l}\text { Millennium } \\
\text { Ecosystem Assement } \\
\text { - MEA (Evaluación de } \\
\text { Ecosistemas del Milenio) }\end{array}$ & $\begin{array}{l}\frac{\text { https://www. }}{\text { millenniumassessment.org/ } /} \\
\text { documents/document.300. } \\
\underline{\text { aspx.pdf }}\end{array}$ \\
\hline
\end{tabular}


Término

Ampliación (aumento)

Seguridad hídrica
Definición

Fuente

Enlace

El término ampliación se utiliza hoy en día de diversas maneras. En algunos debates se refiere en general a "aumentar", como por ejemplo en "aumentar el tratamiento para el VIH/SIDA". ExpandNet define la ampliación más específicamente como: esfuerzos deliberados por aumentar el impacto de innovaciones de salud probadas con éxito para beneficiar a más personas y fomentar el desarrollo de políticas y programas de manera duradera. "Innovación" se refiere a los componentes de servicio, otras prácticas o productos que son nuevos o que se perciben como nuevos. Generalmente la innovación consiste en un "conjunto de intervenciones" que incluye no solo una nueva tecnología, práctica clínica, componente educativo o iniciativa comunitaria, sino también los procesos de gestión necesarios para una aplicación exitosa. "Probadas con éxito" destaca que las intervenciones que se van a ampliar están respaldadas por pruebas generadas localmente de la eficacia y viabilidad del programa obtenidas mediante proyectos piloto, de demostración o experimentales, o mediante la introducción inicial en un número limitado de sitios locales. Los "esfuerzos deliberados" definen la ampliación como un proceso guiado, en contraste con la difusión espontánea de las innovaciones. "El desarrollo de políticas y programas de manera duradera" señala la importancia del fomento de la capacidad institucional y la sostenibilidad.

"La capacidad de una población para salvaguardar el acceso sostenible a cantidades adecuadas de agua de calidad aceptable para mantener los medios de vida, el bienestar humano y el desarrollo socioeconómico, para garantizar la protección contra la contaminación del agua y los desastres relacionados con el agua, y para preservar los ecosistemas en un clima de paz y estabilidad política". Esta es la definición propuesta por ONUAgua para que sirva como punto de partida para el diálogo en el sistema de las Naciones Unidas.

Un área de tierra que lleva el agua a un río,

Cuenca

hidrográfica
ONU-Agua drenando a través del paisaje en afluentes y canales principales del río. También se llaman cuencas, cuencas de drenaje o cuencas fluviales. http://www.who.int/

OMS immunization/hpv/deliver/ nine steps for developing a scalingup_strategy who 2010. pdf https://www.unwater.org/ publications/water-securityinfographic/ 


\section{Referencias}

CDB (Convenio sobre la Diversidad Biológica) (2004). Enfoque por ecosistemas (Pautas del CDB). Montreal: Secretaría del Convenio sobre la Diversidad Biológica. 50 págs.

Cohen-Shacham, E., Walters, G., Janzen, C. y Maginnis, S. (2016). Nature-Based Solutions to Address Societal Challenges (Soluciones basadas en la naturaleza para abordar desafíos sociales). Gland, Suiza: Unión Internacional para la Conservación de la Naturaleza y de los Recursos Naturales. 10.2305/IUCN. $\mathrm{CH} .2016 .13$.en

Cohen-Shacham, E., Andrade, A., Dalton, J., Dudley, N., Jones, M., Kumar, C., Maginnis, S., Maynard, S., Nelson, C., Renaud, F., Welling, R. y Walters, G. (2019). Core principles for successfully implementing and upscaling Nature-based Solutions (Principios fundamentales para la aplicación correcta y la ampliación de soluciones basadas en la naturaleza). Environmental Science and Policy 98: 20-29. https://doi.org/10.1016/j. envsci.2019.04.014

de Coninck, H., Revi, A., Babiker, M., Bertoldi, P., Buckeridge, M., Cartwright, A., Dong, W., Ford, J., Fuss, S., Hourcade, J.-C., Ley, D., Mechler, R., Newman, P., Revokatova, A., Schultz, S., Steg, L. y Sugiyama, T. (2018). Strengthening and Implementing the Global Response (Fortalecer y ejecutar la respuesta global). En: Global Warming of $1.5^{\circ} \mathrm{C}$. An IPCC Special Report on the impacts of global warming of $1.5^{\circ} \mathrm{C}$ above preindustrial levels and related global greenhouse gas emission pathways, in the context of strengthening the global response to the threat of climate change, sustainable development, and efforts to eradicate poverty. IPCC. https://www. ipcc.ch/report/sr15/chapter-4-strengtheningand-implementing-the-global-response/

Holling, C.S (1973). Resilience and stability of ecological systems (Resiliencia y estabilidad de sistemas ecológicos). Annual Review of Ecology and Systematics 4: 1-23. https://doi. org/10.1146/annurev.es.04.110173.000245

Holling, C.S. (ed.) (1978). Adaptive Environmental Assessment and Management (Evaluación u manejo ambientales adaptativos). Londres: John Wiley and Sons. 377 págs.

Holling, C.S. (1986). The resilience of terrestrial ecosystems: local surprise and global change (La resiliencia de los ecosistemas terrestres: sorpresa local y cambio global). En: W.C. Clark y R.E. Munn (eds.), Sustainable Development of the Biosphere, (Cap. 10: 292-317). Cambridge, R.U.: Cambridge University Press.

IPBES (Plataforma Intergubernamental Científico-Normativa sobre Diversidad Biológica y Servicios de los Ecosistemas) (2019a). Global assessment report on biodiversity and ecosystem services of the Intergovernmental Science- Policy Platform on Biodiversity and Ecosystem Services (Informe de la evaluación global sobre biodiversidad y servicios de ecosistemas de la Plataforma Intergubernamental Científico-Normativa sobre Diversidad Biológica y Servicios de los Ecosistemas). E.S. Brondizio, J. Settele, S. Díaz y H.T. Ngo (eds.). Bonn, Alemania: Secretaría de la IPBES. https://ipbes.net/global-assessment 
IPBES (Plataforma Intergubernamental

Científico-Normativa sobre Diversidad Biológica y Servicios de los Ecosistemas) (2019b). Summary for policymakers of the global assessment report on biodiversity and ecosystem services of the Intergovernmental Science-Policy Platform on Biodiversity and Ecosystem Services (Resumen para responsables de la formulación de políticas del Informe de la evaluación global sobre biodiversidad y servicios de ecosistemas de la Plataforma Intergubernamental Científico-Normativa sobre Diversidad Biológica y Servicios de los Ecosistemas). S. Díaz, J. Settele, E.S. Brondízio, H.T. Ngo, M. Guèze, J. Agard, A. Arneth, P. Balvanera, K.A. Brauman, S.H.M. Butchart, K.M.A. Chan, L.A. Garibaldi, K. Ichii, J. Liu, S.M. Subramanian, G.F. Midgley, P. Miloslavich, Z. Molnár, D. Obura, A. Pfaff, S. Polasky, A. Purvis, J. Razzaque, B. Reyers, R. Roy Chowdhury, Y.J. Shin, I.J. Visseren-Hamakers, K.J. Willis y C.N. Zayas (eds.). Bonn, Alemania: Secretaría de la IPBES. 56 págs. https://ipbes.net/news/globalassessment-summary-policymakers-finalversion-now-available

IPCC (Grupo Intergubernamental de Expertos sobre el Cambio Climático) (2018). Global Warming of $1.5^{\circ} \mathrm{C}$. An IPCC Special Report on the impacts of global warming of $1.5^{\circ} \mathrm{C}$ above pre-industrial levels and related global greenhouse gas emission pathways, in the context of strengthening the global response to the threat of climate change, sustainable development, and efforts to eradicate poverty. IPCC. https://www.ipcc.ch/sr15/

IPCC (Grupo Intergubernamental de Expertos sobre el Cambio Climático) (2019). IPCC Special Report on Climate Change, Desertification, Land Degradation, Sustainable Land Management, Food Security, and Greenhouse Gas Fluxes in Terrestrial Ecosystems (Informe especial del IPCC sobre el cambio climático, la desertificación, la degradación de la tierra, la ordenación sostenible de la tierra, la seguridad alimentaria y los flujos de gases de efecto invernadero en los ecosistemas terrestres). Resumen para responsables de la formulación de políticas. IPCC. https://www.ipcc.ch/srccl/

UICN (Unión Internacional para la Conservación de la Naturaleza) Resolución 69 sobre la definición de soluciones basadas en la naturaleza (Resolución 6.069 de la UICN de 2016). Resoluciones de la UICN, Recomendaciones y otras decisiones 6-10 de septiembre de 2016. Congreso Mundial de la Naturaleza, Honolulu, Hawai'i, EE. UU. https:// portals.iucn.org/library/sites/library/files/ resrecfiles/WCC_2016_RES_069_ES.pdf

OECD (Organisation for Economic Co-operation and Development) (2020). http://www.oecd. org/dac/financing-sustainable-development/ blendedfinance-principles/ accessed: 11 May 2020.

PwC y WWF (Fondo Mundial para la Naturaleza) (2020). Nature is too big to fail - Biodiversity: the next frontier in financial risk management. (La naturaleza es demasiado grande para fracasar. Biodiversidad: la próxima frontera en la gestión del riesgo financiero). Suiza: PWC y WWF. http:// www.pwc.ch/wwf-report

Rockström, J., Steffen, W., Noone, K. et al. (2009). A safe operating space for humanity (Un espacio seguro para que funcione la humanidad). Nature 461: 472-475. https://doi. org/10.1038/461472a

Rogers, K.H., Luton, R., Biggs, H., Biggs, R., Blignaut, S., Choles, C.G., Palmer, A.G. y Tangwe, P. (2013). Fostering complexity thinking in action research for change in social-ecological systems (Fomentar el pensamiento complejo en la investigación 
de acción para el cambio en los sistemas socioecológicos) Ecology and Society 18(2): 31, 10.5751/ES-05330-180231

Sharp, R., Tallis, H.T., Ricketts, T., Guerry, A.D., Wood, S.A., Chaplin-Kramer, R., Nelson, E., Ennaanay, D., Wolny, S., Olwero, N., Vigerstol, K., Pennington, D., Mendoza, G., Aukema, J., Foster, J., Forrest, J., Cameron, D., Arkema, K., Lonsdorf, E., Kennedy, C., Verutes, G., Kim, C.K., Guannel, G., Papenfus, M., Toft, J., Marsik, M., Bernhardt, J., Griffin, R., Glowinski, K., Chaumont, N., Perelman, A., Lacayo, M. Mandle, L., Hamel, P., Vogl, A.L., Rogers, L., Bierbower, W., Denu, D. y Douglass, J. (2020). InVEST User Guide (Guía de usuario de InVEST). The Natural Capital Project, Stanford University, University of Minnesota, The Nature Conservancy y World Wildlife Fund.

Smith, R.D. y Maltby, E. (2003). Using the Ecosystem Approach to implement the Convention on Biological Diversity: Key issues and Case Studies. (Utilizar el enfoque por ecosistemas para implementar el Convenio sobre la Diversidad Biológica: Temas clave y estudios de casos) Gland, Suiza y Cambridge, R.U: UICN. https://doi.org/10.2305/IUCN.

\section{CH.2003.CEM.2.en}

Steffen, W., Richardson, K., Rockstrom, J., Cornell, S.E., Fetzer, I., Bennett, E.M., Biggs, R., Carpenter, S.R., de Vries, W. y de Wit, C.A. (2015). Planetary boundaries: guiding human development on a changing planet (Fronteras planetarias: Guiar el desarrollo humano en un planeta cambiante). Science. https://doi. org/10.1126/science.1259855

Waltner-Toews, D. y Kay, J. (2005). The evolution of an ecosystem approach: the diamond schematic and an adaptive methodology for ecosystem sustainability and health ( $\mathrm{La}$ evolución de un enfoque ecosistémico: El esquema de diamantes y una metodología adaptativa para la sostenibilidad y la salud de los ecosistemas). Ecology and Society 10(1): 38. https://doi.org/10.5751/ES-01214-100138 


\section{UICN}

UNIÓN INTERNACIONAL PARA LA

CONSERVACIÓN DE LA NATURALEZA

SEDE MUNDIAL

Rue Mauverney 28

1196 Gland, Suiza

Tel +41 229990000

Fax +41 229990002

NbSStandard@iucn.org

www.uicn.org/es 